\title{
Cognitive Grammar in Contemporary Fiction
}




\section{Contents}

\section{Chapter 1. Introduction}

1.1. Cognitive Grammar in fiction

1.2. Methods and texts

1.2.1. Text choice: Contemporary and postmodern fiction

1.2.2. Postmodern texts: A stylistic profile

1.2.3. Online reader reviews

1.3. Cognitive linguistics in stylistics

1.4. Structure of book

\section{Chapter 2. Cognitive Grammar: An overview}

2.1. Grammar as meaning

2.1.1. Grammar as construction

Figure 2.1. The symbolic construction

2.2. CG: Some central concepts

2.2.1. Trajector and landmark

2.2.2. Image schemas

2.2.3. Construal

2.2.4. Grounding construal relationships

Figure 2.2. Maximally objective vs. maximally subjective construal

2.2.5. The compositional path

2.2.6. Action chains

2.2.7. Reference points and scanning

Figure.2.3. The reference point model

2.2.8. The current discourse space

Figure 2.4. The current discourse space.

2.2.9. Fictive simulation

2.3. CG as a discourse framework

2.3.1. Defining discourse

2.3.2. Scalability

2.4. CG and other cognitive models

2.4.1. Text World Theory

2.4.2. Schema theory

2.4.3. Deictic shift theory

2.4.4. Mind-modelling

2.5. Review

Chapter 3. Action chains and grounding in Enduring Love

3.1. Introduction

3.1.1. Action, energy, process

3.2. Enduring Love 
3.3. Grounding perspective

Extract 3.1. Enduring Love

3.4. Narrative urgency and 'the generation of multiplicity'

3.5. Action chains and clausal grounding

Table 3.1. 'Run' phrasal constructions

3.5.1. Modality and metaphor

3.6. Nominal grounding: Schematicity vs. specificity

Figure 3.1. (Under-) specificity of reference: The hot air balloon accident

3.7. Conclusion: 'What were we running toward?'

3.8. Review

Chapter 4. The reference point model: Tracking character roles in The New York Trilogy

4.1. Introduction

4.1.1. Reference points in fiction

4.2. The New York Trilogy and the postmodern quest

4.2.1. Layers and targets

Figure 4.1. Narrative layering

Table 4.1. Schematised model of actants and processes

Figure 4.2. RPM after Dimovitz's (2006) reading of The Trilogy

4.3. Reader response: Tracking character roles

Table 4.2. A cognitive typology of reference

Figure 4.3. RPM after Todorov (1977): Equivalent targets in City of Glass

Figure 4.4. RPM after R1 (2011): The discarded target

4.4. (R)evoking targets

Extract 4.1. City of Glass

Extract 4.2. Ghosts

Extract 4.3. The Locked Room

4.5. Conclusion: 'The story is not in the words; it's in the struggle'

4.6. Review

\section{Chapter 5. Interrelated references and fictional world elaboration in Coraline}

5.1. Introduction

5.2. Construal: Production and reception

5.2.1. Construction schemas

5.3. Elaboration and world comparison: The 'other world' of Coraline

Extract 5.1. Coraline

5.3.1. Elaborative relationships

5.4. Reading Coraline

5.5. Resistance and identification

5.5.1. Reader response: Character

Table 5.1. Interrelated reference points in Coraline reviews

5.5.2. Reader response: Fictional world

5.6. Conclusion: 'It was so familiar - that was what made it feel so truly strange'

5.7. Review 


\section{Chapter 6. Mind-modelling perspective in 'Great Rock and Roll Pauses'}

6.1. Introduction: Visual attention in cognitive linguistics and CG

6.2. 'Great Rock and Roll Pauses'

6.2.1. Mind-modelling perspective

6.3. CG and multimodality

Figure 6.1. Updating the CDS of 'Great Rock and Roll Pauses'

Figure 6.2. 'Walking to the Car'

Figure 6.3. 'Lincoln Wants to Say/ Ends Up Saying'

Figure 6.4. "What is going on in here?"'

Figure 6.5. 'Mom's "Art"'

Figure 6.6. 'What I'm Afraid of'

6.4. Event frames

6.5. Multimodal perspective in 'Great Rock and Roll Pauses'

6.5.1. Attentional windowing

6.5.2. Speech presentation

6.5.3. Viewing arrangements and conceptual distancing

6.6. Conclusion: 'Music first, and then the pause'

6.7. Review

Chapter 7. Scanning the compositional path of 'Here We Aren't, So Quickly'

7.1. Introduction

7.1.2. Scanning paths

7.2. 'Here We Aren't, So Quickly'

Extract 7.1. 'Here We Aren't, So Quickly'

7.3. Analysability ('I counted the seconds backward')

Figure 7.1. The analysable text world structures of 'Here We Aren't, So

Quickly', paragraph one

7.4. Components ('Not wilfully unclear, just trying to say it as it wasn't')

Table 7.1. Sequentially accessed locations in 'Here We Aren't, So Quickly'

7.5. Composition ('Everything else happened - why not the things that could have?')

7.6. Conclusion: 'We reached the middle so quickly'

7.7. Review

\section{Chapter 8. Conclusion}

8.1. Introduction

8.2. Overview

8.3. Suitability for stylistics: Scalability and rigour

8.4. Replicability

\section{References}

Appendix

Index 


\section{Chapter 1. Introduction}

\subsection{Cognitive Grammar in fiction}

Stylistics is the study of linguistic patterns in texts. Put simply, it is the exploration and consideration of the relationship between linguistic choice and literary interpretation. With its roots in rhetoric (see Burke 2014; Cockcroft and Cockcroft 2014; Hamilton 2014), stylistics can be thought of as the intersection between English language and English literature - although its application is not necessarily confined to literary texts. At the core of stylistics is the idea that language choices directly impact upon the way that readers perceive and understand what they read. The discipline therefore offers a way of analysing texts that places a focus on language at the forefront of study.

Recently, the study of stylistics has taken a cognitive turn, and cognitive poetics (also known as cognitive stylistics) has emerged as a progressive field of research that offers a renewed focus on readerly interpretation by drawing on cognitive science, cognitive psychology and, more recently, cognitive linguistics (Tsur 1992; for an overview of the field see also Harrison and Stockwell 2014). Like previous stylistic analysis, cognitive poetics is similarly premised on the 'concern that any readerly interpretative account must be underpinned by transparent textual evidence'; but the incorporation of cognitive methodologies means that the study of cognitive poetics additionally 'offers a reconnection of literary scholarship with natural readers' (Harrison and Stockwell 2014: 218-219).

Considering the insights drawn from systemic-functional models over the past few decades and the revolutionary analyses that cognitive linguistics has brought to the 
fore, several of the difficulties that arise in the stylistic application of Hallidayan, cognitive linguistic and narratological frameworks seem to be resolvable from the perspective of Langacker's Cognitive Grammar (Langacker 1987, 1990, 1991, 2008, 2009; see also Croft and Cruse 2004; Evans and Green 2006; Taylor 2002).

Cognitive Grammar in Contemporary Fiction puts forward the idea that Cognitive Grammar (CG) can and should be included in the stylistics 'toolkit' (Wales 2014). Recent studies have shown its suitability for a range of analyses, from Critical Discourse Analysis (Hart 2014a, 2014b) to second language acquisition (Arnett and Jernigan 2014; Matsumoto 2008). Specifically, this book argues that CG offers a means of accounting for experiential organisation, the attenuation of experience and how it is simulated, in a literary reading. Thus, this volume offers a framework compatible with cognitive poetics' renewed focus: drawing connections between textual patterns and the interpretative and experiential responses of natural readers.

Cognitive Grammar in Contemporary Fiction develops, almost from an incipient point, the application of CG concepts in literary analysis, and aims to establish a verifiable framework and clear methodological principles for their application. In many of the analyses in this book it is suggested that a stylistic account using CG can help expand on current literary linguistic models, which is an approach commonly adopted by some of the initial CG stylistic analyses (see, for examples, Giovanelli 2013; Harrison et al. 2014; Harrison and Stockwell 2014; Herman 2009a; Nuttall 2014; Stockwell 2009).

As much as possible this text follows the definitions of central CG concepts that appear in Langacker's most recent overview of the field: Cognitive Grammar: A Basic Introduction (2008). Due to Langacker's prolific number of publications in CG over the past few decades, this focus on his most recent work will provide a more current, 
unified and informed theoretical foundation. The central CG concepts applied in this volume are introduced and defined in Chapter 2.

\subsection{Methods and texts}

\subsubsection{Text choice: Contemporary and postmodern fiction}

CG is a type of grammar from cognitive linguistics that is premised on the idea that all language is embodied (see Chapter 2 for an introduction to the model and its main concepts). CG further claims to be a usage-based grammar, a term which holds that 'there is no principled distinction between knowledge of language and use of language (competence and performance in generative terms), since knowledge emerges from use' (Evans and Green 2006: 478). This label seems to be applied somewhat loosely, however. Though the original work on CG does focus on language and its use, and considers how the choice of different grammatical structures determines inference of different conceptual content, all of the textual illustrations in the original accounts (see, for examples, Langacker 1987, 1991) are manufactured examples of language. In other words, there is a lack of consideration of real linguistic utterances, in real contexts.

If CG is truly a usage-based discipline, it should be directly applicable to the language of literature. Literature is certainly a 'use of language'; linguistically encoded by the particular choices made by, and through the competence of, an author.

The text examples included in Cognitive Grammar in Contemporary Fiction are pieces of British and American contemporary literature that fall between 1987 and 2011. According to Padley (2006: 9), the period of contemporary fiction starts from around 1945, although this is debated amongst critics and theorists. The texts used in this study are 'contemporary' according to most definitions, however. Two of the texts 
are from the latter end of the twentieth century - Auster's The New York Trilogy (2004), originally published in 1987, and Ian McEwan's Enduring Love (1997) - and the remaining three are twenty-first century: Coraline (Gaiman 2002); $A$ Visit from the Goon Squad (Egan 2011); and 'Here We Aren't, So Quickly' (Foer 2010). In order to further test the suitability of the CG model for stylistic analysis, Cognitive Grammar in Contemporary Fiction considers these literary examples in various forms and sizes and outlines the stylistic patterns across an entire novel (Chapter 4), a novella (Chapter 5), a short story (Chapter 7), and particular novel chapters and extracts (Chapters 3, 5 and 6). Using the texts as data in this way will help test CG's scalability; its effectiveness as a model for micro-, meso- and macro-levels of literary discourse.

It is perhaps necessary to emphasise that the literary texts included in this book will be considered as data, chosen for exemplary purposes. In order to test rigorously the boundaries and benefits of CG's application to literature, it is necessary to choose literary texts that both typify or challenge particular stylistic patterns. In other words, to effectively test the CG principles in turn, the texts considered in each chapter have been selected in order to be illustrative. Therefore while much of the analysis incorporates literary criticism alongside cognitive-linguistic models, the analysis is cognitive-stylistic primarily and not an extended overview of how contemporary fiction should be defined, or a summary of literary criticism on each text or genre.

\subsubsection{Postmodern texts: A stylistic profile}

While contemporary, the texts used here can also generally be labelled as postmodern, which means that, due to the features of the form, the linguistic construction of the narrative storyworld is self-consciously, and often frequently, foregrounded. As identified in the previous section, although the focus of this book will 
be on how CG can be used as a stylistic tool rather than a commentary on the nature of postmodernism, the fact that the texts analysed throughout the book share commonalities of stylistic features means that a brief summary of postmodern fiction is beneficial as a starting point.

It is difficult to be too definitive in an outline of postmodern fiction, however, as the term has been much contested since the early 1980s. This is arguably because, as Herman (2011: 275) summarises,

[p]ostmodern narratives are often arbitrary and indeterminate. They reveal a delight in disorder, discontinuity and ambiguity and a correspondingly cavalier attitude toward the conventions of coherent plot, realistic characterization, and clearly identifiable settings.

Put simply, '[n]othing about postmodernism is uncontroversial' (Herman, Jahn and Ryan 2005: 456). The 'discontinuity' of postmodern fiction tends to be shown through stylistic techniques such as a non-linear narrative structure and the self-conscious structuring of time and space, for examples (see Smethurst 2000); two features which will be considered in more detail in Chapters 3, 6 and 7, in particular. Along with these fundamental narrative components, postmodern fiction also subverts traditional notions of character (Fokemma 1991; McHale 2012). In other words, and as emphasised in Herman's quotation above, it presents a 'cavalier attitude' towards 'realistic characterization'.

Although 'arbitrary and indeterminate', there are commonalities among postmodern texts. One of the central concerns of postmodern fiction, for example, is the subversion or destabilisation of narrative development. Postmodern texts are often fundamentally metatextual in that they are 'fictions about the order of things, discourses which reflect upon the worlds of discourse' (McHale 1989: 164). In his later volume, Constructing Postmodernism (1992: 155), McHale goes on to say that postmodern texts 
use two strategies to achieve this destabilisation of fictional world construction. Firstly, he argues that destabilisation is caused by 'weakening', which occurs through narrative embedding or distancing - for example, through the introduction of a 'frame narrative', or where the narrative voice is mediated through more than one diegetic level (see Chapter 4 of this book for a discussion of layered diegetic levels of narration). Secondly, he suggests that destabilisation can occur through world 'mirroring' (McHale 1992: 155) which occurs when a world-within-a-world is represented in a text (a concept that will be useful for the parallel-world structure presented in the analysis of Coraline in Chapter 5).

Nicol (2009: xvi) builds on McHale's checklist, and identifies the following as 'the most important features' - those that are 'especially dominant' - in postmodern fiction:

(1) a self-reflexive acknowledgement of a text's own status as constructed, aesthetic artefact

(2) a implicit (or sometimes explicit) critique of realist approaches both to narrative and to representing a fictional 'world'

(3) a tendency to draw the reader's attention to his or her own process of interpretation as $\mathrm{s} /$ he reads the text

(Nicol 2009: xvi)

Although Nicol takes care to emphasise that these are also concerns of other types of texts, these three features are certainly applicable and also 'dominant' in many of the texts used for analysis in this book. The first analysis chapter in Cognitive Grammar in Contemporary Fiction, Chapter 3, for example, features an extract from the opening of Ian McEwan's Enduring Love (1997) with a first person narrator who keeps re-asserting his presence in the narrative. The narrator describes a significant dramatic event, and explicitly signposts the fact that this is an event he has thought about repeatedly. As such, the 'constructedness' of the narrative is foregrounded self-reflexively throughout the scene. Equally, The New York Trilogy (Auster 2004) in Chapter 3 displays the second stylistic feature from Nicol's checklist: it provides an explicit critique of both realist 
approaches to fiction and to literary criticism itself (see Dimovitz 2006; Lavender 1993). These ideas will be expanded on throughout the book.

Often postmodern texts' self-consciousness occurs through narrative interrelation, the postclassical extension of intertextuality (see Mason 2014; see also Bakhtin 1973; Kristeva 1981). Narrative interrelation is a cognitive model of reading, influenced by schema theory (see Bartlett 1932; Cook 1994; Schank and Abelson 1977; Semino 1995) which assesses the processes whereby when a reader reads a text they draw intertextual links connecting all narratives - not just literary ones. The definition itself is more cognitive and wide-reaching than intertextuality (Mason 2014). When intertextuality is referred to in this book (in Chapter 5, primarily), it shall be applied in terms of the broader definition of narrative interrelation as mentioned here.

In summary, then, it could be argued that postmodernist fiction is concerned with creating and distorting a fictional world, and with foregrounding its own linguistic construction. These techniques (schema-subversion, linguistic self-consciousness and narrative discontinuity) often work together to create what McHale (1987: 148) identifies as an 'ontological flicker', or what Cobley (2001: 241-242) calls a narrative 'rupturing effect' (which he identifies is also known as 'breaking frame'). This process coincides with Nicol's third feature of postmodernist fiction listed above, and refers to how the text explicitly draws attention to the reader's own interpretation of what they are reading. The self-consciousness of form means that in postmodernist literature, as in modernist literature, the text's linguistic construction is continuously foregrounded as a central and identifying theme. Postmodernist fiction differs from modernist styles, however, in that these texts also frequently experiment with 'the very process of worldbuilding' (McHale 2012: 146).

In order to examine Nicol's third prominent feature of postmodern fiction - that it has 'a tendency to draw the reader's attention to his or her own process of 
interpretation' - online reader review data will be used alongside the linguistic analysis of this study.

\subsubsection{Online reader reviews}

Reader response is a popular and expanding field of research in stylistics, and one which uses various methods to investigate literary interpretations. The quantitative, empirical studies in this area use psycholinguistic methods such as eyetracking and recording reading processing times, amongst others (see Kuiken and Miall 1994; Miall 2006; Miall and Kuiken 1999, 2002; Short and van Peer 1989; Steen 1991). Miall (2006: 29) discusses how such empirical research into reader responses has shown that readers do not just read with the aim of interpretation. Studies involving the 'think aloud' method in which readers are asked to verbalise their responses during or immediately after reading, have led him to conclude that 'a literary text is more likely to speak to the individual through its resonances with the individual's autobiographical experiences' (Miall 2006: 29). In Literary Reading he further argues that few empirical studies have been conducted into how real, natural readers read (Miall 2006: 23). Indeed, Burke (2011) questions whether it is even possible to conduct an empirical experiment that produces data of purely natural reading experiences.

One way of accessing more naturally occurring literary interpretations is to use more qualitative methods, as evidenced in studies which explore reading as a form of social practice (see Allington and Swann 2009, 2011; Fuller 2008; Frank 2010; Green, Strange and Brock 2002), or to collect and analyse naturalised reader review data from reading group responses (Gavins and Stockwell 2012; Long 2003; Peplow 2012; Swann and Allington 2009; Whiteley 2011) or from online sources (Gregoriou 2012; Harrison and Stockwell 2014). 
The research in this volume aligns itself partly with these latter approaches. As examples and data to help explore readerly construal (in Chapters 4 and 5, in particular), Cognitive Grammar in Contemporary Fiction considers reader contributions from online book recommendation platforms (see Harrison and Stockwell 2014). These websites include Amazon and Goodreads, which are considered two of the five 'most popular' recommendation services (Fitzpatrick 2010). These data comprise reviews, narrative summaries and interpretations, as well as reflections on the emotional experience of reading. The reviews are also a means of recommending books to other readers with similar tastes in reading, or, conversely, recommending against a particular text. A major advantage of using online reader review data is that it helps to avoid the observer's paradox. Online reader reviews are situated responses to texts that have not been affected by researcher-led questions, so arguably form a data set of more naturalised reader responses. Additionally, the study of reader reviews will help the consideration of CG's scalability (see Section 2.3.2), as reviews tend to be a summative overview of the reading experience; a summary in which a reader identifies the salient parts of their reading experience.

The first reader review dataset is considered in the second analysis in this volume (Chapter 4), and uses 11 reviews from Amazon and Goodreads of The New York Trilogy (Auster 2004). The reviews have all been anonymised, and so for ease of differentiation they are labelled by numbers from R1-R11. The second reader review dataset (Chapter 5) comprises reviews of Coraline (Gaiman 2002). Again, this includes 10 reviews from Amazon and Goodreads readers, and these are labelled with letters (RA-RJ). The reviews from the latter two datasets were selected due to their popularity (top-rated by other readers as being most 'helpful' (see Amazon.com), or most 'liked' (see Goodreads.com)), as well as whether they addressed the topic under consideration. Where the reviews are reproduced in the chapters, all spellings, grammar and emphases 
are as they appear in the original. The anonymised reviews in their entirety can be found in the Appendix.

It is also worthwhile briefly mentioning the ethical considerations of using such datasets. In line with Allington (2007), I argue that it is reasonable to use these reviews as datasets, since they have been uploaded onto the internet and are universally accessible (i.e. they are 'open access'). As such the comments are considered as equivalent to other forms of writing that are equally openly accessible, such as reader letters published in newspapers, for example (see Allington 2007: 50).

\subsection{Cognitive linguistics in stylistics}

Since the 1970s, systemic-functional grammar (Halliday 1971, 1973, 1978) has been a cornerstone of the field of stylistics. The relationship between systemicfunctional grammar and the field of cognitive linguistics in general has been discussed by Nuyts (2007: 552), who suggests that the main differences between the two fields may be dependent on their approaches in research design. Nuyts argues that cognitive linguistics uses contrived examples of language to exemplify particular linguistic phenomena, whereas systemic-functional linguistics instead focuses on applications to literature. The relationship between CG and Halliday's systemic-functional model is discussed in more detail in Chapter 3.

Many cognitive linguistic theories, however, have been applied to literature successfully (see Freeman 2006, 2007 for an overview of cognitive linguistics for literary applications). One of the most popular areas of research, for example, is the exploration of conceptual metaphors (Lakoff and Johnson 1980) in fiction. Conceptual metaphor theory has specifically been applied as a discourse-level literary framework 
(see Browse 2014; Crisp 2008; Freeman 1995; Gibbs 2002; Kövecses 2002; Steen 1989); an application that, as Cognitive Grammar in Contemporary Fiction outlines, is similarly successful with CG.

Throughout this book, the CG concepts are applied in stylistic analyses alongside existing literary linguistic and cognitive linguistic models. In the following analyses these existing models provide an established starting point in order to scaffold the CG analysis which is, at this stage, exploratory. Rather than suggesting that CG replaces these existing frameworks, this study instead argues that the application of CG can expand upon these approaches.

These frameworks include but are not limited to: Text World Theory (Gavins 2000, 2003, 2007; Werth 1995a, 1995b, 1999), Cognitive Semantics (Talmy 2000a, 2000b, 2011; Yuan 2014), systemic-functional grammar (Halliday 1971, 1973, 1978, 1985; see also Berry et. al 1996; Halliday and Hassan 1976; Halliday and Matthieson 2003), mind-modelling (Stockwell 2009; Stockwell and Mahlberg 2015) and deictic shift theory (Duchan, Bruder and Hewitt 1995; Green et al. 1995). These literary- and cognitive-linguistic models will be introduced briefly in Chapter 2 and discussed further in the analyses throughout the book.

The next section provides an overview of the structure of the volume. The italicised key terms are defined in more detail Chapter 2.

\subsection{Structure of book}

Cognitive Grammar in Contemporary Fiction is divided into eight chapters. Each chapter builds upon and incorporates the concepts that have been previously explored. In this way, the terms and applications of CG are used cumulatively, with the aim of 
providing a cohesive discourse framework for future literary linguistic application. Each chapter presents a CG stylistic account of a particular text and from these literary examples 'touchstone' passages (Herman 2009a: 123) will be selected for close analysis, while references are also made to the narratives as a whole.

Chapter 2 begins by introducing CG. This chapter presents the key CG concepts used throughout the book, addresses the scalability of these ideas and offers a definition of discourse. Although Cognitive Grammar in Contemporary Fiction does not provide an exhaustive application of all aspects of the CG model, this second chapter provides an overview of what are, arguably, the more central concepts. Following this introduction, each substantive analysis chapter (Chapters 3 - 7) offers an illustrative analysis using this CG methodology in a literary linguistic application. Crucially, Chapter 2 also highlights the fact that the application of CG concepts for stylistic analysis is, of course, different from the original application of these ideas. It is argued that the literary linguistic application of CG presented in this book, however, is not a radical departure from the original parameters of the model. Indeed Langacker (2008: 457-99) himself identifies the potential for these concepts to provide an account of discourse constructions as a 'frontier' of the development of the field.

The concept of action chains is one of the most popular areas of CG research in a literary linguistic context (see, for examples, Rice 2012; Stockwell 2009, 2014; Yuan 2014). Chapter 3 considers how a consideration of CG's action chains is a useful stylistic tool to explore the linguistic patterns of scenes that move from descriptions that are fast-paced and high-action to those that are modalised and comparatively 'slower'. The chapter begins by outlining some similarities with, and crucially differences between, CG's action chains and a more traditional systemic-functional grammar analysis of linguistic processes (Halliday 1971, 1973; Halliday and Matthieson 2004). The analysis considers how action is presented in the famous opening scene of Ian McEwan's 
Enduring Love (1997), in which the narrator recounts a traumatic event: a fatal hot air balloon accident. The CG concept of grounding - where a discourse participant is situated in relation to the speech event - in particular, is explored. This is pertinent for this text because the event is narrated very self-consciously: the narrator Joe Rose grounds himself within different planes of point of view throughout the scene, and the represented action sequences oscillate between high energy and more modalised description, and between descriptions that are more ambiguous and then, conversely, more specific. It is argued that the conflation of these contrasting style features into a single stylistic gestalt problematises the text's narrative urgency (Simpson 2014) profile.

With an emphasis on readerly construal, Chapter 4 explores how Langacker's reference point model (from CG's prominence) provides a conceptual structure for representing how readers arrive at different interpretations of the same text. In particular, this chapter explores how readers can track the literary protagonist, and his changing identities, in The New York Trilogy (Auster 2004); a post-modern detective text that comprises three partly interrelated narratives and that famously layers and complicates character- and reader-roles. The first part of the chapter summarises the critical reception of the text, which focuses on how The Trilogy clearly situates itself as a post-modern text. The second part of the chapter summarises the reader responses to the text, exploring how CG's reference point model can successfully account for the plurality of character roles. The final section of this chapter briefly considers a finegrained textual analysis, observing how the character roles are represented at the micro-level of the three stories.

Coraline (Gaiman 2002) is a contemporary fairy tale that has parallels with many other stories, as observed in the reader reviews of this novella, but although it exhibits features of entrenched - or familiar - structures (namely, fairy tales and the Gothic) the 
text also departs from and subverts these genre templates. To explore this subversion, Chapter 5 extends the application of construal operations, and observes, in particular, the idea of the divided audience of the novella. The first half of this chapter considers text world creation through character construal, and centres on a clausal analysis of an extract from the text when Coraline walks through the 'other living room' (Extract 5.1). This textual analysis builds upon the ideas presented in the nominal grounding analysis in Chapter 3, and further explores the construal concepts specificity, schematicity and elaborative relationships. This analysis draws on Text World Theory (Gavins 2007; Werth 1999) and schema theory (Bartlett 1932; Cook 1994) to explore the world construction of the text. The second half of this chapter extends CG's reference point model further to examine how reference points can act as placeholders for text world creation, and how readers both resist and identify with the fictional world of the text.

Chapter 6 elaborates on CG's concept of profiling by drawing upon Leonard Talmy's (2000a, 2000b) cognitive semantic equivalent: attentional windowing. This chapter discusses the relationship between attentional windowing and profiling and between windowing and gapping in a multimodal context. The CG analysis here explores the chapter 'Great Rock and Roll Pauses' from Jennifer Egan's (2011) A Visit from the Goon Squad, which is written as a PowerPoint presentation. Rather than a slideshow for a public presentation, however, 'Great Rock and Roll Pauses' defeats the usual form/content pairing associated with the genre and instead the slides present the diary of a twelve-year-old girl, Alison. This analysis draws on mind-modelling (Stockwell 2009) to explore the depiction of the central character, and to consider how the representation of perspective alters throughout the chapter.

Chapter 7 provides a holistic analysis of the short story 'Here We Aren't, So Quickly' (Foer 2010) using CG's compositional path of construction. 'Here We Aren't, So Quickly' originally appeared in The New Yorker magazine. As is typical of Foer's writing 
style, this short story is highly experimental in form. Among other stylistic features, the text moves between first, second and third person modes of narration successively, and the story is composed of a series of list-like, non-sequitur sentences which outline events that have (or have not) happened. These snapshots of domestic moments appear to recount the history of a relationship shared between the 'you' implied addressee and the speaking 'I' persona. This analysis explores how text worlds are created at each successive level of narration, and suggests how CG's compositional path, negative filters, and scanning processes are useful models to explore the fragmented narration of this experimental short story.

Finally, Chapter 8 concludes by providing some closing remarks on the analysis, and gestures towards future research in the field. It identifies the clear potential for CG to be scaled up to produce a cognitive discourse framework for contemporary literary texts, and finally argues that CG is a stylistic model worthy of further consideration. 


\section{Chapter 2. Cognitive Grammar: An overview}

\subsection{Grammar as meaning}

CG is a model of grammar which, along with other cognitive linguistic models, asserts that all language is embodied. Put simply, embodiment refers to how our use and understanding of language is shaped by our physical experience with the world. As such, CG considers how readers and speakers experientially engage with the language they use and process. First developed in the late eighties, CG remains unchanged in its fundamentals (see Langacker 1987, 1990, 1991, 2001, 2008), and, '[o]wing to subsequent findings in modern linguistics, cognitive science, and psychology that support its claims, [CG] has lost some of its radical image and gained many adherents' (Bennett 2014: 29). The 'radical image' presented by CG is attributed to its opposition to Chomskyan grammar. CG departs from the latter in its fundamental claims, which are firstly that grammar is symbolic and imagistic in nature, and secondly that cognition itself shapes language: both in terms of its production and comprehension. CG asserts that all units of language are meaningful, and are constituted by a pairing of meaning with form.

The defining claim of CG that sets it apart from other models of grammar, though, is the argument that grammar is inherently meaningful, and

[n] ot only is it meaningful, it also reflects our basic experience of moving, perceiving and acting on the world. At the core of grammatical meanings are mental operations inherent in these elemental components of moment-to moment living. When properly analysed, therefore, grammar has much to tell us about both meaning and cognition. 
While there are many sub-disciplines within cognitive approaches to grammar, Langacker's model of CG is considered the 'most detailed and influential' in the field of cognitive linguistics (Evans and Green 2006: 481).

\subsubsection{Grammar as construction}

Construction grammars in cognitive linguistics are part of a wider group to which Langacker's CG belongs (see Bergen and Chang 2005; Bergs 2009; Croft 2001; Goldberg 1995, 1996; Heine 1997; Hockstra and Sybesma 2004; Kay and Fillmore 1999; Östman and Fried 2005). Cognitive approaches to grammar, and the different types of construction grammars, are generally defined by a cognitive-linguistic approach to syntax (Evans and Green 2006: 225). CG belongs, in particular, to the inventory-based construction grammars (see also Croft 2001; Goldberg 1995; Kay and Fillmore 1999; Lakoff 1987) and places central importance on the organisation and categorisation of linguistic units, also known as constructions.

A linguistic construction itself is a 'symbolic unit' comprising a 'syntactic configuration' (Evans and Green 2006: 247), which can be conceptually represented as in Figure 2.1. 


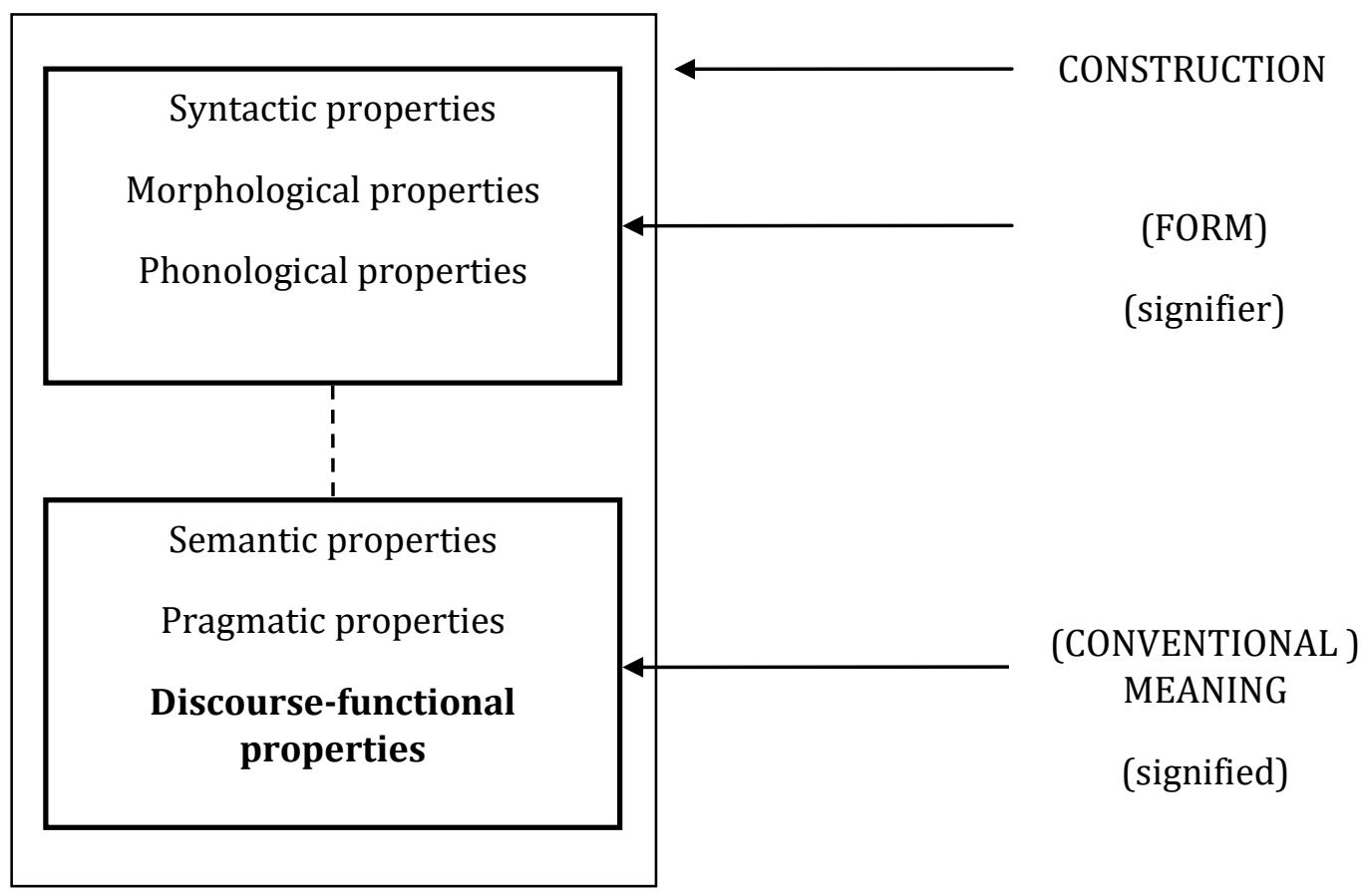

Figure 2.1. The symbolic construction (adapted from Evans and Green 2006: 258. My emphasis in bold).

As can be seen in Figure 2.1, a linguistic construction can be sub-divided in terms of its form and conventional meaning (cf. stratification in Halliday and Martin 1993). A construction in CG differs from constructions used in other grammars in that Langacker separates the two units, the form and conventional meaning, into different 'poles': the form and formal structure constitutes the phonological pole, and the functional structure is labelled as the semantic pole. Langacker regards the relationship that connects these poles as a kind of 'symbolic correspondence' (Croft 2001: 18); a term that will be referred to throughout the analyses.

It is argued that these syntactic constructions form a (loosely) 'structured inventory' in the mind, which in turn is organised into a taxonomic network (Langacker 1987: 63-76). This network is seen as hierarchical: a clause can be further broken down into its component parts, separated into verb types, participant roles, and so on. In Cognitive Grammar in Contemporary Fiction it is argued that, when scaled up and extended into a discourse framework, this network organisation can also account for 
units of language that are larger than the clause (for example, it can be used to describe linguistic patterns of a particular text, or literary genre, and so on). These arguments will be elaborated on in the latter half of this chapter.

\subsection{CG: Some central concepts}

The following sections outline the CG concepts that will be applied throughout this book (see Langacker 1987, 1991, 2008 for a more detailed account of these ideas, and for how they are introduced and applied in Langacker's original work; see also Bennett 2014; Croft and Cruse 2004; Taylor 2002). Additionally, both Harrison et al. (2014) and Giovanelli and Harrison (Forthcoming) provide an overview of these key ideas, and specifically apply these terms in stylistic contexts.

\subsubsection{Trajector and landmark}

Alongside constructions, Langacker's trajector and landmark alignment is a central distinguishing feature of CG. Generally speaking, trajector and landmark are the grammatical equivalent of figure and ground from psychology and perception (Hamilton 2003: 56). The trajector is the entity in a scene that attracts our attention in some way and it stands (or, in some instances, moves) against the background of the scene, which is the landmark.

Consider, for examples, the following sentences:

1. The penguin (tr) is on the iceberg $(\mathrm{lm})$.

2. The iceberg (tr) moves under the penguin (lm).

3. The iceberg (tr) is under the penguin ( $\mathrm{lm})$.

In sentence (1) the penguin is the trajector and the landmark is the iceberg. Conversely, in sentence (2) the iceberg becomes the trajector and the penguin becomes the 
landmark. The differentiation between these two trajector-landmark relationships is dependent upon construal processes. In these two sentences, the same scene is represented. However, the difference in profiled trajector pertains fundamentally to where the reader's attention is directed; with the first sentence directing more immediate attention to the penguin, and the second focusing initial attention on the iceberg. It is also important to note that trajector and landmark relationships are classified according to primary and secondary attentional focus, rather than 'any specific semantic role or conceptual content' (Langacker 2008: 72). This means that the trajector-landmark relationship can be construed statically (as instantiated through the stative verb 'is' in sentence (1) and (3)), or dynamically (as in the dynamic verb 'moves' in sentence (2)).

\subsubsection{Image schemas}

In cognitive linguistics, image schemas are seen as 'schematized patterns of activity abstracted from everyday bodily experience' (Langacker 2008: 32; see also Hampe and Grady 2005). In other words they are 'templates for the conceptualisation of situations' (Langacker 2008: 7); 'ontological skeletons' (Kimmel 2011) which pertain to the most basic of human concepts and understanding. They are also concepts that have been supported by recent evidence from neuroscience (see Dodge and Lakoff 2005).

An image schema describes prototypical trajector-landmark relationships and represents the relationship in terms of conceptual space. The image-schematic relationship between a trajector and landmark is often encoded, as in sentences (1)-(3) by a preposition or prepositional phrase ('under'/'on'). 


\subsubsection{Construal}

Construal is one of the central concepts of the CG model, and will underpin all the analyses in this book. According to Langacker's (2008: 43) model, the meaning of an utterance comprises both conceptual content and a particular construal of content, which is 'our manifest ability to conceive and portray the same situation in alternate ways' (see also Croft and Cruse 2004; Verhagen 2007). In order to describe construal Langacker (2008: 55) uses a visual metaphor. He likens the linguistic content of an utterance to the scene, construal to the way in which the scene is viewed, and the conceptualiser to the viewer of that scene (see also Langacker 1993a for construal 'universals'). This READING A TEXT IS VIEWING A SCENE conceptual metaphor is also carried further to describe other aspects of CG, such as the previously mentioned trajector and landmark alignment, as well as to other sub-concepts of construal. Langacker (2008: 55) does take care, however, not to claim that construal is directly analogous with physical viewing (see also Pleyer and Schneider 2014).

Many of the preliminary applications of CG - for stylistics and in other contexts have explored construal (see, for examples, Forrest 1996; Nuttall 2014; Pleyer and Schneider 2014; Tabakowska 1993; van Peer and Chatman 2001; Wójcik-Leese 2000). This is perhaps because construal as an organising frame is one of the more accessible starting points of a cognitive-linguistic analysis. In literary-linguistic contexts, it is clear that such ideas can build on the established body of research concerning point of view in fiction (see Chatman 1978; Fowler 1996; Genette 1972; McIntyre 2006; Simpson 2004).

CG identifies four broad classes of construal phenomena:

a. Specificity concerns how detailed, or conversely, how schematic, the scene is. Is the text written with a high resolution of detail, or conversely, is the description 
more vague? Langacker (2008) identifies that constructions can display varying levels of specificity. In the following example, the progression from more schematic to more specific lexical choices can clearly be seen. This is described in CG as elaboration:

thing $>$ object $>$ book $>$ picture book $>$ the brightly coloured graphic novel

b. Focusing entails the selection of conceptual content and consequently issues of foreground/background and figure/ground distinction from Gestalt psychology, as well as the relationship between given and new information.

c. Prominence outlines how expressions have certain bodies of conceptual content, which constitute the base of the utterance. When attention is drawn to a substructure of this base this is called a profile. For example, the reference to a book provides a base of conceptual content, also known as the maximal scope. If a page, the spine of the book or the font is mentioned in an utterance, these different aspects or immediate scopes of the maximal scope are profiled. In language profiling can be atemporal (as in this latter book example) or else encoded through a process (for example, the verb kick conceptually profiles a person's foot, which as a substructure evokes the rest of the person's leg (immediate scope) and the rest of the body (maximal scope)). More generally the act of profiling accounts for the cognitive processes involved in metonymy (see also Dirven and Pörings: 2002; Langacker 2008: 66).

d. Perspective relates to the overall viewing arrangement which connects the viewer with the scene being viewed. Within the context of fiction, perspective relates to the narrator or focaliser of the scene. This category also outlines 
dynamicity, which pertains 'to how a conceptualization unfolds through processing time' (Langacker 2008: 73). Processing time refers to the actual time of reading, whereas CG's conceived time instead refers to time as represented within a text.

Essentially, then, we can see that construal operations function as types of focal adjustments (Langacker 1987) instantiated through particular linguistic cues.

\subsubsection{Grounding construal relationships}

The fourth category of construal, perspective, can also be further explained through the idea of grounding. Grounding is a 'semantic function' and 'not a grammatical category' (Langacker 2008: 272), and can be differentiated from the ground of figureground alignment although it shares the same conceptual roots (Langacker 2008: 259). Broadly speaking, '[t]he ground can be seen as the 'platform' from which the speaker and hearer conceptualize the matter at hand and it encompasses the speech event itself and the time and place of speaking' (Bennett 2014: 35). In other words, grounding is the process whereby a speaker and hearer (or writer and reader) are situated within a particular viewing arrangement; how they 'are in some way connected to an expression' (Bennett 2014: 35).

In its original application, Langacker (2008: 259-62) described the ground of discourse in relation to spoken discourse between two conversational participants (as seen in Figure 2.2). The ground of a linguistic construction can either be overt (i.e. clearly signposted through deictic markers (see Freeman 1997), tense or modality, for example), covert (i.e. not explicitly attached to a speaking 'platform'), or halfway between the two. 
Additionally, there are two broad types of grounding: nominal and clausal, which, like many other CG concepts, are generally separated according to thing and process. On the one hand '[c]lausal grounding [...] situates the profiled relationship with respect to the speaker's current conception of reality' (Langacker 2008: 259), and this is marked through linguistic features such as modality or markers of time. In nominal grounding, on the other hand, and here Langacker (2008: 259) provides the examples 'the, this, that, some, a, each, every, no, any', 'the speaker directs the hearer's attention to the intended discourse referent, which may or may not correspond to an actual individual' (Langacker 2008: 259). These ideas will be returned to in more detail in Chapter 3.
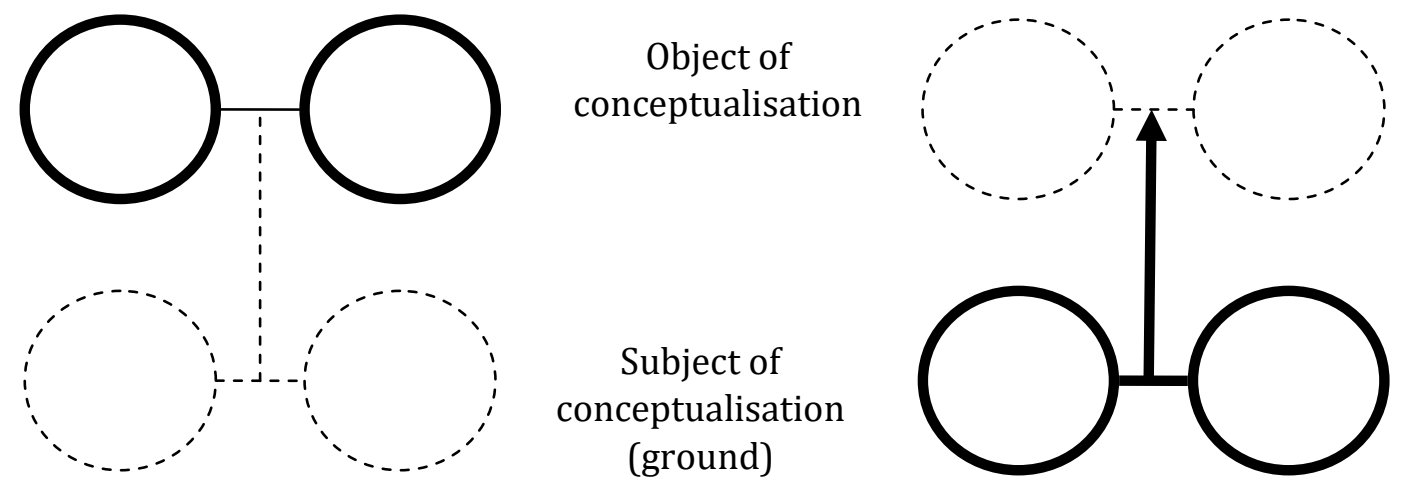

Figure 2.2. Maximally objective (left) vs. maximally subjective (right) construal; after Verhagen (2007: 61-62) and also summarised in Harrison et al. (2014: 10).

Generally speaking, a construal can be either subjective or objective. Subjective construal is a 'manner of viewing [...] inhering in the subject rather than the object of conceptualisation' (Langacker 2008: 537); whereas the opposite is true for objective construal. Verhagen (2007: 877) points out that Langacker uses the word 'subjective' here as 'a matter of vantage point', rather than as a description of a speaker's attitude. How subjectivity/objectivity impacts upon the relationship between conceptualiser and object of conceptualisation is represented in Figure 2.2. 
Verhagen (2007: 65) further suggests that an example of a more objective expressions would be something like a reference to an object in isolation (the examples he provides are, lamp, desk, chair) and suggests conversely that more subjective expressions could include constructions such as greetings and apologies (hey, sorry) that are more oriented towards the conceptualiser. Verhagen does highlight, however, that these examples are problematic because all expressions, either explicitly or implicitly, indicate a relationship that connects the object of conceptualisation - the things being described - and the ground of discourse (see Langacker 2008: 259-262). Put simply, every linguistic construction includes varying levels of subjectivity and objectivity, depending on whether the object or the conceptualiser is more prominent.

\subsubsection{The compositional path}

The compositional path is one of the main substructures of the construal process focusing. In describing how we understand linguistic meaning, Langacker (1987: 292) refers to how the relationship between different levels of language. In particular, he identifies three 'facets', which are 'functionally and experientially distinguishable', of how we distinguish the relationship between semantic components and the composite expression they combine to create:

The composite structure

The component structures

Analyzability a 'unified', 'seamless' conceptualization that includes the full content of the expression;

represent limited 'chunks' of this content dissociated from the whole for coding purposes;

recognition of the contribution that each component makes to the composite conceptualization. 
In other words, the compositional path of a linguistic construction refers to the process by which readers can understand how a composite linguistic construction (an entire text, for example) has been created out of smaller units of language.

When explaining compositional paths, Langacker (2008: 61) differentiates between fixed and novel composite linguistics expressions, and argues that they 'exhibit varying degrees of analyzability; that is, they vary in how salient the component structures are in relation to the composite conception, and how strongly they contribute to its emergence'. Langacker (2008: 61) suggests that with a novel expression in particular there is a higher degree of analysability, as it can be more easily dismantled in order to be understood. Alternatively, '[w]ith a fixed expression [...] the composite conception does constitute a prepackaged unit, so instead of being newly constructed it need only be activated'. For instance, a fixed noun such as umbrella represents what in CG terms is called a degenerate path: each component cannot be analysed as contributing to its overall construction. The composite morpheme cannot be further analysed, as it does not comprise component semantic structures. This can be contrasted directly with the clear compositional path delineated by a more novel expression like rain shield, which conversely has analysable morphological component structures $($ rain + shield $)$. The distinction between fixed and novel expressions pertains to entrenched linguistic constructions: expressions which are so frequently used or familiar as to be automatically processed as a unit and therefore 'require little conscious monitoring' (Langacker 2008: 16).

Furthermore, the connection between the composite semantic structure of an expression and its compositional path is said to constitute a 'foreground/background relationship' (Langacker 2008: 60), with the macro-, composite structure forming the primary focus, and the component semantic structures together forming the background. 


\subsubsection{Action chains}

Action chains in CG refer to the archetypal roles - prototypical grammatical relationships - that result from the selection of a particular verb. Langacker (2008: 355) uses a metaphor of a billiard ball table to describe how action chains - the displacement of 'energy' through verb choices - work in language. He describes how, in a game of billiards, one ball is struck and consequently moves to hit another, which in turn transfers energy onto that ball, and so on. This causes an action chain, with the initial energy serially displaced as it becomes transferred from one entity to the next.

The archetypal roles discussed here will include: agent, patient, instrument, experiencer, mover and zero roles. Firstly, an agent is the sentence's subject, which provides the source of energy, and the patient is the opposite: the object which 'undergoes an internal change of state' (Langacker 2008: 356). The instrument is the medium between agent and patient roles and is the object or entity which conducts the energy from one archetype to another. The experiencer correlates to the participants involved in Halliday's (1971) mental reaction processes: it is the participant which has an immanent experience, and therefore is always a sentient entity. The mover is simply an object which moves, and can be either animate or inanimate. Finally, the zero role is held by a participant which does nothing more than occupy a state or location (see Langacker 2008: 356).

Agent and patient are superordinate categories which can include other roletypes. Generally speaking, the agent is an energy source, whereas a patient is an energy sink. Equally, some of these roles have inherent kinetic energy (for instance, a mover or an agent), whereas others only experience energy transfer from another entity (for example, instrument or experiencer roles) (see Stockwell 2009: 183-190). 
Langacker's archetypal roles can be broadly related to Hallidayan roles of transitivity, in which different clausal roles are labelled according to firstly the type of process in which they are involved, and secondly the part that they play in that process (Butler \& Gonzálvez-García 2005; see also Nuyts 2007 for an exposition on the relationship between systemic-functional grammar and CG). In transitivity, sentences are divided into categories based on their process types: existential, material, verbal, relational and mental. The attendant participants to these specific processes are labelled accordingly. A few of these include, for example, behaver, sayer, actor, experiencer, senser and so on (see Halliday 1971, 1973, 1978, 1985; see also Berry et. al 1996; Halliday and Hassan 1976; Halliday and Matthieson 2004. For a simplification of agent roles from a cognitive perspective, see also Dowty 1991).

This is a similar approach to construction grammars. Goldberg (1995: 47-8), for instance, similarly suggests that participant roles in complex events should be categorised by the actions associated with them. Goldberg offers the examples of the verbs 'rob'/'steal', which denote the specific participant roles of robber and victim. Thus, particular verb choices profile particular participant roles, because verb processes are conceptually dependent on the participant who performs the action (Langacker 2008: 104). Arguably Langacker's action chain model simplifies Hallidayan roles, and instead offers a cognitive account of verb processes that is based on the idea of energy - where it is created, how it is used and where it becomes displaced.

Although it is problematic to simply assume direct equivalence between a grammatical participant and a literary participant (i.e. a literary protagonist or character), if a participant in both grammatical and literary terms is defined as an entity that performs an action, parallels between the two roles can clearly be seen. Following Herman (2002), this book argues that rather than assuming direct equivalence between the two types, literary characters are simply cast as different grammatical participants 
at alternating points in the discourse. The role or roles that a character occupies has a direct bearing on the construal of that character. In this way, characters and the processes they participate in are fundamentally connected in narratives.

\subsubsection{Reference points and scanning}

Scanning concerns how a conceptualiser construes a particular scene. In other words, it refers to the fact that how our attention is directed is a dynamic process in reading. How we read or scan a text is often dependent on reference points, which are 'the (initial) focus of attention' at which a referent is introduced: the first mention of a subject (Croft and Cruse 2004: 51). As Littlemore and Taylor (2014: 8) explain,

Whenever we wish to locate a particular object in our surroundings, or direct our listener's attention to it, we typically do so by appealing to a salient reference point. Candidates for the reference point function are features of the landscape, large immovable objects, as well as human beings (especially speaker and hearer) and animate creatures more generally.

Additionally, a target is an expression or phrase which refers back to the original reference point, and the dominion is the 'set of potential targets' (Langacker 2008: 83) instantiated by a given reference point.

4. Rob noticed that he had finished his cup of tea.

For example, in sentence (4) 'Rob' is the perceptually salient entity: the initial reference point and subject of the sentence. The personal pronouns 'he' and 'his' work anaphorically to refer back to the original reference point (Rob) and therefore function as targets in this example. 


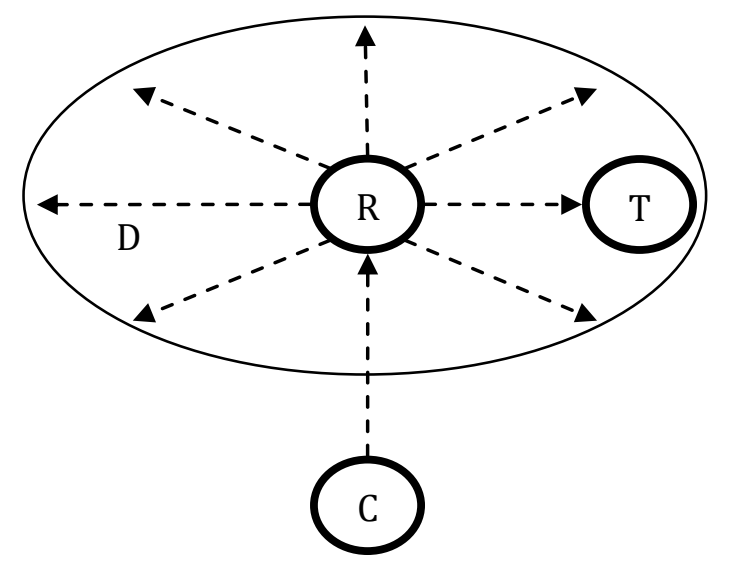

$\mathrm{C}=$ conceptualizer

$\mathrm{R}=$ reference point

$\mathrm{T}=$ target

$\mathrm{D}=$ dominion

$-\cdots=$ mental path

Figure 2.3. The reference point model after Langacker (2008: 84).

Langacker uses the reference point model (hereafter RPM) as a kind of scanning process within perspectival construal. In CG, Langacker tends to use the RPM to talk about possessive constructions, as the possessor 'functions as a reference point to establish a dominion in which the appropriate referent of the head noun can be selected' (Croft and Cruse 2004: 51). The RPM therefore describes a particular scanning process along a particular path, and elucidates comparison as well as referentcontextualisation in language. The RPM has already been shown to have potential in stylistic analyses: for tracing protagonists across texts (van Vliet 2009), and for capturing literary texture and atmosphere (Stockwell 2009). These ideas will be extended in greater detail in Chapters 4 and 5.

Sometimes, once the end of the discourse has been reached, these chains need to be reconceptualised through the process of backtracking. These are intuitive labels to describe simply how we are sometimes required to reconceptualise (or more specifically in a literary context, re-read) a unit of language in order to change the construal of the reference point in question (see Forrest 1996 for an analysis of reconstrual in speech; see also Harrison and Nuttall (In preparation) for an empirical account of CG in re-reading). 
More generally, in CG there are two types of scanning: summary and sequential.

Summary scanning is basically additive, and the processing of conceptual components proceeds roughly in parallel [...] sequential scanning, on the other hand, involves the successive transformations of one configuration into another.

(Langacker 1987: 248)

Langacker again uses a visual metaphor to differentiate between the two types: he describes the two processes as the difference between regarding a photograph (summary) as compared to viewing a film (sequential). As such, a summary scan occurs when the scene viewed is static, whereas a sequence scan occurs if the scene depicts movement of some kind. A succession of reference points (which function as linguistic points of contact for these two scanning processes) can create a scanning chain (Langacker 1987), with a reader's attention running from one figure to the next.

In its original application, summary and sequence scanning are used to describe how we process nouns and verbs. It is suggested that nouns are processed by summary scans, and conversely since verbs profile a process, these are scanned sequentially. Broccias and Hollman (2007: 5) use the example pairing of enter and into to illustrate this idea. Though the conceptual content of both these lexical choices is intuitively similar', in CG terms we process the verb enter as a sequence scan, and into - a static preposition - as a summary scan. Chapter 7 scales up these ideas to account for sequential comprehension; how readers are required to 'piece together' textual elements sequentially in order to comprehend a complete narrative.

\subsubsection{The current discourse space}

The final aspect of CG that will be applied in this book is the current discourse space (hereafter CDS). This model relies on the cognitive linguistic concept of a frame, which is considered the largest organisational unit of language (Lehrer and Kittay 1992: 
4; see also Fillmore 1985, 1992). Other related structures include Langacker's notion of base, and the concept of a domain, both of which are shared across Langacker, Fillmore and Lakoff's work (as observed by Croft and Cruse 2004: 16).

Langacker (1987, 2001, 2008) groups linguistic information into the collective CDS, which was originally discussed within the context of spoken conversation. The CDS is a conceptual model that outlines how participants keep track of ongoing discourse, and belongs to the superordinate construal process focusing. As mentioned above, the CDS is based on cognitive-linguistic representations of space and frames. These are concepts discussed in both cognitive poetics (Emmott 1992, 1995, 1997, 2003) and in cognitive linguistics more generally (see Lehrer and Kittay 1992). Similar structures also include Fauconnier's $(1985,1997)$ mental spaces and the conceptual templates of scripts and indexing (Schank and Abelson 1977). These are, of course, all theoretical structures: organising systems which enable description and exploration of the cognitive processes involved in language comprehension. Points of contact between the CDS and other similar structures in stylistics (such as Text World Theory) are discussed in the next section.

One of the most useful aspects of the CDS for this study is that, because it encompasses the wider context of a language event, it is one of the few components of CG that explicitly acknowledges the potential for exploring larger linguistic constructions. Langacker (2008: 59) argues that '[a]s discourse unfolds, at each step the current expression is constructed and interpreted against the background of those that have gone before', and continues that '[o]nly certain portions of the CDS are specifically invoked and brought to bear on the interpretation of any particular utterance' (2008: 281). These 'portions' (the scope or focus at a given stage of the discourse) constitute a discourse frame. As a discourse unfolds, therefore, interlocutors negotiate a series of discourse frames, each produced by updating the previous one. These interdependent 
frames are alternately labelled as the minus frame (previous discourse frame), zero frame (current discourse frame), and plus frame (anticipated discourse frame), as represented in Figure 2.4 (see also Langacker 2001: 151).

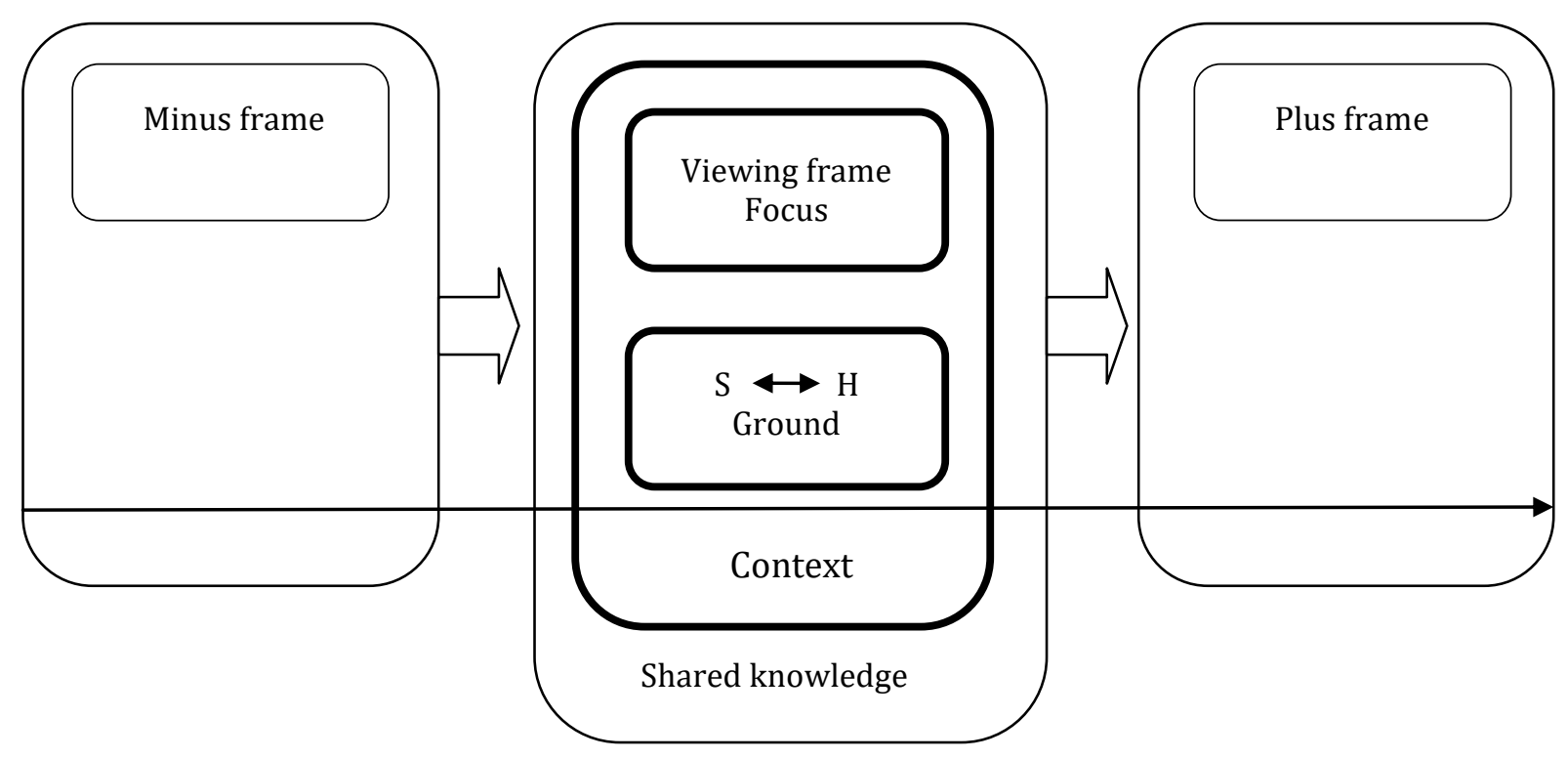

Figure 2.4. The current discourse space. Diagram after Langacker (2001: 145).

The CDS provides a structured account of anticipatory frames, or of how, in a reading context, a reader can expect a plus frame which is based on what they have read previously: the ground established in the minus frames of discourse. It also provides a sequential account of a discourse event by conceptually framing where reading knowledge is stored in a reader's working memory, and how this relates to the frames of discourse which they expect to follow. Aspects of shared and extra-textual knowledge become incorporated into the ground of the discourse that connects the speaker and hearer (also known as linguistic P (producer) and R (receiver), as identified in Figure 2.4). Only those aspects of shared knowledge that are relevant to the frame in focus become incorporated into the emergent viewing frame (also known as attentional frame) structure. 


\subsubsection{Fictive simulation}

An important central component of CG that will be introduced here - that makes it particularly pertinent for a literature-focused study - is the idea of attenuation, related to fictive simulation. Although this is not part of the CG 'framework' as such, it is an idea that underpins any CG account of language. CG observes that,

every linguistic utterance is a representation that is attenuated to a greater or lesser degree from the actual experience; every piece of language helps to create a simulation in the user's mind that operates as a heuristic for understanding.

(Dabrowska and Divjak 2015)

This idea is central to the idea of embodiment, which, as mentioned earlier, refers to how our use and understanding of language is shaped by our physical experience with the world. As Dabrowska and Divjak identify here, the experiences readers have in reading - and with processing language in general - are attenuated (i.e. 'filtered down') versions of real-world experiences. Of course, as readers we know that ‘conceptualization transcends immediate experience' (Langacker 2008: 540). In other words, fictive simulation is a reader's ability to vicariously experience the fictional worlds they read about.

\subsection{CG as a discourse framework}

\subsubsection{Defining discourse}

The main aim of this book is to apply these central CG concepts to the micro-, meso- and discourse-level of literary texts. As such, it is worthwhile to offer a brief explanation of how discourse will be defined in this study, particularly because it is itself 
a widely applied term that pertains to many different referents within literature, socioand applied linguistics and stylistics (see Wales 2001: 113-114).

Langacker (2008: 457) himself switches between definitions of the label. He refers to discourse as the level above the text (as supported by Halliday 1973, who further argues that discourse is above the level of language and relates to wider semiotic systems), and also as a spoken event (see Fairclough 1989 and wider critical discourse analyses). Langacker does, however, stress the importance and usefulness of exploring grammar at the discourse level of language. He describes (2008: 457) how,

[d]iscourse is where structure, use, and acquisition come together. Language is learned through its interactive use in social contexts. Its emergence from usage and social interaction is thus a key factor in describing linguistic structure.

According to Herman (2002: 117), however, discourse equals narrative. In his definition, discourse refers to stretches of text which comprise narratorial content of character, scene and action, which in turn constitute a complete story or narrative. Herman (2002: 146) further argues that a 'narrative genre' can be seen as comprising 'preference-rule systems'. In other words, particular types of narrative (i.e. an epic, or an allegory) are more likely to comprise or have preference for particular ratios of process types or action sequences. Of course, narrative grammars more generally have also been existence for some time (see, for examples, Greimas 1971, 1973, 1977; Pavel 1973; Prince 1973; Propp 1968).

Herman's view of narrative genres mentioned here is similar to Langacker's (2008: 477-85) definition of a discourse genre, which is similarly 'characterized by conventional linguistic units [and] embody our expectations about the genre and serve as templates in producing and apprehending new instances' (Langacker 2008: 478). In order to comprehend a discourse genre, Langacker uses schemas to categorise the necessary knowledge. He (2008: 478) argues that, 
[o] ur knowledge of a given genre consists in a set of schemas abstracted from encountered instances. Each schema represents a recurring commonality in regard to some facet of their structure: their global organization, more local structural properties, typical content, specific expressions employed, matters of style and register etc.

Here, in Langacker's definition, a discourse genre is defined as a usage-based system of linguistic commonalities and preferences. This is similar to the traditional formalist definition of discourse (see Chatman 1978; Genette 1980, 1988). As opposed to the chronological plot of a narrative, discourse is generally seen in narratological terms as 'the manner or means by which the plot is narrated' (Simpson 2004: 20; see also Tomashevsky 2002).

Cognitive Grammar in Contemporary Fiction conflates these definitions and use s discourse to refer firstly to the storyworld of fiction as applied in other cognitive-poetic frameworks such as Text World Theory (Werth 1999) and contextual frame theory (Emmott 1997), and secondly as a means of referring to literature as an example of situated language use. In other words, this book will consider units of language that stretch above the level of the text. Much of this exploration will therefore look at macropatterns of language, and how sentence- or clausal-level patterns combine to contribute to the overall form of the literary text.

\subsubsection{Scalability}

In order to consider the discourse level of literary narratives, one of the key concerns that need to be considered in this study is whether clause-grammar and discourse-grammar are reconcilable. This is particularly important since CG has rarely been applied beyond the clausal level of language. Indeed, the application of CG in this way has been identified as a potentially unachievable feat (see Pincombe 2014: 175). 
However, there is evidence to suggest that this is possible. Following CG's claim that units of language form constructions, some cognitive linguists acknowledge that literary narratives can be similarly categorised. For example, Dancygier (2012: 31) argues that '[s]tories can, naturally, be treated as linguistic constructions', and Traugott and Pratt (2008: 43) similarly argue that '[d]escribing a text in terms of its grammar involves viewing it as a single whole in which certain structures are simultaneously present'. If these views are aligned with the type of linguistic construction put forward by CG, then, a narrative can be seen as constituting a wider unit of construction, with poles of both form and conventional meaning.

Dancygier (2008: 65) does maintain, however, that it is problematic in narratology to assume a direct link between the micro-, meso- and macro-levels of discourse, saying that the discussion of narrative macro-levels [...] is seen as independent of the speech and thought representation phenomena (or the micro-level)'. She further argues (Dancygier 2008: 65) that, because of this,

there are numerous questions which such an analysis cannot address, such as the problem of the interaction between the levels, the emergence of the higher level based on narration at the lower level, or horizontal connections across different paths.

Instead, she asserts that blending theory (and in particular the notions of 'crossspace mapping, embeddings, and the attendant inheritance phenomena' (65)) can account for the interaction between the levels more successfully. This opinion suggests that an amalgamated approach - that is, the use of other disciplines (blending, in Dancygier's application, but CG in this book) alongside existing narratological models can help produce a more successful scaling between the clause and discourse-level of texts. 
In addition to blending theory, other cognitive linguistic theories have proven to be similarly scalable in the wider field. Conceptual metaphors, for instance, are extended to a more macro-linguistic unit in Kövecses' (2002) discussion, in which micro-instances of metaphors are said to combine and interrelate into larger and more underlying conceptual structures of texts (labelled as mega-metaphors). Equally, schema theory has been combined with an updated model of intertextuality to suggest how narrative interrelation - links between narratives - works on a more macro-scale within the reading process (see Mason: Forthcoming).

Additionally, and even more pertinently, the capacity of cognitive linguistic models to scale up is also identified by van Vliet's (2009) study of CG's reference point model. In this paper van Vliet observes firstly that cognitive linguistics actively promotes the scalability of models, and uses Text World Theory to help bridge the reference point model for a macro-literary analysis. Van Vliet (2009: 442) specifically looks at 'reference maintenance' and 'global reference points' - character references, in particular -across stretches of texts in third person narratives (see also Stockwell 2009 for an application of reference points in a literary context, and Chapters 4 and 5 of this volume for extended accounts of a macro-application of the reference point model).

The fact that successful integration and application of such cognitive-linguistic approaches can be carried out provides evidence for assuming that CG can also be developed into an effective literary-linguistic discourse framework. It seems important, however, that concepts are not applied in isolation. All three cognitive stylistic studies mentioned here - Mason's (Forthcoming) study of schema theory and narrative interrelation, Dancygier's (2008) account of blending and narratology, and van Vliet's (2009) consideration of the reference point model alongside Text World Theory explore the connections between more than one framework. The way various theories within cognitive linguistics interrelate needs much more exploration, as also noted by 
Evans and Green (2006: 780) in their identification of the future challenges of cognitive linguistics. To begin to address this challenge, Cognitive Grammar in Contemporary Fiction will observe the connections between CG and existing cognitive-poetic, narratological and cognitive-linguistic models of literary narratives.

\subsection{CG and other cognitive models}

In scaling up these central CG concepts, this book will consider the following cognitive poetic models for literary analysis.

\subsubsection{Text World Theory}

Text World Theory (Werth 1995a 1995b, 1999; Gavins 2007) is a discourseprocessing model which has been applied in stylistics to account for how readers create mental representations of the fictional worlds they read about. The theory splits the comprehension of literary discourse into three interconnecting levels. The first world that a reader encounters, which deals with these areas of context, is the discourse world, for Text World Theory is '[f]irst and foremost [a] discourse framework' (Gavins 2007: 8). The first-level discourse world encompasses the experiential baggage surrounding the writer, reader, and the immediate situational context. It is established and cognitively produced by two participants: the $\mathrm{P}$ (producer, speaker, author) and the R (receiver, hearer, reader) (Werth 1995a). The discourse world of any text is created through processes of negotiation, wilful communication and incrementation (Gavins 2007). Furthermore, these acts require perceptual, experiential, linguistic, and cultural information. The creation of the discourse world is thus 'highly dynamic' and one which continually evolves throughout the reading process (Gavins 2007: 20). 
After the initial discourse world, a reader encounters the fictional world of the text: the text world proper. Text worlds are created and maintained through worldbuilders (the description of objects, location, characters) and function-advancers (processes that help to advance the plot in some way). Stylistic shifts signpost a change in the parameters of the text world (for examples, alterations of perspective, the modalised language or a shift in the spatiotemporal parameters of the narrative) invite a reader to conceptualise a sub-world (Werth 1999; Lahey 2004) or a world-switch (Gavins 2007).

The relationship between Text World Theory and CG has already begun to be explored (see Nuttall 2014; Giovanelli 2013; Harrison: In preparation). Nuttall (2014), for example, discusses the benefits of applying aspects of CG alongside Text World Theory and specifically observes the sequential scanning of world-building information in an extract from The Handmaid's Tale (Atwood 1985). Nuttall further argues that CG offers a nuanced and fine-grained framework for exploring the role of specific language choices in the conceptualisation of text worlds. These ideas are revisited in Chapter 7 of this volume.

Similarly, I argue elsewhere (In preparation) that stylistic representations of the discourse of dementia (specifically Elizabeth Is Missing (2014) by Emma Healey) can be explored through a combined CG and text world analysis. Elizabeth Is Missing is centred on the protagonist Maud, who has dementia. As a narrator Maud is extremely unreliable and often forgets facts and events even as they are unfolding around her. Consequently, the novel is characterised by a stylistic contrast between the vague and the specific; the remembered and the forgotten. In order to explore this contrast this paper argues that a stylistic analysis using CG's reference points can shed further light on how Maud's 'characteristic cognitive habits' (Semino 2008: 269) are represented in the text, and how these in turn impact upon text world construction. The analysis draws upon CG's 
reference point model and scanning processes, in particular, to explore the representation of 'mind style' (Fowler 1996; Semino 2002) - and of episodic memory in literary texts.

There are some obvious similarities between the text world model and CG's CDS. The CDS, as identified by some cognitive linguists, is the CG equivalent of a matrix text world (Kamp and Reyle 2003; Nuttall 2014). For instance, the linguistic producer and receiver in the CDS are the conceptual equivalent of writer and reader respectively, constituting the primary participants involved in the ground of the speech (or rather, reading) event. Furthermore, Langacker's CDS viewing frames create attentional frames that are conceptually similar to those structures described in Text World Theory. These viewing frames comprise, on a primary level, the context and shared knowledge of the discourse participants, as well as the discourse relationship between the participants within a grounded speech event (like the discourse world). The similarity between readerly grounding, in particular, and discourse world structure has been drawn elsewhere (see Browse 2014; Sánchez-García 2007: 210-11). Similarly, the currently viewed frame as outlined in the CDS - the focus, at a given stage of the discourse - is again conceptually similar to a text world structure.

The relationship between CG and Text World Theory will be explored in Chapter 7, in particular.

\subsubsection{Schema theory}

Originally an Artificial Intelligence term, a schema is a name given to a particular set of information. For example, people may have a going to the cinema schema, which comprises a sequence of events that are normally followed, as well as items and locations that are typically encountered within this scenario: arriving at the cinema, 
purchasing a ticket, buying popcorn, finding a seat, and so on. Schemas can be triggered by particular headers, which cue particular pieces of background information. For example, reading that a character is planning a trip to the cinema would activate this set of information listed here. Schemas are a useful way of thinking about texts, as they explain why, even with the most minimal textual cues, readers can nevertheless create rich and detailed text worlds. Schemas are a way to 'fill in the gaps' in text processing (Bartlett 1932; Cook 1994; Dolezel 1995; Schank and Abelson 1977; Semino 1995; Stockwell 2007).

In CG schemas are mentioned in the context of image-schemas which, as defined earlier in this chapter, are prototypical relationships between the trajector and the landmark in language. Schematicity is also identified as a part of the construal category specificity. As also observed, lexical choices can be either highly detailed or conversely much less detailed: language in texts can vary on a cline from the more schematic to the more specific, or vice versa. In other words, with less specific descriptions readers are required to activate their background knowledge in order to fully conceptualise what they are reading about.

From these definitions of schemas it is clear how, in cognitive poetics more generally, the recognition of particular schemas has been shown to influence the way readers respond to texts (Cook 1994; Harrison and Mason: Forthcoming; Mason 2014). Schema recognition, maintenance and neglect in texts can influence how readerly attention is directed throughout the reading process, as explored in more detail in Chapter 4 of this volume.

\subsubsection{Deictic shift theory}


The study of deixis in linguistics concerns orientation in language. Deixis is centred on the idea that context is needed in order to understand where the conceptualiser is positioned, and how this positioning is encoded through particular linguistic signposts - such as markers of time, space, and so on. Traditional examples of deixis start with spatial signposting: for example, through particular demonstrative pronouns it is possible to indicate a proximal (this cup of tea) or distal (that cup of tea) relationship between the conceptualiser and the scene being described.

Applications of deixis in cognitive poetics extend these ideas further to include how, during the reading experience, readers are able to project themselves into a different point of view: the deictic centre (or origo) of a narrator. This process is known as Deictic Shift Theory (Duchan, Bruder and Hewitt 1995; Green et al. 1995).

In CG, deixis helps determine grounding in discourse (explored in more detail in Chapter 3). The idea that readers are able to displace their point of view in the reading process further builds on CG's idea of fictive simulation: our ability to experience and conceptualise situations that are 'virtual realities' (Langacker 2008).

\subsubsection{Mind-modelling}

The final cognitive poetic concept that will be drawn on in this book is the process mind-modelling (Stockwell 2009; Stockwell and Mahlberg 2015; see also 'world view' in Fowler 1996; 'Theory of Mind' in Zunshine 2006; and 'mind style' in Semino 2008). Put simply, mind-modelling is the process by which we perceive and understand minds other than our own. The term is Stockwell's re-labelling of Theory of Mind (ToM) to refer to how readers model minds within the context of reading. Mind-modelling is therefore a means of 'narrative processing' (Belmonte 2008: 199) rather than referring to a general psychological process. The need for this specific label is due to the fact that 
ToM is itself a 'slippery' term; and superordinately refers to 'the attribution of mental states in general' (Belmonte 2008: 193).

The relationship between mind-modelling and CG, and how stylistic choices in general can impact upon characterisation, will be elaborated on in Chapter 6, in particular.

\subsection{Review}

Chapter 2 has introduced CG as a cognitive linguistic model, which, in its original application, is used to analyse linguistic constructions below the level of the clause. The chapter has outlined the central CG concepts that will be used for stylistic analyses in this book. Finally, this chapter has considered the potential for 'scalability' of these central CG concepts, and has identified existing frameworks within the field of cognitive poetics that will help to scaffold and extend these ideas for literary linguistic application.

Chapter 3 presents a CG account of action sequences in a fictional context: specifically, the opening scene to Enduring Love (McEwan 1997). The analysis explores how shifts in clausal and nominal grounding, and consequently variations of objectivity/ subjectivity in the construal of the conceptualiser, impact upon the text's sense of pace or 'narrative urgency' (Simpson 2014). 


\section{Chapter 3. Action chains and grounding in Enduring Love}

\subsection{Introduction}

Alongside construal, action chains is one of the most central - and arguably most accessible - areas of CG. This chapter considers how CG's action chains and grounding can be used as stylistic tools to explore the linguistic patterns of scenes that are fastpaced and high-action, but also, conversely, modalised and disrupted by mental processes and narratorial interjections.

The chapter begins by introducing the scene that will be under consideration here, the opening passage of Ian McEwan's Enduring Love (1997), and positions the extract - its themes and style - within the wider context of the novel. The latter half of the chapter provides a CG account of the text that focuses, in particular, on how narratorial grounding, action chains and modalised constructions impact upon the text's 'narrative urgency' profile (Simpson 2014). It is observed that this opening scene presents a revision of the prototypical trajector-landmark profile relationship, the 'canonical viewpoint' (Langacker 1991: 123) that prototypically positions a moving trajector against a static landmark. The analysis demonstrates how the narrative overall outlines a subjective construal that profiles different viewing platforms from within separate text worlds.

\subsubsection{Action, energy, process}

Since Halliday's (1971) revolutionary analysis of transitivity patterns in Golding's The Inheritors, the study of action sequences and participants has traditionally been a 
central concern of stylistics. This original analysis showed how transitivity patterns can represent the particular ideologies of a text. Essentially, the formula of participant-andprocess underpins linguistic constructions; and patterns of participant-and-process relationships across a text directly influence its register, genre and overall style. Traditionally, transitivity is often applied to texts that display action sequences - or at least, transitivity analyses consider the grammatical representation of characters who are associated with more powerful processes (characters who are the performer of the action) in contrast with more passive characters (those who are acted upon or are in receipt of the action). In summary, the types of analyses have shown to be useful for exploring power dynamics and implications of agency in texts (see, for examples, Burton, 1982; Ji and Shen, 2004; Kennedy 1982; Mills, 2002).

It has recently been argued, however, that a transitivity analysis does not offer a holistic sense of how action is represented in a scene (see Simpson and Canning 2014 for a study of how an account of negation, ellipsis and presupposition can enrich a transitivity analysis), and it seems a logical step to consider how a cognitive linguistic account of action may help to address this. Following on from traditional structuralist accounts, many cognitive linguistic analyses focus on representations of action in language under different guises: force dynamics (Talmy 1988, 2000a, 2000b), energy chains (Kimmel 2011; Stockwell 2009), action structures (Herman 2002) and fictive motion (Matlock 2004, 2010; Yuan 2014). Effectively these analyses concern the notion of energy displacement: where it is sourced, how it is transferred, and where it sinks - a concern that underpins cognitive linguistics as a whole (Matlock 2010).

As Simpson (2014) posits, a sense of 'narrative urgency' is created in texts through comparison: a scene that has narrative urgency is often emphasised because it follows a scene that has comparatively less urgency. Stockwell (2014) similarly observes this phenomenon with a CG account of two contrasting passages from $\mathrm{H}$. G. 
Well's (1898) The War of the Worlds. In his chapter 'War, Worlds and Cognitive Grammar', Stockwell describes how a 'grammar of anticipation' accounts for the more descriptive, modalised scene, and how conversely a 'grammar of action' describes the text world creation in the more active scene.

Observing a scene of action - or contrasting scenes of action and inaction - is clearly a logical starting point in the study of force dynamics and action chains in fiction; but what about those scenes that fluctuate between mental and material processes in quick succession? Or, as is the case with the text chosen for analysis here, how can we analyse a passage that conflates both action and inaction into a stylistic gestalt?

\subsection{Enduring Love}

Enduring Love (McEwan 1997) is a contemporary British novel that has also been adapted for the screen (2004). Described as McEwan's 'most 'scientific' novel' (Ridley 2009: 7), the text is focalised from the perspective of the scientist Joe Rose who, after witnessing a balloon accident with his girlfriend Clarissa at the beginning of the novel, is stalked by another witness of the tragedy, Jed Parry. Parry has De Clérambault's syndrome; a real psychological disorder characterised by the delusion in a person that another (usually a person of higher social or professional standing) is in love with them. The novel follows Jed's pursuit of Joe, whose relationship with Clarissa starts to break down as his paranoia increases.

This opening extract from the novel sets the scene and defines the parameters of the ambiguously referenced 'event'. It oscillates between the narrated event and the present spatiotemporal location of the perceiver (narrator) in the aftermath of the event; recalling with precision what happened, and in what order. Described by critics 
as 'shocking' (Ridley 2009: 8), 'powerful' (Head 2008: 120), 'harrowing' (Schemberg 2004: 55) and 'painful' (Mars-Jones 1999), this scene is one of the most discussed of the novel, and the 'situation of crisis' - the hot air balloon incident - is argued by some to form a 'metaphor for the endurance or failure of relationships' (Childs 2007: 131) which runs throughout the text as a whole.

The scene begins with Jo and Clarissa sharing a picnic in a field. Jo narrates the incident, and the style choices create the impression that the narrative has been constructed and reconstructed over and over again; re-imagined from various perspectives and discussed collaboratively in the aftermath. This impression is created, in particular, through the shifting perspectives and the self-reflexively signposted voice of Joe that makes recurrent appearances throughout the narrative.

\subsection{Grounding perspective}

As mentioned in Chapter 2, grounding is a 'semantic function' and 'not a grammatical category' (Langacker 2008: 272), and can be differentiated from the ground of figure-ground alignment although it shares the same conceptual roots (Langacker 2008: 259). The process of grounding in CG was defined as a kind of 'platform' from which the speaker and hearer conceptualize the matter at hand and it encompasses the speech event itself and the time and place of speaking' (Bennett 2014: 35). In other words, grounding is the process whereby a speaker and hearer (or writer and reader) are situated within a particular viewing arrangement; how they 'are in some way connected to an expression' (Bennett 2014: 35).

As also summarised in Chapter 2, there are two broad types of grounding: nominal and clausal, which, like many other CG concepts, are broadly separated 
according thing and process. When taken on their own, a 'noun or a verb by itself merely specifies a type of thing or process', but when taken in context, a 'full noun phrase or a finite clause profiles a grounded instance of a thing or process type (Langacker 1991). Nominal grounding specifically 'pertains to identification and coordination of reference' (Langacker 2009: 180), whereas clausal grounding is marked through linguistic features such as modality or markers of time, and 'situates the profiled relationship with respect to the speaker's current conception of reality' (Langacker 2008: 259).

This text displays a narrator who attempts to hold an objective viewing arrangement relationship with the scene he narrates. However, as the analysis in the next section observes, the language undergoes subjectification through various stylistic means. The grounding remains overt throughout the extract but both the clausal and the temporal grounding elements are altered- the viewing 'platform' changes. Correspondingly, the nominal grounding is also adjusted; and this is marked through the varying degrees of specificity in the description of 'the event' (see Section 3.7). Equally, markers of deixis are manipulated throughout the scene and function to ground the narrative perspective in different, but simultaneous, viewing arrangements.

\section{Extract 3.1.}

The beginning is simple to mark. We were in sunlight under a turkey oak, partly protected from a strong, gusty wind. I was kneeling on the grass with a corkscrew in my hand, and Clarissa was passing me the bottle -a 1987 Daumas Gassac. This was the moment, this was the pinprick on the time map: I was stretching out my hand, and as the cool neck and the black foil touched my palm, we heard a man's shout. We turned to look across the field and saw the danger. Next thing, I was running toward it. The transformation was absolute: I don't recall dropping the corkscrew, or getting to my feet, or making a decision, or hearing the caution Clarissa called after me. What idiocy, to be racing into this story and its labyrinths, sprinting away from our happiness among the fresh spring grasses by the oak. There was the shout again, and a child's cry, enfeebled by the wind that roared in the tall trees along the hedgerows. I ran faster. And there, suddenly, from different points around the field, four other men were converging on the scene, running like me. 
I see us from two hundred feet up, through the eyes of the buzzard we had watched earlier, soaring, circling, and dipping in the tumult of currents: five men running silently toward the centre of a hundred-acre field. I approached from the southeast, with the wind at my back. About two hundred yards to my left two men ran side by side. They were farm labourers who had been repairing the fence along the field's southern edge where it skirts the road. The same distance beyond them was the motorist, John Logan, whose car was banked on the grass verge with its door, or doors, wide open. Knowing what I know now, it's odd to evoke the figure of Jed Parry directly ahead of me, emerging from a line of beeches on the far side of the field a quarter of a mile away, running into the wind. To the buzzard, Parry and I were tiny forms, our white shirts brilliant against the green, rushing toward each other like lovers, innocent of the grief this entanglement would bring. The encounter that would unhinge us was minutes away, its enormity disguised from us not only by the barrier of time but by the colossus in the centre of the field, which drew us in with the power of a terrible ratio that set fabulous magnitude against the puny human distress at its base.

What was Clarissa doing? She said she walked quickly toward the centre of the field. I don't know how she resisted the urge to run. By the time it happened - the event I am about to describe, the fall -she had almost caught us up and was well placed as an observer, unencumbered by participation, by the ropes and the shouting, and by our fatal lack of cooperation. What I describe is shaped by what Clarissa saw too, by what we told each other in the time of obsessive re-examination that followed: the aftermath, an appropriate term for what happened in a field waiting for its early summer mowing. The aftermath, the second crop, the growth promoted by that first cut in May.

I'm holding back, delaying the information. I'm lingering in the prior moment because it was a time when other outcomes were still possible; the convergence of six figures in a flat green space has a comforting geometry from the buzzard's perspective, the knowable, limited plane of the snooker table [...]. I think that while we were still converging, before we made contact, we were in a state of mathematical grace. I linger on our dispositions, the relative distances and the compass point -because as far as these occurrences were concerned, this was the last time I understood anything clearly at all.

What were we running toward? I don't think any of us would ever know fully. But superficially the answer was a balloon. Not the nominal space that encloses a cartoon character's speech or thought, or, by analogy, the kind that's driven by mere hot air. It was an enormous balloon filled with helium, that elemental gas forged from hydrogen in the nuclear furnace of the stars, first step along the way in the generation of multiplicity and variety of matter in the universe, including our selves and all our thoughts.

We were running toward a catastrophe, which itself was a kind of furnace in whose heat identities and fates would buckle into new shapes. At the base of the balloon was a basket in which there was a boy, and by the basket, clinging to a rope, was a man in need of help.

(McEwan 1997: 1-3) 


\subsection{Narrative urgency and 'the generation of multiplicity'}

Simpson (2014) defines narrative urgency as the process whereby readers identify with characters and their narrative goals, and explores this concept through a reader response study. Simpson further argues that the phenomenon is created through the presence of the following stylistic features:

- Simple sentences with a single clause;

- Physical actions and events rather than mental processes;

- More categorical than modalised statements (although deontic modality indicates a higher level of urgency than epistemic modality);

- A short duration (i.e. time frame) of the scene of action;

- Free form of speech/thought;

- Primacy of text world over sub world (i.e location of the scene within the narrative hierarchy).

(summarised from Simpson 2014: 5-7)

Simpson (2014: 7) emphasises that this is not a 'rigid checklist', but rather 'a constellation of stylistic tendencies'. Alongside identifying that the content of a text must be correspondingly urgent in order to avoid pastiche (which draws on CG's central preoccupation with form-meaning pairings in linguistic constructions), Simpson further argues that an embedded character-narrator influences the stylistic profile of a text and consequently how readers respond to it. In other words, if a character-narrator 'is on the same plane of exegesis as the story', they help to provide a 'peg upon which reader and viewer emotion can be 'hung” (Simpson 2014: 10).

In this Enduring Love extract, Joe attempts to be extradiegetic - to hold an omniscient viewing position that allows him to describe the full scope of the scene - but his intradiegetic perspective in the narrative is consistently profiled through grounding mechanisms, as the following analysis shows. As such, a reader is reminded throughout that the description is being mediated through a subjective filter. The analysis in this chapter does not address readerly alignment with narrative goals like Simpson's study 
(although this is certainly a viable direction for future study), but the impressions of urgency, pace and dynamicity are considered in detail in terms of the language and structure of the text.

As a starting point, Simpson's latter two conditions - intradiegesis of narrator and suitability of content-and-style pairing - are fulfilled in the extract: there is a strong symbolic correspondence between the two poles of linguistic construction. Put simply, the form is appropriate for the content.

Arguably, however, this extract complicates the other aspects of the narrative urgency profile. There are, for example, instances of simple sentences ('The beginning is simple to mark'), but there are mainly compound and complex constructions. Equally, the verb choices mostly detail physical actions, but there are mental interjections ('I don't recall', 'Knowing what I know now', 'I don't think') that disrupt the representation of physical action and which also function to modalise the language; to undermine its objectivity. The passage is mostly written through the free form representation of thought, and yet Joe's narrative grounding remains embedded throughout the scene. (These preliminary observations are expanded on in the following two sections).

The time frame is also structured in a way that complicates the duration of the scene. There is a strong impression that Joe is trying to recall the exact chronology of the event (through connectives such as 'Next thing') and that he is trying to access full coverage of the event in terms of the perspective - capturing the same scene from all possible angles and via different temporal grounds ('I was running', 'I ran', 'I see us'). Equally, the movement between the past event and the narrator's current origo disrupts the chronology and makes the text recurrently self-reflexive. The narrator makes it clear that he is lingering in the prior moment because it was a time when other outcomes were still possible' (McEwan 1997: 2). 
The complication of duration largely occurs, however, because of the final item on Simpson's narrative urgency checklist: the location of the scene within the narrative hierarchy. There are two superordinate text world platforms that structure the narrative: the one grounded in Joe's present (TW1), in which he is narrating the story, and the one set in the past the time frame and details of the 'incident' (TW2). The platform of the first text world indicates that some time has passed between the present ground of the speaker and when the described event took place - certainly enough time for an 'obsessive re-examination' in the aftermath - while the conceived time of the incident is shown as passing quickly; as being 'minutes away'. Verhagen (2007: 65) identifies that the use of 'past tense locates an event outside the ground, thus outside the scope of the immediate experiences of the conceptualizers in the ground, without differentiating between them'. Thus, the relationship between Joe and the scene itself is a complicated one. The second text world - the one that is anchored in the past that describes the incident -forms the attentional focus of this passage, but the experience is outside of the immediate scope of the conceptualiser. As such these events are, grammatically speaking, 'outside the ground' of the narratorial conceptualiser, but Joe nevertheless tries to re-imagine - and re-experience - the scene through various viewing platforms.

These re-imagined platforms are established through deictic shifts in perspective, as through his account Joe amalgamates the points of view of different perceivers and different origos (Green et al. 1995). For example, the narrative of TW2 moves from the 'I' narrator, to the birds' eye view ('through the eyes of the buzzard we had watched earlier'), to Clarissa's approach (she 'was well-placed as an observer'), to a collective advance with multiple agents ('What were we running toward?'). This reexperiencing of the scene means that throughout the extract Joe's perspective remains either explicitly on-stage (i.e. when speaking from his grounded position within TW1) 
or implicit and more off-stage (as in the case of the imagined buzzard origo and the other viewpoints detailed in TW2). The presence of TW1 means subjectifies all the descriptions in TW2. In short, the text outlines an 'egocentric viewing arrangement' (Langacker 1987: 488-9).

In addition to the shifts in grounding, the use of predication coupled with role choice throughout the scene creates a sense of ineffectual action; of stopping and starting. In other words, there is a sense of high urgency and action, but simultaneously, contrastingly, of hopelessness: this scene has already happened, and as much as the narrator wills a different ending, all versions of the narrative are leading to the same outcome.

\subsection{Action chains and clausal grounding}

As Kimmel (2011: 238) argues, '[w]e can easily think of suspense or denouement as a PATH with a variation of FORCE intensity over time'. The archetypal roles in this extract demonstrate a variation of force intensity, which complicates Simpson's second feature of narrative urgency listed. There is a predominance of high energy verbs, but these are coupled continuously with experiencer roles. There are categorical assertions and mathematical, specific language, but at the same time modalised, metaphorical and lexically underspecified constructions are presented. The PATH of action is therefore not a straightforward one.

The verb 'run', in its various forms, appears 9 times in the short extract - a lexical choice referenced in every paragraph: 


\begin{tabular}{r|c|l} 
Next thing I was & running & toward it. \\
\hline I & ran & faster \\
\hline $\begin{array}{r}\text { Four other men were } \\
\text { converging on the scene, }\end{array}$ & running & like me. \\
\hline Five men & running & silently toward the centre \\
\hline $\begin{array}{r}\text { to my left two men } \\
\text { it's odd to evoke the figure } \\
\text { of Jed Parry [... }\end{array}$ & ran & side by side \\
\hline $\begin{array}{r}\text { I don't know how she } \\
\text { resisted the urge to }\end{array}$ & running & into the wind. \\
\hline What were we & running & \\
\hline We were & running & toward? \\
\hline
\end{tabular}

Table 3.1. 'Run' phrasal constructions.

These choices are in addition to other high-energy verb choices: 'racing', 'sprinting', 'rushing', 'walked quickly', and so on. In Table 3.1 is it clear to see that on a macro-level, the agents in these constructions move from being centred on the first person ('I was running', 'I ran'), to identify a collective group of agents ('four other men', 'five men', 'two men'), to single out one or two specific agents - Jed Parry and Clarissa - to finally group the action around a first person plural agent ('were we', 'we were'). This alteration in agents parallels Joe's shifting perspective: he is demonstrating the assorted views of the event, and in casting others as agents in the scene in addition to himself he seems to indicate that he alone was not culpable.

The first paragraph of the passage (Extract 3.1) starts with a definitive description of the 'beginning'. Both Joe and Clarissa are cast in agent roles that detail past progressive processes ('I was kneeling', 'Clarissa was passing', 'I was stretching'); incomplete actions that establish that 'this was the pinprick on the timemap' before their situation became disrupted. The metaphorical use of 'pinprick' in this construction evokes a police evidence board; a calculated mapping out of events. This evidence board interpretation is further emphasised through the high level of specificity and elaborated description: they were sitting under a 'turkey oak', about to drink 'a 1987 Daumas 
Gassac'. At the reference of a 'shout', the coordinating conjunction 'Next thing' signals a shift in perspective as the 'transformation' becomes 'absolute'. At this point the construal undergoes subjectification as Joe's experiencer perspective becomes more prominent, through both explicit first person reference and the evaluative lexical choices: 'I don't recall'. This subjectification is further emphasised in the following construction:

What idiocy, to be racing into this story and its labyrinths, sprinting away from our happiness among the fresh spring grasses by the oak.

(McEwan 1997:1)

The metaphorical use of 'racing' and 'sprinting' here manages to both keep the construal subjective (by referencing the conceptualiser's experiencer role within the viewing frame), but also objective in that it keeps a reader's attention trained on the physical action (the 'running') within the narrated event. Like the verb 'run', 'race' and 'sprint' are, in image-schematic terms, processes that require strong purveyors of energy, requiring an agent which exerts a considerable amount of force. Thus a clear parallel is drawn between the high agency and energy of the description of the events in the field, and Joe's description of his own thoughts. This parallel is reinforced in this latter half of the construction where 'happiness' is represented as a physical landmark; a location left behind.

The beginning of the second paragraph shifts the perspective to the buzzard's eye view, and this time Joe's reconceptualised experiencer role is grounded in the present: 'I see us from two hundred feet up'. The construal in this paragraph moves from being grounded in the first person, to the 'eyes of the buzzard', to referencing an earlier time in the day ('the buzzard we had watched earlier'), and then returning to the buzzard's viewing platform: 'five men running silently toward the centre of a hundredacre field'. For Clarissa and Joe, the buzzard formed a background part of the overall scene prior to the incident. From the platform of retrospection, however, Joe profiles 
this memory of the buzzard and displaces the ground of his perspective to the bird's eye view. Though the buzzard is not referenced directly again until the end of the paragraph, this point of view is maintained covertly through the perspectival scope: the viewing frame here observes 'a hundred-acre field', figures which are both '[a]bout two hundred yards' to the left of Joe, as well as the 'line of beeches on the far side of the field a quarter of a mile away' - all spatial references that are construed from a bird's eye view that offers a wide-reaching and maximal scope not available to Joe's immediate experience at the time. The buzzard is then explicitly reinstated as a reference point - a salient entity in the scene - at the end of the paragraph ('To the buzzard, Parry and I were tiny forms') but again the sense of perspectival scope afforded by the buzzard's perspective is also mentioned again implicitly, through the underspecified description of the balloon with its 'puny human distress at its base'.

Arguably there is a conflation of viewpoints, however, as this maximal scope of the scene is referenced at the same time as Joe's first-person perspective is reinstated. In other words, Joe anchors his movements through first person pronouns ('I approached from the southeast, with the wind at my back') and references direct orientation ('my left'), while simultaneously describing the full details of the rest of the scene (which he would only know about if he had access to the information afterwards, or if he had imagined another perspective). This blurring of perspectives complicates the grounding: what are the actual spatiotemporal parameters of the description? Which parts of the scene were experienced at the time, and which were 'filled in' later? This can further be seen in the grounding predications used in conjunction with other attractors: the indefinite labels of the beginning of the scene ('a child', 'a man') are contrasted with full nominals here ('John Logan, 'Jed Parry').

That Joe's description of the event has been thought about and discussed before is very clear. The third paragraph in Extract 3.1 explicitly highlights Clarissa's role in 
shaping the story, for, as many critics observe, both 'Joe and also Clarissa obsessively retell the story of the accident [and] turn it into a narrative' (Palmer 2007: 295). Joe shifts perspective to show Clarissa's part in the scene and it is clear that this detail, at least, has been provided retrospectively, as signposted through the reporting clause: 'She said she walked quickly to the centre of the field', and elaborated with his own evaluation: 'I don't know how she resisted the urge to run'.

At this point in the scene, the action chains become less dynamic. The characters and attractors are cast in low-energy agent or experiencer roles primarily - 'describe' (x2), 'saw', 'said', 'know', 'told', 'waiting'- and the mover/agent roles assigned are, again, comparatively to the earlier paragraphs, either paired with mid-low energy processes ('walked quickly', 'caught up', 'promoted') or cast in passive constructions ('What I describe is shaped by what Clarissa saw too', '[Clarissa] was well placed as an observer'). The scene at this stage becomes like a tableau, while the return to the buzzard's perspective here fittingly references Langacker's billiard ball metaphor for action sequences: 'the convergence of six figures in a flat green space has a comforting geometry from the buzzard's perspective, the knowable, limited plane of the snooker table'.

\subsubsection{Modality and metaphor}

The conflation of viewing platforms is also signposted through Joe's modalised language, which becomes much more overt in the third and fourth paragraphs as the description becomes increasingly stative and as Joe's experiencer role - his TW1 platform - equally becomes more prominent. Words of estrangement (Fowler 1996) are used in the very opening ('I don't recall') to distance Joe from the events he is describing, and this modalised language is developed here further through 
approximation (he describes the car 'banked on the grass verge with $\underline{\text { its door, }}$ or doors, wide open', and references another character who is positioned '[a]bout two hundred yards to my left') and also, predominantly, through verba sentiendi ('Knowing what I know now', 'I think', 'I understood' ‘I don't know' 'I don’t think') (Uspensky 1973). In CG, 'I think' is an epistemic marker; 'an instance of "objectification" whereby the primary subject of conceptualization is construed as part of its own object of conceptualization' (Verhagen 2007: 71). In other words, through such epistemic constructions, Joe continuously places himself explicitly within the viewing frame. This functions as a reminder throughout the narrative that the scene is being filtered and mediated through his perspective, and thus allows readers to question this perspective as an object of scrutiny: just how objective is his account?

More generally, modality is identified as 'that part of language which allows us to attach expressions of belief, attitude and obligation to what we say and write' (Simpson 2002: 123). In cognitive linguistics, modal auxiliaries are seen as holding potential energy (see Evans and Green 2006). Langacker (2008: 299) argues that a semantic property of modal auxiliaries is that they profile 'a highly schematic process'. He further argues that ' $[\mathrm{b}]$ ecause they profile force tending toward an action, the source verbs [of modals] are both force-dynamic and future-oriented' (Langacker 2008: 304; see also Langacker 1999a). In CG, therefore, modality is seen to create latent energy; a kind of projected reality. In other words, a modalised expression displays a potential reality; it has 'weaker momentum' in terms of achieving real event status (see Browse 2014 and Stockwell 2014 for considerations of modality in CG). This approach is also taken in Text World Theory, where the use of a modal creates a world-switch that is secondary to the text world proper (see Browse 2014; Gavins 2007; Lahey 2004).

At this point in the narrative, Joe draws attention to the conceived time of the text; he highlights time as 'an object of conception' (Langacker 2008: 110). Like with the 
lexical choices at the end of the first paragraph, here material processes are paired with his experiencer status: 'I'm holding back, delaying the information'; 'I linger on [...]'. This recurrence of Joe's clausal grounding draws attention to the 'constructedness' of the narrative (Nicol 2009). Equally, as identified in the previous section of analysis, the presence of modality in this scene again creates a subjective construal - in other words, his evaluation has greater prominence and his authorial voice is foregrounded.

Other lexical choices signpost the extent of the narrator's 'obsessive reexamination' of the event, and although the antagonist Jed is the character who suffers with Clerembault's syndrome, Joe's perspective here shows a similar inclination toward obsession. It is argued that '[b]ecause of his occupation, Joe has a tendency to consider scientific explanations for events' (Palmer 2009: 296), and this is apparent through the technical descriptions in the extract. The spatial markers, for example, are expressed through specific prepositional phrases ('in sunlight', 'under a turkey oak', 'on the grass', 'across the field'), and with exacting geographical information, 'comforting geometry' and 'mathematical grace' ('I approached from the southeast; a hundred-acre field; 'two hundred yards to my left'). This specific and exacting description outlines the information categorically - a stylistic feature that helps increase the narrative pace of the scene according to Simpson's list.

Just like the contrast between categorical and modalised expressions, however, metaphorical descriptions throughout the extract act to counterbalance the technical language, such as the following construction at the end of the third paragraph:

The aftermath, the second crop, the growth promoted by that first cut in May.

(McEwan 1997: 2)

Again, this evaluative, more emotive language further subjectifies the construal. The reference to the 'aftermath' of the accident as a 'growth' both evokes the dominion of 
farming maintained through the reference to 'the second crop', but also opens up a secondary dominion; its definition within a medical context.

The final two paragraphs of the scene focus more solely on the event in the field, as the maximal scope of the scene is finally shown, and the metaphorical language here becomes so self-referential as to 'break frame' (Cobley 2001):

What were we running toward? I don't think any of us would ever know fully. But superficially the answer was a balloon. Not the nominal space that encloses a cartoon character's speech or thought, or, by analogy, the kind that's driven by mere hot air.

(McEwan 1997: 3)

Reviewer Mars-Jones (1999) describes such a 'sharp-elbowed nudge to the reader' as not occurring until later in the novel, but in the first example listed here a reference to the constructedness of the narrative ('the nominal space that encloses a cartoon character's speech or thought') - and to narratorial unreliability ('mere hot air') - is signposted self-reflexively at this early stage in the novel, even if framed as a negated construction.

Clearly, the language undergoes subjectification throughout the passage, and the pace of the scene is both hastened and slowed down by particular lexical choices. This next and final section of the analysis considers the part of the scene that forms the focus - either off-stage or on-stage - of all of the descriptions. Joe's narrative conflates the description of the air balloon itself, the situation of danger and the terrible repercussions of the event and describes them collectively, in both literal and figurative constructions. Like the reference to 'happiness' as a physical location in the first paragraph, this conflation of references again acts to draw a clear parallel between the physicality of the scene and its emotional consequences: they are interconnected and inseparable as the object of attention from Joe's perspective. 


\subsection{Nominal grounding: Schematicity vs. specificity}

Stockwell (2009: 184) argues that in high action scenes '[y]ou might expect clausal action chains to be short and direct, but with very close co-reference and highly normative dominion traces'. In this scene, despite the stylistic features which do fit the 'high action', narrative urgency profile as previously observed, the co-reference between the noun phrases which describe the 'situation of crisis' (Childs 2007) are not necessarily 'normative' ones. Instead, 'the moment' is instead described cataphorically, with targets indicating previous reference points which at times seem normative in the sense of being clearly connected through grammatical anaphora ('the danger' > 'it') or through simply providing more detailed information ('a balloon' > 'an enormous balloon filled with helium'). At other times, however, these connections are disconnected. This latter example, for instance, introduces a reference point which in other any context would be harmless ('a balloon'), but then the elaborative target ('an enormous balloon filled with helium') causes an immediate reconstrual (see Forrest 1996) of the sense of scale. This simultaneously acts to draw a connection between something benign, and 'the danger' of 'the colossus' previously mentioned.

Equally, readers are aware that it is an 'event', but also a 'scene' (more stative); that it is both a 'beginning', and yet also 'a catastrophe':

the beginning

the moment

$>$ the pinprick on the time map

the danger

$>$ it

the scene

the colossus

the encounter

$>$ it

the event

$>$--the fall -

what happened in a field waiting for its early summer mowing 
a balloon

$>$ an enormous balloon filled with helium

a catastrophe

$>$ a kind of furnace in whose heat identities and fates would buckle into a new shape

Full elaboration: At the base of the balloon was a basket in which there was a boy, and by the basket, clinging to a rope, was a man in need of help

Figure 3.1. (Under-) specificity of reference: The hot air balloon accident.

Figure 3.1 shows the pairing of reference points with their successive targets (shown through the use of arrows) at the sentence level in the text. Of course, grammatically speaking and at the macro-level of the text, all mentions or elaborations of 'the incident' after its very first mention ('the beginning') are targets to the original reference in the sense that all expand on the original description with incremental detail. It is clear to see how each successive description elaborates on and contributes to the holistic or maximal scope of the scene.

Readers make connections between the targets and reference points in this extract despite the lexical underspecification (Emmott et al. 2006) because the event is an attractor (Stockwell 2009). It fulfils particular criteria for holding our attention (see Stockwell 2009: 25)- it is large ('the colossus'), it is hazardous ('the danger'), and it holds some inherent action ('the event', 'the fall') and is noisy ('There was the shout again, and a child's cry') in comparison to the other attractors (the figures who are 'running silently') but in other ways it does it is not a typical attractor. It is not given direct agency - and in fact causes the energy sink for many of the actions. In other words, the particularly prominent trajectors - the human attractors in this scene -are 'running toward it'; it occupies a static location in the scene and holds a patient role superordinately, despite being the focus of the attention.

Arguably, however, the descriptions become increasingly - or rather, more obviously - co-referential, as the more granular parts of the scene begin to combine to 
form the scene in its entirety, the full scope of which is finally revealed at the end of Extract 3.1: 'At the base of the balloon was a basket in which there was a boy, and by the basket, clinging to a rope, was a man in need of help'. This final sentence represents a series of image-schematic relationships ('at the base of', 'in which', 'by the basket') which creates increasing granularity of expression; what Langacker (2008: 83-5) calls a 'nested locative' construction.

Overall it could be argued that the references to 'the event' are ambiguous and, at times, contradictory. Just when it appears that readers are provided with more specific information which elaborates on the previous reference, the descriptions then become less specific once the situation has been reconstrued. This is signposted through a shift in grounding predications, which move from the definite to the indefinite:

$$
\text { the event }>\text { the fall }>a \text { balloon }>a \text { catastrophe }
$$

This shift from the definite to the indefinite acts to defocus the event in the final descriptions. It seems that the closer the narrator gets to it, the more he wants to 'linger in the prior moment' and not examine the event too closely. Instead he profiles different elements of the maximal scope - 'its base', 'helium', 'base of the balloon', 'basket', 'rope' - rather than the scene in its entirety, as if to maintain distance between himself and the event. Contributing to this defocusing process, the use of metaphorical noun phrases to describe the event ('the moment' > 'the pinprick on the time map'; 'a catastrophe' > 'a kind of furnace in whose heat identities and fates would buckle into a new shape') opens up new dominions than those previously established. In other words, if we consider the final 'furnace' metaphor here as a target it does not obviously, or directly, refer back to the initial reference point: 'the moment'. It does, however, connect thematically with 'the danger', and 'a catastrophe', and on a more literal level of course 
with the description of the helium in the balloon. Again, these kinds of descriptions act to bring certain portions of the scene on-stage, while pulling back from offering a holistic description until the final line of the extract.

Stockwell (2009: 182) further argues that 'close co-referential chaining across sentences and clauses should also increase the sense of pace, since this would mean that focus is being held and sustained rather than meandering around a scene'. As this analysis has shown, the reference chains here are both close and disparate; increasing the pace in one instance to only stall it in another. The focus of the scene continually shifts, but rather than this tracking a 'meandering' route around the narrative, the variation in reference and action chains show a narrator who is so focused on the event and the accurate representation of parts of the scene as to lose sight of the bigger picture.

\subsection{Conclusion: 'What were we running toward?'}

Overall, this analysis has shown that the conflicting representations of action chains, grounding and lexical specificity complicate how this extract fits Simpson's (2014) narrative urgency profile. Summatively, Birkerts (1998) describes this scene as 'the climactic event [that] takes place right at the outset', and he further reviews the energy transferral as adhering to a single 'macro-design' (Herman 2002): 'the essential action can be described as "falling"'. These perceptions of the scene can be traced to the stylistic choices of the text. The attention placed on the event marks it out as a climactic and powerful moment; certainly one that warrants 'obsessive re-examination'.

It has been observed that the scene oscillates between processes that are forceful - holding strong image-schematic power (as in the high-energy verb choices) - and those comprising more latent energy that create a sense of conceptual remoteness 
between the speaker, Joe, and the material being described (as signposted through the modalised descriptions and the metaphorical language, for example). Rather than a separation of these stylistic traits into two distinct contrasting passages, the scene instead represents language features that both reinforce and stall its pace and sense of narrative urgency within the same stylistic gestalt.

In conclusion, CG provides an account of style features that arguably impact on narrative urgency, and that could be considered as part of its stylistic profile: namely, (1) action chains (2) under-and over-specification and (3) grounding/ subjectification of construal.

Firstly, a consideration of action chains has helped to describe the pace of this opening scene. Although there is not as much variation according to the associated process type as seen in the Hallidayan model, a CG account is instead driven by an explanation of energy; describing where it is created, how it is used and where it becomes displaced. A CG analysis of energy therefore helps to consider, through a nuanced and close textual analysis, the level of force inherent in a particular lexical choice. More generally, an action chain analysis indicates the relationship between figure and ground at the macro-level of the text; demonstrating the image schemas that underlie the passage and which 'contribute the dynamic scaffolds of a scene' (Kimmel 2011: 237). It was observed how the figure/ground relationships changed throughout Extract 3.1, with Joe and the other characters as moving and thinking 'attractors' that form the focus in many of the constructions, but with the static 'event' superordinately acting as the locus of their attention throughout the text. Both Joe (the conceptualiser) and the scene (the object of conceptualisation) are therefore profiled at alternating points in the discourse. The profiling of this fixed event in comparison to the more dynamic narrator/characters both disrupts the narrative urgency, and yet 
simultaneously heightens it. It creates an inevitable sense of momentum; a point of orientation around which the action occurs.

Secondly, the analysis here has observed how movement from descriptions which are more granular to those that are more fully specified can disrupt the narrative urgency of a text. In the final section of analysis it was observed how one of the 'stalling' features in Extract 3.1 is the prevalence and prominence of under-specified event. A study of construal, and the varying levels of specificity for description, allows a way to explore the direction of greater or lesser attentional focus on particular aspects of the scene. The level of specification indicates how proximal or remote the conceptualiser is from their material - and by extension this references the fact, as in the case of this opening passage, the narrator was not privy to the full scope of the event at the outset. He is not a reliable narrator as we are left unsure of which parts of the scene were experienced first-hand, and which were added (or imagined) afterwards.

Thirdly, CG's grounding helps to explain this relationship between the narrator and the scene being described, for it is a linguistic phenomenon that 'reflects the asymmetry between the subject and object of conception: that is, the conceptualizer and what is conceptualized' (Langacker 2008: 260). This means that the text moves from more objective to more subjective construals of the scene according to what is the focus of the viewing frame at any given moment in the narrative. Equally, as has been shown in the analysis here, the two main platforms for grounding the narrative are the time of the event itself, and the aftermath - the current text world of the narrator and conceptualiser Joe. The nominal grounding and varying levels of specificity, in particular, show his scientific perspective: his desire to provide a complete, objective narrative. However much Joe tries to be objective in his descriptions, though, his presence as a narrator is always signposted - either offstage or onstage - which filters the level of neutrality. This supports another central theme of the novel identified by 
many of the critical reviews: namely, that subjective construal is inevitable - 'that unreliability is an ineradicable part of what we are' (Birkerts 1998).

\subsection{Review}

To summarise, this chapter has presented a CG account - applying central CG concepts, such as grounding, action chains, reference points and specificity - of the sentence and phrasal levels of a literary extract. This chapter has argued that a stylistic analysis using CG can successfully describe the chaining of action and energy across a passage that comprises both modalised and high-action process descriptions, and that combines both a grammar of anticipation and a grammar of action (Stockwell 2009) into a single stylistic gestalt. Unlike Nuttall's (2014: 98) analysis of the 'collage'-like structure of The Handmaid's Tale that invites readers to construct the fictional world sequentially, this scene from Enduring Love does not maintain a consistent level of subjectivity. Instead there is movement from the conceptualiser, to the object of conceptualisation, and then back again. These ideas are considered in greater detail in the analysis of Chapter 7.

The next chapter returns to the idea of the CG's reference point model, in particular, to consider how readers keep track of references and targets across a longer stretch of narrative: Auster's The New York Trilogy (2004, published 1985-1986). Drawing on reader response data, the analysis specifically explores how readers can keep track of a complex narrative in which character roles are constantly changing. 


\section{Chapter 4. The reference point model: Tracking character roles in The New York Trilogy}

\subsection{Introduction}

The New York Trilogy is a famously complex detective narrative that comprises three partly interrelated stories (City of Glass, Ghosts and The Locked Room) that were originally published in a sequence (Auster 1985-1986). The essential narrative components of the three stories can be summarised collectively. Each story features a male protagonist tailing another character at the request of a third party, but the aim of each request is unclear. Although primed for action, the protagonist in each story does not end up fulfilling the detective role laid out for him, but rather follows a path of introspection that ultimately ends up changing his identity. In the process of tailing another character, the identity of the protagonist in turn becomes variously displaced: he is cast in the role of author, criminal, detective and writer, but these identities are layered and constantly changing. As such, it is a convoluted text, which requires readers to continuously adjust to the multivalent identities of each protagonist throughout the narrative.

Drawing upon reader review data (listed in the Appendix, R1-R11), the first part of the analysis demonstrates how CG's reference point model (RPM) can help conceptually model idiosyncratic interpretations of the text. Specifically, the RPM analysis explores how readers keep track of the shifting character identities within The Trilogy. The second half of the analysis provides a CG account of how the character roles are represented on a more micro-level in the three stories. This in turn allows a conclusion to be drawn about the 'macro-designs' (Herman 2002) - the linguistic templates or stylistic patterns - that form the basis of The Trilogy. 


\subsubsection{Reference points in fiction}

The analysis in Chapter 3 identified the description of the event - the hot air balloon incident - and described this as a reference point in the scene. In other words, it was a salient part of the scene around which other descriptions were oriented. Figure 3.1 details the targets that refer to this reference point. The analysis in Chapter 4 builds on these ideas to outline how such orienting reference points work at the macro-level of a text. In this chapter, the analysis focuses specifically readers' response to the character roles within The Trilogy.

There are two previous applications of CG's RPM that are particularly useful here: Stockwell's (2009) analysis of literary texture in Bleak House, and van Vliet's (2009) discourse-level application of reference point anaphora in literary fiction.

Stockwell uses a CG action chain analysis alongside the RPM to describe the transmission of energy and literary texture created by the extended references to water in a passage from Bleak House, which is infused with water imagery. A section of this passage (Dickens 1994, published 1852: 7-8) is as follows:

The waters are out in Lincolnshire. An arch of the bridge in the park has been sapped and sopped away. The adjacent low-lying ground, for half a mile in breadth, is a stagnant river, with melancholy trees for islands in it, and a surface punctured all over, all day long, with falling rain.

In this analysis Stockwell (2009: 180) discusses the process of evocation, whereby potential referent points form targets within the dominion: the 'set of associations' attached to the initial reference point. Stockwell highlights how, in this Dickens passage, the trajector (the 'waters') forms a reference point from which other targets are formed. 
Stockwell observes how reference points and dominion tracing also function to outline the transferral of energy in this Bleak House extract. For instance, 'the waters' have an agent role here: they form the energy source. On the other hand, the 'arch' holds a patient role in that it is affected by the waters' sapping and sopping action: it forms the energy sink. Other associative targets from the original reference point can subsequently be traced in the passage: 'sapped', 'sopped', 'stagnant river', 'falling rain' and so on. These targets are therefore chained across the passage as co-referents and function to create a particular literary texture.

Following this analysis, Stockwell lists a number of ways in which the application of the reference point model can be useful in literary linguistic analyses. Firstly he identifies that the reference point model outlines the relationship between cohesion and coherence in the production of literary texture. Secondly, it captures both the tone and atmosphere of a piece of literary discourse. Thirdly it accounts for experientiality and radial adjustment (a label with visual connotations, which describes how you can zoom in or out of a text in order to comprehend it successfully), and finally it highlights the importance of text-drivenness. In other words, the model can explain how structures of knowledge can be instantiated through 'specific traces' in a literary text (Stockwell 2009: 182). These ideas will be addressed in the analysis below.

Stockwell's analysis successfully demonstrates how a RPM analysis offers a finegrained account of literary texture. But, as mentioned in the Chapter 2, it is well documented that cognitive linguistics promotes the scalability of models; and van Vliet (2009: 440) similarly argues that linguistic phenomena present in sentence level can also be scaled to apply to the discourse level of texts. Van Vliet's (2009) reference point analysis extends the methods used in Stockwell's study to provide a discourse level analysis of the RPM in literary application. In this study, van Vliet looks at reference maintenance (2009: 442) in third person narratives, where proper name/ pronoun 
reference plays a more important role than in, for example, first person texts. As a starting point for analysing reference points in narrative, van Vliet suggests that researchers 'must consider 'the flow of attention throughout discourse' (2009: 447); and bear in mind that 'the representation of narratives (in terms of dominions) is primarily a conceptual rather than linguistic construct' (2009: 448).

This latter point is particularly important. The following analysis is a conceptual account of how reference points are maintained across the narrative, and not a purely traditional 'grammatical' one. Furthermore, the analysis in this chapter combines the methods used in both Stockwell and van Vliet's studies. It firstly considers reference maintenance at the macro level of the text (Sections 4.2-4.3), and secondly it observes how these reference points are maintained through specific textual choices (Section 4.4).

\subsection{The New York Trilogy and the postmodern quest}

The critical literature written on The Trilogy draws out the differences between the classic detective story, the contemporary detective story and the postmodern detective quest (Alford 1995; Cobley 2012; Dimovtiz 2006; Jones and Ells 2011; Lavender 1993; Little 1997; Rowen 1991; Russell 1990; Segal 2010). McHale (1992: 147) defines classic detective fiction as texts that are 'organized as a quest for a missing or hidden item of knowledge'. An alternative definition is offered by Cobley (2012: 237), who discusses verisimilitude in contemporary detective fiction and describes the propensity for contemporary crime fiction to firstly include a murder, considered by the genre as 'the only crime of note', and secondly to be realistic. 
The Trilogy differs from these two straightforward descriptions. It is largely branded a postmodern, metafictional text (Russell 1990; Shiloh 2002, 2010) in that it 'self-consciously and systematically draws attention to its status as an artefact in order to pose questions about the relationship between fiction and reality' (Waugh 2002: 2; see also Currie 1995). This description is certainly applicable to The Trilogy, with many of the critics arguing that the novel is self-reflexive and self-conscious in its use and manipulation of critical theory, in particular. Put simply, the text is a sort of 'postmodern primer' (Dimovitz 2006: 615), which seems to parody particular aspects of literary theory - namely Chatman's (1978) model of ideal/implied author (Lavender 1993).

Alongside the self-awareness of the text, it is also frequently noted that the basic narrative components of the detective genre are not fulfilled in The Trilogy. As an overall construction, the form is seen as incomplete and there is a lot of gapped (Talmy 2000a, 2000b; see Chapter 6) information. As such, the resolution (Labov 1972) in each of the stories is seen as ambiguous or simply missing. Although this is seen to be a common stylistic trait in detective fiction (Cobley 2012), the level of missing information is taken to the extreme in The Trilogy. Lavender (1993: 220), for example, points out how the story finishes in the middle of the event processes, 'at that place where it is most profligate of potential solutions, and then abandoned never to be resolved'. Little (1993: 133), on the other hand, argues that despite the actions of the author/writer, the narrative plots are 'continually foiled' in The Trilogy. In imageschematic terms, there is no clear demarcation of SOURCE-PATH-[GOAL], and the '[t]he movement of the novel as a whole can be plotted as a series of [...] ellipses' (Lavender 1993: 233). In other words, Auster's overall style has a 'refrain of nothing' (Little 1993: 134) that complicates its overall construction, and consequently readers' reception of it. 


\subsubsection{Layers and targets}

Of postmodernist fiction it is said that '[c]lues no longer point to anything certain; signifiers have drifted away from what they signify' (Rowen 1991: 225). Consequently the linguistic construction of The New York Trilogy shows a kind of weakening of symbolic correspondence between the two poles of form and meaning. This separation creates a problematic relationship between the role of the narrator and the reader, which means that Chatman's (1978) model of narrative layers is mentioned in much of the critical material written on The Trilogy (See, for examples, Rowen 1991; Lavender 1993).

Chatman's (1978) model outlines the levels of readership and authorship in a given text, as shown in Figure 4.1.

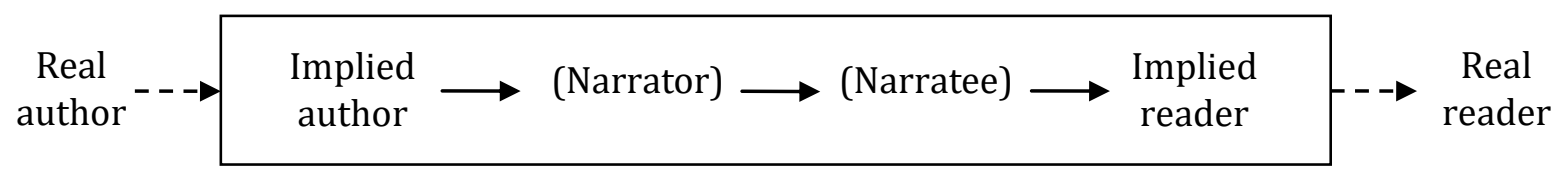

Figure 4.1. Narrative layering, from Chatman (1978: 151).

The implied reader is a construct assembled by the real reader: 'it is a picture, based on the text in its totality, of the kind of reader or archetypal reader that real readers assume that the text has or had in mind as its audience' (Toolan 2001: 68). Arguably, previous literary material written on The Trilogy has relied upon this latter construct. The complexity of textual figures means that the situated or real reader of The Trilogy has been overlooked, because it is difficult to map the relationship between the reader and the narrator/ implied author roles directly. Through observing reader reviews alongside an analysis of The Trilogy, the analysis in this chapter incorporates a reception-based analysis beside the more typically discussed authorial end of the 
spectrum. This is important as, at the reception end of the reading process, Toolan (2001: 67) labels the reader as a 'core participant' in the narrative transaction and the narratee and implied reader as secondary entities.

Although it is arguably difficult to draw connections between real readers and the implied authors/ narrators of this narrative, similarities have been drawn between the three respective narrator roles at the discourse-level of The Trilogy. Dimovitz (2006), for example, discusses how, if indeed each of the three stories are the same story (as maintained by the narrator at the end of the third story The Locked Room), then there are a few ways in which we can draw equivalences between the characters. He observes that the most likely interpretation is that the final narrative voice can be regarded as the narrator/author of all three of the stories. This interpretation 'places the narrator of The Locked Room in the position of the unreliable narrator of City of Glass, [and] Quinn in the position of Fanshawe' (Dimovitz 2006: 623). In this way, Dimovitz uses his construal of a singular narrative voice to draw parallels between the archetypal roles of the three respective protagonists, as seen in Table 4.1.

\begin{tabular}{|c|c|c|c|c|c|c|c|}
\hline $\begin{array}{l}\text { City of } \\
\text { Glass }\end{array}$ & narrator & reconstructs & Quinn & $\begin{array}{l}\text { who } \\
\text { watched }\end{array}$ & Stillman & $\begin{array}{l}\text { At the } \\
\text { request } \\
\text { of }\end{array}$ & Stillman \\
\hline Ghosts & narrator & & Blue & & Black & & White \\
\hline $\begin{array}{l}\text { Locked } \\
\text { Room }\end{array}$ & narrator & & Fanshawe & & $\mathrm{X}$ & & $\mathrm{Y}$ \\
\hline
\end{tabular}

Table 4.1. Schematised model of actants and processes, from Dimovitz (2006: 623).

Here Dimovitz draws schematic connections between each participant and the actions they perform at the macro-level of the text. In the above table he summarises the main processes of the three stories, identifying how in each story a narrator reconstructs the protagonist, who in turn watches another main character. At the global 
level of the text, Dimovitz casts the three protagonists in superordinate experiencer roles (introduced through the two mental processes 'reconstructs' and 'watched'); but at the same time they hold patient roles, as they are ultimately all instructed in their actions by a third party ('at the request of').

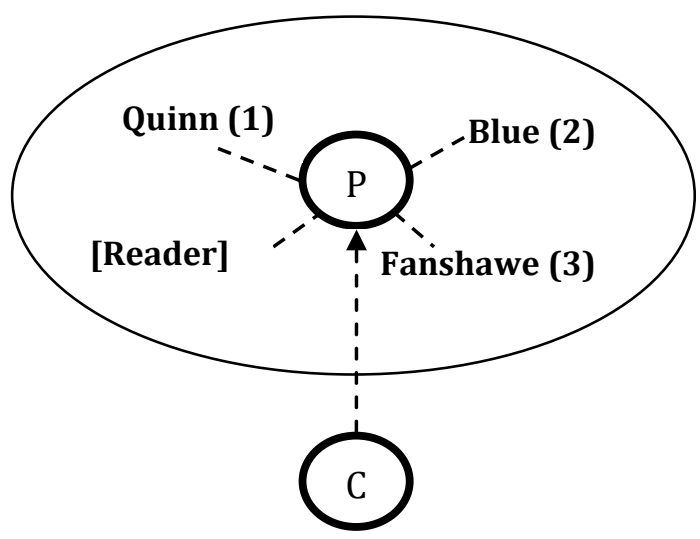

Figure 4.2. RPM after Dimovitz's (2006) reading of The Trilogy.

Drawing such equivalence between the three protagonists of the three stories means that, arguably, readers (or conceptualisers (C)) can identify each of the three characters as a potential target for the reference point of the generic discourseprotagonist (P) role. This can be conceptually represented through CG's RPM, as shown in Figure 4.2.

Like the other reviews of the text, Dimovitz observes the production as opposed to reception end of the text, despite the lack of a fourth wall in The Trilogy and the somewhat 'intrusive' use of metafiction (as argued by R9 in the next section of analysis). The following analysis uses reader review data to address how this 'intrusive' narrative style breaks down the ontological boundary between the world of the text and the world of the author and reader, so much so that readers are required to take a more instrumental role in the construction of the narrative, as indicated in Figure 4.2. 


\subsection{Reader response: Tracking character roles}

Following Langacker's (2008) RPM, Stockwell (2009: 182; see also Stockwell 2000: 148) identifies different types of recall which explain the various processes through which readers can track references in a text (Table 4.2).

New evocation

a neologistic or proper noun reference point, directly placed by the current position in the text into working memory

\begin{tabular}{l|l}
\hline Old evocation & a reference point from experiential
\end{tabular}
memory, directly placed by the textual realisation into working memory

Renewing invocation

a target, maintained textually in working memory by cohesive devices and anti-shift devices

Recalling invocation

a target, revivified from recent, semi-active memory into active working memory (often from recent co-text)

Gradual revocation

the loss of a target from working memory by non-mention, or by occlusion of other, newer reference points and targets

Defeased revocation

the deletion by negation or verbrevocation of a target, and its subsequent non-reappearance.

Table 4.2. A cognitive typology of reference (Stockwell 2009: 182; 2000: 148).

The old evocation of the reference points seen in The Trilogy can be attributed to the genre itself. Detective fiction has many set features, including the types of roles readers expect to see played out by the characters. Sometimes these evocations can cross ontological boundaries. Todorov (1997: 49), for instance, draws clear parallels across the ontological boundary of detective fiction, likening the [real] author to the criminal, and the [real] reader to the detective in his summary: 'author: reader = criminal: detective'. Rather than keeping reader and writer roles outside of the 
narrative transaction proper, Todorov's view brings the reader and writer roles into the narrative transaction.

This is a process which becomes even more complicated in The Trilogy by the fact that each character has multiple roles and new evocations are generated continuously, layering simultaneous targets for the same reference point. In the first story, City of Glass, for instance, the protagonist Quinn is originally a writer, who becomes a detective through a case of mistaken identity. An enactor of Auster himself appears in the novel as a writer, but someone who is initially believed to be a detective. This layering of identity means that all four roles (writer/reader, criminal/detective) become potential targets for the protagonist Quinn (Q), as seen in Figure 4.3.

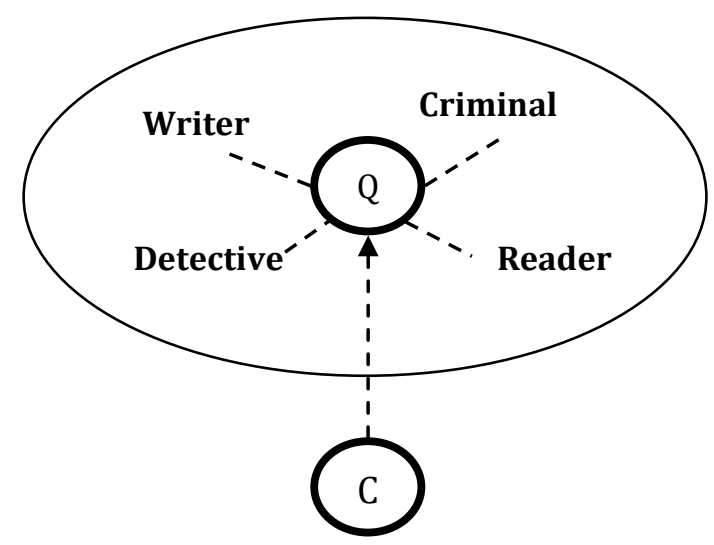

Figure 4.3. RPM after Todorov (1977): Equivalent targets in City of Glass.

Clearly, it is the way that these roles are evoked, invoked and revoked that complicates the reading of this text. The typology of reference in Table 4.2 will therefore be a useful guide to exploring the changing roles within The Trilogy. In general both critics and readers (see reviews R1-R11 in Appendix) comment upon the convoluted and 'perplexing' (R7) process of tracking the character roles across the three stories. While Langacker (2008: 490-1) argues that conceptual overlaps across linguistic constructions create cohesion, here it seems that the plurality of potential targets has the opposite effect. 
A common conceptual metaphor used in reading, which is perhaps particularly applicable to both traditional and unconventional detective fiction, is that READING IS A GAME (Herman, Jahn and Ryan 2005). The rules of this game are said to be governed by two central questions: (1) 'Whodunit?' and (2) Who is guilty? (Herman, Jahn and Ryan 2005: 103). Some reviewers have extended this metaphor even further and develop new associated conceptual metaphors for how we read this particular literary text: such as READING IS A JOKE ('Auster is also having fun playing games with us', R7; 'Auster plays with the reader, the three books of the trilogy are like puzzle pieces that connect only at times', R8; 'I do wonder whether the whole thing was a joke by the author to write a meaningless book and wait for people to assign meaning that isn't really there', R10) or perhaps that READING IS AN EXPERIMENT ('There is surely a vagueness [...] as if it were an experiment the author is playing with the reader', R8).

R10, in particular, argues that the rules dictated by the underlying READING IS A JOKE format means that these two central questions are not answered ('Yes, there are detectives in the book, and they do detecting, but they aren't investigating crimes, and they are all ultimately unsuccessful in their work'). Here R10 draws on the old evocation of the narrators as detectives, but their inability to perform the expected actions ('investigating crimes') complicates her reception of the text. Consequently she argues that reading The Trilogy is 'ultimately pointless', and that the figures and the reference points of the text are too complicated and ambiguous to fulfil the evaluation of the narrative: the necessary part of the discourse which wards off the 'so what?' question (Labov 1972) ('And when you get to the end, you wonder - what on earth was the point of that?', R10).

One of the cohesive ties across the three stories is the fact that, ironically, none of them presents a complete narrative. On the integral role of closure in detective fiction, Segal (2010: 155-7) says that the notion of 'closure' is a spatiotemporal phenomenon, 
and one which should be dynamically considered at the level of the literary discourse as a whole. Cobley (2012: 290) in turn states that there is actually a 'tendency towards lack of resolution in some crime fiction'.

In The Trilogy the notion of 'closure' is discussed by many of the readers. The text is seen as not only unfinished but unbalanced, as readers are offered 'more questions than answers' (R6). R8 similarly notices the lack of conclusion, saying that the text presents 'mysteries without resolution', which creates a 'sense of vagueness'; put simply, there is no 'tidy solution' to the narrative. Despite this 'unsettling experience' (R7), however, some reviewers view this experience positively:

- ' it gets your brain working and that's a good thing' (R7)

- It's 'intelligent yet entertaining' (R1); and

- 'it is a book that will make you think. Like it or dislike it, it is in many ways an uncomfortable read that will lead you to a deeper awareness of consciousness and torment, while also bringing you the peace of recognition' (R8).

The prominence of the puzzle format and the high level of intellectual demand of the text mean that the overall reception of some of the reviewers remains ambivalent. R7, for example, professes: 'I enjoyed it - i don't really know why', a position also shared with R10: 'OK, I read this all the way through. I'm not entirely sure why, but because I did, I'm giving this book 3 stars'.

This division amongst reviews can also be traced to the difficulties in tracking the character roles throughout The Trilogy, and many reviewers have drawn parallels between the protagonists across the stories or between other elements of the narratives. For these readers, references and targets are invoked throughout the reading experience. For instance, R3 identifies repeated world-builders that become motifs in the stories: 'I was also impressed with the way that each of these novellas had similarities in their plots and repeated elements, such as the red notebook or the names, but they still remained separate entities'. This is a common construal as seen in the 
other reviews. R5, for instance, says that the stories are 'intricately connected', although she acknowledges that these connections are not necessarily made explicit. Like Dimovitz (2006), for this reader the renewing invocation occurs through a summary of each protagonist's shifting roles:

In each case [story], the follower is transformed, by turn, into the followed. Each man begins to lose his grip on who he is. Identities are fluid, confounding, and often exchanged-sometimes over and over.

In contrast, R1's review identifies a different reading experience and follows the characters in another way. Rather than invoking connections between the stories throughout her reading experience, R1 instead identifies the revelation at the end of the third story that Fanshawe is the narrator of the first story functions as a recalling invocation. This leads R1 to retrospectively account for connections between the stories, although she identifies that the middle story Ghosts is the problematic piece in the sequence:

I assumed that the book being a trilogy is composed of 3 totally unrelated stories since I read in the write up that the stories were published one at a time in a weekly magazine in the 80s. However, to my surprise, at the end of the 3rd story - The Locked Room (which by itself was the best among the 3) - it was revealed that the detective looking for Fanshawe was the main character in the first story, The City of Glass. So, I had to think back on how the three stories relate to each other but I could not really figure out how the second - Ghosts - fit into the whole story as the main characters were named after colors - Blue, Black, Brown and White.

What happens for R1 after finishing the third story is a process of reconstrual ('I had to think back on how the three stories relate to each other'). Studied by Forrest (1996: 150) in relation to spoken discourse, this process is said to occur '[i]f the initial viewpoint on the scene is not one that meets the speaker's discourse goals (for example, because the speaker's visual attention was drawn to a referent that is not important or thematic)'. Here, R1's attention is drawn to the referent Fanshawe ('it was revealed that 
the detective looking for Fanshawe ['D' in Figure 4.4] was the main character in the first story'), which, as mentioned, creates a recalling invocation for the first narrator. This, however, does not meet R1's discourse goal ('but I could not really figure out how the second - Ghosts - fit into the whole story as the main characters were named after colors'), and therefore the reference point for the second narrator (Narrator 2) becomes a defeased revocation:

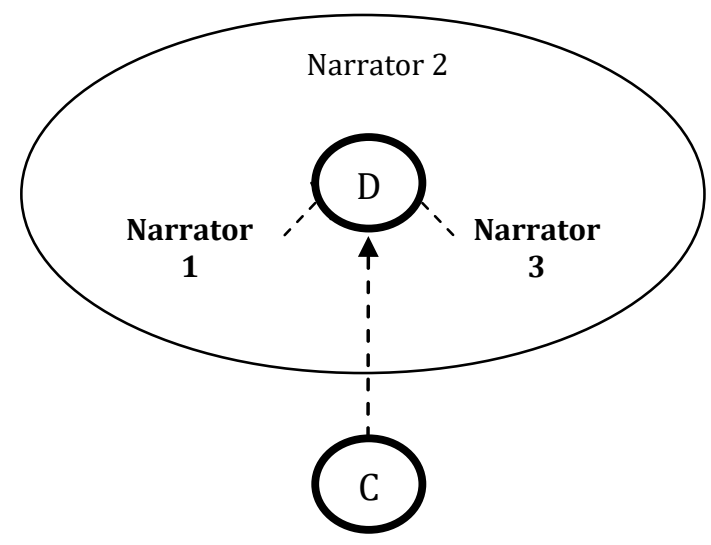

Figure 4.4. RPM after R1 (2011): The discarded target.

For R1 the lack of discourse goal accomplishment - and the deletion of a connection to Ghosts - seems to be brought about by the names, the proper noun reference points, themselves. Langacker (1991: 293) argues that human protagonists 'tend to be maintained as topics over long sequences of clauses. An established topic is unlikely to be coded lexically by a full nominal - some kind of pronominal reference [...] can generally be expected'. The difficulty in the second story for this reader is that the characters are not 'established' clearly initially, and the lack of an original full nominal as a reference point here sets the characters Blue, Black and White apart from the other 'human protagonists' in The Trilogy. Certainly this labelling dehumanises the characters and emphasises their functional role, which perhaps explains why they are revoked more readily than other targets ('I could not figure how the second - Ghosts - fit into the whole story', R1). 
Conversely other reviewers find that the similarities between references in The Trilogy serve a dissonant rather than a cohesive function. Breaking the fourth wall, and crossing the boundary of fiction into reality, are also much discussed in the reviews and whether the characters are 'realistic' or not seems to be a problem for some readers. R9 in particular seems to merge his construal of the implied author and real author in his interpretation of the text, claiming that the choice to repeat names is purposeful on the part of real world Auster, and that Auster is trying to make the point 'that names don't matter', and that 'only the story' is important. Consequently, R9 identifies that this technique prevents the narrative from becoming 'immersive'. R6 views The Trilogy similarly, stating that the lack of separation between the Auster real-world and textworld personas causes a struggle to believe the 'genuineness' of the characters, and that, consequently, the text poses 'more questions than answers'. Additionally, R7 asserts that the lack of separation between the roles at the production end of the narrative scale means that throughout the text Auster is demonstrating his 'ability to create fictional characters, exploring how much of the characters are invention and how much autobiographical', which complicates the relationship between the roles of real and implied author.

This relationship between plot and character is also discussed by other reviewers. R11, for example, says that a 'realm of unreality' is instantiated through the use of colour names, and the plot is unimportant compared with how a reader 'reformulates', or reconstrues, the characters: 'This reformulation is where Auster has staked his claim. He no longer wants to be the elephant in the room, he is dragging it out in front by the trunk!' Here R11 attributes greater attention and significance to how readers read the text, as opposed to the plot of the text itself. R11 goes on to extend this idea more widely, and describes The Trilogy as a metaphor for 'reading and writing a novel, with one character being the writer, one the reader, and one the publisher'. In 
their discussion of plot and character the reviewers also oscillate between sentence and discourse-level discussions of the text. R11, for example, says how the 'sentence-tosentence writing is somehow magically interesting', while others summarise the macrothemes of the text and across the three stories: how, '[i]n each case, the follower is transformed, by turn, into the followed' (R5), or how, in superordinate terms, the text is essentially 'a study on the watcher and the watched' (R1).

In trying to make sense of the text and its themes, and as is common amongst reader reviews in general, some of the reviewers have drawn upon the role of narrative interrelation (Mason 2014) in The Trilogy and thus recall reference point knowledge from old evocations. There are, for example, references to other writers of thrillersuspense fiction, '(see Evanovich, Clancy, King, Patterson, etc)' (R4), and references to similar or recommended books: Endgame (R3); The Unburied and The Horned Man (R7); Don Quixote and The Body Artist (R1), or to art (Escher) (R1). Although most of the reviewers seem to draw these connections simply as points of comparison, R6 is more negatively evaluative: she identifies postmodern fiction in general as following a 'formula' which involves simply copying 'former masterworks', and identifies allusions to the Bible, and writers Shakespeare, Melville and Dante as evidence of this formula in The Trilogy. R6 further argues that such allusions mean that the text lacks 'genuineness'.

It could be argued that such parallels with other characters or writers from experiential memory cause a reader to widen their dominion to include intertextual connections as potential targets. These references are an example of how idiosyncratic reading histories can generate a wider list of targets with which to draw parallels: potentially, the wider the reading history, the greater number of targets generated. These ideas are returned to in Chapter 5. 


\section{4. (R)evoking targets}

This next section considers how the process of tracking character roles works on a more micro-level within The Trilogy, through the close analysis of three extracts from the text.

The first story in The Trilogy, City of Glass, sets the scene for the collection by establishing a complex layering of participant roles from the outset. Quinn, a writer pretending to be a detective and mistakenly assumed to be Paul Auster (who is detective, in the story), follows Peter Stillman senior (one of two characters with the same name), who apparently is trying to kill Peter Stillman junior. Clearly, such a narrative structure is difficult to summarise simply - largely because, as Richardson (2002: 53) identifies, it is actually an example of an 'impossible story'. As the following analysis observes, Quinn begins as an on-stage character who occupies various agent/patient/experiencer roles. He is not explicitly referenced in the second story, though he is invoked off-stage later in the third story The Locked Room. At the beginning of The Trilogy, however, in City of Glass he holds a central reference point role. He is introduced as a new evocation around which other targets are subsequently oriented.

The second story is a variation of the first, except Ghosts veers even further into abstract themes. As previously mentioned, this construal is evoked by the choice of names: Blue is hired by White to follow Black and provide weekly reports on his behaviour. Most of the narrative of this second story describes Blue sitting in an apartment watching Black from across the street. Similarly, The Locked Room, the final story in The Trilogy, follows the themes established in the opening two stories. Here, readers encounter an unnamed narrator who becomes obsessed with his childhood friend, the famous author Fanshawe, following his (alleged) death. The unnamed narrator begins to take over Fanshawe's life: he claims ownership of Fanshawe's works 
of fiction, marries his widow and moves into his house, only to discover that Fanshawe is still alive, and that he had intended for this sequence of events to happen.

As observed previously, Dimovitz (2006) maintains that similarities in the actions performed by the protagonists create similarities between the protagonists themselves. In this way it can be argued that all three narrators become conceptually equivalent targets - targets available to be invoked at any point in the narrative because of similarities between the processes in which they participate. In this view, the unnamed 'I' persona who narrates The Locked Room - and who is visible at the beginning of City of Glass (see Extract 4.1) - therefore holds a superordinate agent role in The Trilogy and forms a universal reference point across the three stories. In addition Dimovitz summarises the process types in The Trilogy as 'reconstructing' and 'watching' (see Table 4.1), which can be labelled as behavioural processes, instantiating experiencer and agent roles for the participants involved actively with the process, and patient roles for those being reconstructed or watched. In the schematic participant + role breakdown outlined in Table 4.1, it is clear to see the shifts between the archetypal roles assumed by the three main protagonists, who are patients in the first instance and experiencers in the second.

In order to observe how these roles work at the micro level of The Trilogy, the following sections provide a close stylistic analysis of Extracts 4.1, 4.2 and 4.3 using some of the central CG concepts introduced so far.

\section{Extract 4.1. City of Glass}

As for Quinn, there is little that need detain us. Who he was, where he came from, and what he did are of no great importance. We know, for example, that he was thirty-five years old. We know that he had once been married, had once been a father, and that both his wife and son were now dead. We also know that he wrote books. To be precise, we know that he wrote mystery novels. These works were written under the name of William Wilson, and he produced them at 
the rate of about one a year, which brought in enough money for him to live modestly in a small New York apartment. Because he spent no more than five or six months on a novel, for the rest of the year he was free to do as he wished. He read many books, he looked at paintings, he went to the movies. In the summer he watched baseball on television; in the winter he went to the opera. More than anything else, however, what he liked to do was walk. Nearly every day, rain or shine, hot or cold, he would leave his apartment to walk through the city -never really going anywhere, but simply going wherever his legs happened to take him.

New York was an inexhaustible space, a labyrinth of endless steps, and no matter how far he walked, no matter how well he came to know its neighbourhoods and streets, it always left him with the feeling of being lost. Lost, not only in the city, but within himself as well [...]The world was outside of him, around him, before him, and the speed with which it kept changing made it impossible for him to dwell on any one thing for very long. Motion was of the essence, the act of putting one foot in front of the other and allowing himself to follow the drift of his own body. By wandering aimlessly, all places became equal, and it no longer mattered where he was. On his best walks, he was able to feel that he was nowhere.

(Auster 2004: 3)

At the beginning of Extract 4.1, it is immediately apparent that there are two figures in the narrative: the narrator (the conceptualiser) and the character Quinn (the object of conceptualisation). The narrator's voice overtly grounds the discourse, immediately creating a shared discourse ground between the narrator and the reader through the use of first person plural pronouns. He says, for instance, that 'there is little that need detain us', and asserts four times that 'we know' particular pieces of information already:

We know [...] that he was thirty-five years old that he had once been married that he wrote books that he wrote mystery novels

(Auster 2004: 3)

Although the narrator owns that these facts 'are of no great importance to us' (Auster 2004: 3), this information is given introductory emphasis. Regarding particular details from Quinn's social profile, an attentional zoom is created whereby readers receive increasingly specific details about Quinn's life: 'We also know that he wrote books. To be precise, we know that he wrote mystery novels'. Through these elaborated details 
readers are provided with a list-like profile of Quinn, primarily outlining his physical and social qualities.

This introduction of Quinn is the first instantiation of his character, and forms the information that establishes his initial reference point in the narrative. This means that every other potential target or participant role associated with Quinn returns to the information established here, in the new evocation. As readers begin to learn more information about Quinn, the ground becomes much more covert as the narrator retreats into the background - becoming less salient - and there is a pronoun switch to third person which marks Quinn as the new focus of attention:

To be precise, we know that he wrote mystery novels. These works were written under the name of William Wilson, and he produced them at the rate of about one a year.

(Auster 2004: 3)

With this shift to Quinn as the object of conceptualisation, readers are told in the same sentence that his books 'were written under the name of William Wilson' (Auster 2004: 3). Automatically, then, at the first evocation of Quinn 'William Wilson' is added to the dominion as a parallel target role. In other words, Quinn's introduction as a salient reference point in the narrative automatically invites a plurality of target roles: his character role is layered at the outset.

Once Quinn has been introduced in the extract, he is superordinately represented as an agent; as the initiator of his actions. He is attached to both mental processes ('He read many books, he looked at paintings') and material processes ('he went to the movies'), which delineate aspects of both his social and physical character (Halliday 1971, 1985). The list of actions casts Quinn in various different roles: mover ('he went to the opera'), experiencer ('he watched baseball on television'), agent ('he would leave his apartment to walk through the city'), but ultimately this list of activities simply catalogues the routine that governs his life. The list structure suggests his 
actions are more automatic than autonomous. When his walks are mentioned towards the end of Extract 4.1, for example, this role also necessitates a deferral or separation of agency: these walks are characterised by 'never really going anywhere, but simply going wherever his legs happened to take him'. In this process the agency is assigned specifically to his legs rather than his entire self (see Burton 1982; Halliday 1971; Ji and Shen 2004; Mills 2002).

Like a puppet, Quinn is established as having a predominantly functional role with actions which seem to be determined outside of his control. Overall, then, Quinn is characterised as an agent and mover, but nevertheless one that is subject and secondary to the advancement of the plot ('The world was outside of him, around him, before him, and the speed in which it kept changing made it impossible for him to dwell on any one thing for very long').

\section{Extract 4.2. Ghosts}

For in spying out at Black across the street, it is as though Blue were looking into a mirror, and instead of merely watching another, he finds that he is also watching himself [...]

Of Black, of White, of the job he has been hired to do, Blue now begins to advance certain theories. More than just helping to pass the time, he discovers that making up stories can be a pleasure in itself. He thinks that perhaps White and Black are brothers and that a large sum of money is at stake - an inheritance, for example, or the capital invested in a partnership. Perhaps White wants to prove that Black is incompetent, have him committed to an institution, and take control of the family fortune himself. Another theory that Blue puts forward has White and Black as rivals, both of them racing towards the same goal - the solution to a scientific problem, for example - and White wants Black watched in order to be sure he isn't outsmarted. Still another story has it that White is a renegade agent from the FBI or some espionage organization [...] For Black is no more than a kind of blankness, a hole in the texture of things, and one story can fill this hole as well as any other. 
Extract 4.2 establishes a 'new idleness' (Auster 2004: 145). This is because in Ghosts, the protagonist Blue spends the majority of his time remaining in his flat, 'spying out at Black across the street'. The extract opens by casting Blue as an experiencer ('spying', 'looking', 'finds', 'watching'). During this 'spying' process Blue in turn recasts White and Black into various roles as he tries to decipher the reasoning behind his mission: 'Of Black, of White, of the job he has been hired to do, Blue now begins to advance certain theories'. He sees them as brothers, business partners, FBI agents, murderers, kidnappers, and '[a]nother theory that Blue puts forward has White and Black as rivals, both of them racing towards the same goal'.

Like with Extract 4.1, Blue's agency as a character is somewhat displaced. The action of the story remains in hypothetical scenarios rather than as something in which Blue is directly involved, as suggested through epistemic markers: he 'begins to advance certain theories'; he 'discovers' and 'thinks'. Much of the story is therefore characterised by the relationship between activity and inactivity; and between events that happen within the fictional world, and those that are displaced within a projected reality through modalisation (Langacker 2008). While Blue tries to imagine the role of the other protagonists in his 'list of [...] stories', the roles are nevertheless framed within his speculations. As such, even when material processes are included (i.e. 'racing'), they are filtered through Blue's experiencer status: 'He thinks that perhaps[...]'. The prominence of these self-reflexive references in The Trilogy instantiates a 'rupturing effect' (Cobley 2001: 239). They function to increase distrust of the reliability of the narrator/protagonist, and foreground Auster's real author role as a reference point: readers are reminded, for instance, that '[m]ore than just helping to pass the time, [Blue] discovers that making up stories can be a pleasure in itself'.

Here an obvious parallel can be drawn between Blue and readers of The Trilogy: just like Blue, we are trying to question motives and reasons behind the actions of The 
Trilogy participants. The role Blue adopts as creator of these stories invokes the role of implied author in this passage. Blue's theories, as well as our own, represent 'a hole in the texture of things'. Despite this claim, however, arguably not just 'any' story can fill the gap; the potential roles that Blue casts White and Black in are within the broad dominion of crime. Furthermore, despite the list of hypothetical scenarios, the passage ends with a declarative statement: 'For Black is no more than a kind of blankness, a hole in the texture of things, and one story can fill this hole as well as any other'. Despite a reader's and Blue's speculations, ultimately there is no definitive answer to the particular role that Black plays in the story - and this final admission acknowledges that, actually, maybe the answer is not important.

The use of present continuous ('spying out', 'racing towards the same goal', 'returning in his mind', 'starting over again') throughout Extract 4.2 is also interesting. These verbs are all related to behavioural or mental processes, but are also verbs relating to motion: they express ongoing movement, but yet movement which is immanent - they are thoughts framed as actions (similar to Joe's descriptions of 'racing' and 'sprinting' in Section 3.5 in Chapter 3). This relationship between action and immanence draws a parallel between Quinn and Blue, as there is an inversion of processes attached to the respective characters. Quinn is a mover at the end of Extract 4.1, whereas Blue is an experiencer primarily. Quinn is described as exploring 'the inexhaustible space' of New York, and its 'labyrinth of endless steps' through his walks;, whereas Blue, conversely, is described as exploring in the sense of introspection: he 'has never given much thought to the world inside him [...] it has remained an unknown quantity, unexplored and therefore dark, even to himself'. Like Quinn, on whose 'best walks he was able to feel he was nowhere', ultimately feeling 'lost', Blue similarly does not know how to definitively navigate the 'world inside him'. 


\section{Extract 4.3. The Locked Room}

After ten minutes of fighting off the impulse, I at last opened the notebook. I read steadily for almost an hour, flipping back and forth among the pages, trying to get a sense of what Fanshawe had written. If I say nothing about what I found there, it is because I understood very little. All the words were familiar to me, and yet they seemed to have been put together strangely, as though their final purpose was to cancel each other out. I can think of no other way to express it. [...]I lost my way after the first word, and from then on could only grope ahead, faltering in the darkness, blinded by the book that had been written for me. And yet, underneath this confusion, I felt there was something too willed, something too perfect, as though in the end the only thing he had really wanted was to fail even to the point of failing himself. I could be wrong, however. I was hardly in a condition to be reading anything at that moment, and my judgment is possibly askew. I was there, I read those words with my own eyes, and yet I find it hard to trust in what I am saying.

(Auster 2004: 313-314)

In this final extract - and in the final story more generally - the grounding once again becomes more overt through the use of first person 'I'. This signals the potential for conflation of real author/ implied author/ narrator targets - a process which is signposted particularly as Fanshawe, the narrator of the first story, is also referenced here as the author of the notebook that is introduced in the first story. As the unnamed narrator walks away from Fanshawe and reads the red notebook, he observes a reconstrual (Forrest 1996) of the same story in that 'the words were familiar [and] yet they seem to have been put together strangely' - a process which parallels the reader's position (see R1's construal of the discarded target in Figure 4.4). Like in the previous passage, the modality becomes increasingly heightened. He does not come across as completely in control of what he is doing or thinking, and this is reinforced by the examples of words of estrangement ('they seemed to have been put together strangely') and verbs of perception ( 'I felt'; 'I find').

Primarily, the unnamed narrator here holds an experiencer role ('I read steadily', 'I found there', 'I understood very little', 'I can think', 'I felt') and again, like with the 
previous extract, the material processes which are used describe a mental process: reading.

The sense of getting 'lost' in reading therefore becomes framed as an experiential process, and this signposts a circularity to The Trilogy: Quinn is 'lost' on his walks at the beginning, and this final narrator is 'lost' 'after the first word' of reading the notebook. In this way, the physical processes are paralleled with experiential ones: and, arguably, becoming lost in a book or lost in a physical location amount to the same thing in The Trilogy (see R4). The extract finishes by grounding this final story even more overtly. The tense shifts to present tense and the first person position of the narrator is reinforced ('I could be wrong'; 'my judgment is probably askew'; 'I find it hard to trust in what I am saying'), and these grounding elements further subjectifies the construal. This means that the narrative closes with an ambiguous account of the narrative; one that could belong to any one of the protagonists evoked across the three stories.

\subsection{Conclusion: 'The story is not in the words; it's in the struggle'}

Langacker argues that reference point relationships work most effectively where 'the mental path is discrete' and that 'scanning along the path is primarily to find or identify the element ultimately arrived at' (Langacker 2008: 83). It can be seen that the path of progression in The Trilogy is so unclear as to render the objective identification of reference points (or protagonist roles) a near impossible task. This is because, as this analysis has shown, clearly the protagonists are cast in different roles and assume different identities in The Trilogy. 
Essentially the novel presents the arbitrariness of 'the question of authorship' (R9) and therefore can be seen to represent a deconstruction of literary theories, as noticed by critics and reviewers (R9; see also Lavender 1993). Arguably, a stylistic account of CG's RPM helps to remove the problem of the hierarchy of roles in traditional narratology systems (such as Chatman's outline of narrative layers). The RPM helps to describe how the identities assumed in The Trilogy (implied author, character, narrator) have conceptual equivalence. Equally, the novel similarly presents the arbitrariness of these narrative roles. The actions of the protagonists are the same, even if the nominal references vary.

Regarding the interchanging nature of character roles in the novel, McHale (1992: 291) comments that,

Auster's detectives are literally 'absorbed' in their respective cases, coming to identify so completely with their subjects as to lose all sense of their own identities; or they renounce their quests just short of the final revelation, and the role of cognitive hero is transferred to the author - or to an author.

Throughout the reading of The Trilogy, therefore, rather than a specific target coming necessarily and definitively into the foreground, various potential targets (or roles) for each character become activated as and when dictated by the language, or by the connections made by the individual reader. These references are then invoked or revoked depending on various factors.

Firstly the individual reader's experiential memory has a direct bearing on evocation. This can be seen clearly in the reader reviews: each reader attaches interpretations of the reference point/target relationship by supporting their statements with pertinent processes (micro- or macro- designs) from the text itself, or with other textual evidence revoking intertextual similarities from wider dominions.

A second factor relates to whether a reader commits to or invests in a reconceptualisation of the narrative based on the ending of the text, in which the 
narrator explicitly reveals himself to be the author of City of Glass and Ghosts. At this point in the text this narratorial override instantiates a renewed evocation, since a direct link has been drawn between the narrator of The Locked Room and the previous two stories. This creates a composite reference point (an idea explored in more detail in Chapter 5) that unites Quinn, Blue and the unnamed narrator, and the other potential target roles mentioned as the same reference point. This narratorial override invites a level of cognitive input on the part of readers, and while some of the reviewers spent time reflecting on these connections and acknowledged that ' $[\mathrm{t}]$ hese are stories that demand that the reader NOT check her brain at the door' (R2), others did not wish to reconceptualise the narrative: 'The stories actually seem to all be part of a whole but I have not gone to enough effort to completely figure that out' (R3) (see Section 4.3).

A third factor depends on the recognition of the activity or action attached to the protagonist: superordinately, is the protagonist mainly an agent or an experiencer? Because of this fluidity of targets, The Trilogy disassembles the relationship between form and meaning, the signifier and the signified, and between participant and process. Different readers' labels of the character roles in The Trilogy demonstrate the breadth of alternative construals of the same text, with each interpretation 'compatible with its objectively given properties' (Langacker 1990: 61). The invocation or revocation of the protagonists' identities are not only dependent on a reader's experiential and working memory or their idiosyncratic interpretation of the text, but can also be instantiated explicitly in the literary text itself, as the final section of the analysis observes.

In conclusion, this analysis has combined a consideration of critical material on The Trilogy, Stockwell's (2009) typology of reference and reader response data to explore how readers keep track of protagonist roles as salient reference points in the narrative. Specifically, the RPM account has helped to explore the complex structure of this text: it has identified that the protagonist roles across the narrative are dynamic 
and layered, and has allowed a description of how these identities are instantiated, maintained, recalled or erased - the 'adjustment' processes that are central to reading (Stockwell 2009: 182). In addition to observing how these 'adjustment' processes work on the macro-level of the text, the analysis has also shown how this works through specific textual mechanisms: the close, textual analysis considered how the actions of the protagonist, in particular, seem to affect how his role is perceived ('Is what a person does equivalent to who he is?', R5).

\subsection{Review}

This application of CG's RPM has observed how readers can track changing character roles throughout a literary text, and the analysis has demonstrated how readers can arrive at different interpretations of character/participant roles. It has been discussed how these alternative readings are respectively 'compatible with [...] objectively given properties' (Langacker 1990: 61); that is, the readers display idiosyncratic interpretations that are equally text driven. This application has also shown how a close CG textual analysis can explore character representations at the micro-level of the text, and the corresponding roles which readers assign to protagonists based on their actions.

The next chapter combines the methodology of the previous two analyses of Chapters 3 and 4 to consider (1) how specific/ schematic language works in the elaboration of a fictional world, and (2) how readers respond to these language choices, and draw upon intertextual reference points in order to comprehend the fictional world in its entirety. The analysis considers CG construal processes to show how the fictional world of the contemporary Gothic novella Coraline by Neil Gaiman (2002) is created. 
The latter half of the chapter considers the evaluative reader reviews - which demonstrate either resistance or attachment with the fictional world - in response to the levels of schematicity within the text. This half of the chapter additionally extends the RPM further to examine how reference points can act as placeholders for text world construction. 


\section{Chapter 5. Interrelated references and fictional world elaboration in Coraline}

\subsection{Introduction}

Coraline (2002) is a fantasy novella about a young girl who has recently moved house with her parents. The house they have moved to has been divided into flats, and Coraline has a few unusual neighbours: two elderly ladies who are former thespians, Misses Spink and Forcible, and Mr Bobo, the 'crazy old man' (Gaiman 2002: 10) upstairs who teaches mice to play musical instruments. Coraline is an explorer, and finds a small locked door in her living room that supposedly leads to the empty flat next door, but that during the daytime only opens onto a brick wall. One night, she discovers a tunnel has opened up behind the door, which leads to a flat identical to hers in many ways, yet completely opposite in others (see Extract 5.1). One of the most immediately obvious and disturbing differences is that the entities in this other world have buttons instead of eyes. This other world has been created by the 'other mother', similar to Coraline's own mother and yet simultaneously much more sinister. The other mother kidnaps Coraline's real parents and Coraline must attempt, along with some help from the Cat, to find them, escape the other mother and return home. The story, like Alice in Wonderland (Carroll 1865), concerns parallel worlds that follow distorted real-world rules; and a mirrored-world effect is sustained through comparisons between 'the other world' and Coraline's initial text world. This 'mirroring' (McHale 1992: 155) is shown through lexical pairings and inversions (such as the fact that, for example, Coraline is frequently called 'Caroline' by accident in her world, but only ever 'Coraline' in the other world).

As a fantasy novella, Coraline exhibits features of entrenched (Langacker 2008) structures (fairy tales, and the Gothic), but the text also departs from and subverts these 
genre templates. Many of the reader reviews (see RA-RJ in the Appendix) acknowledge the wider fairy tale tradition to which Coraline belongs, and identify targets from other texts in order to interpret Coraline's character. As in the analysis of The New York Trilogy in the previous chapter, the global reference point (that is, the literary protagonist; see van Vliet 2009) is therefore essential in understanding how readers construe Coraline. The text is arguably built upon a construction schema, which in CG terms is a template for particular linguistic constructions: it 'captures a general pattern for the combination of smaller units into a larger assembly' (Taylor 2002: 589).

This chapter explores firstly how elaboration and schematicity are used in fictional world creation. Secondly, the discussion considers divided responses (identification and resistance) to the text, drawing upon reader reviews that identify intertextual reference points between Coraline and other texts.

\subsection{Construal: Production and reception}

As has been observed, construal is the process whereby 'one and the same situation or event can be linguistically encoded in different ways' (Herman 2009: 128). A writer can choose how they want the information in a sentence to be presented, and can profile different linguistic constructions to achieve particular effects.

This is just one end of the process of reading, however. The other end of the conceptualisation process is anchored in a reader's situation, and although an entity, process or scene may be linguistically signposted in a particular way, there are of course many ways in which a reader can construe a sentence. The number of potential construals becomes ever more multivalent in narrative discourse. As the narrative progresses, the relationships between the sentences, the themes, the metaphors and so 
on, become more and more complex, and this in turn creates multiple potential conceptualisations. This is the case before even taking extra-textual, contextual or emotional factors into account. As Chapter 4 has observed, one reader may construe a discourse in a completely different way to another.

This is not to say that there is an endless number of possible construals, however. This is discussed by Paradis (2005: 565), who states that '[i]n a cognitive account of meaning, multiple readings are expected as a natural consequence of the dynamic view of language. There are, however, not only possibilities but also constraints'. The 'constraint' of textual interpretation is that any construal must retain a degree of 'text-drivenness' (see Werth 1995a, 1995b, 1999). In other words, a particular interpretation must always be grounded in response to the textual mechanisms. Our responses to a piece of literature are in relation to what we read, and therefore are fundamentally connected to cues within the text.

Schank (1982) describes the process of preserving memorable story narratives in the mind as indexing, in which a particular story or type of story becomes stored in the memory and acts as a frame of reference for other stories. Many of the reader reviews for Coraline make reference to schematised knowledge, often discussing similarities with the text and various intertextual sources from their individual reading history. This was also discussed as part of the process of prominence in Chapter 4, where the dominion of the text widened to include intertextual reference points as a potential target (see Chapter 4, Section 4.3). What occurs in relation to the reviews for Coraline more than those for The New York Trilogy, however, is that the reviewers combine and merge these intertextual targets to create a new composite reference point. This term is used here to describe how targets and dominions from different grounds have been conflated to form a new character reference. This is particularly the case 
regarding the character of Coraline, but also in relation to the world of the text and the story's narrative structure.

\subsubsection{Construction schemas}

CG differentiates between an instance and a type of a linguistic construction, for a type in Langacker's (1991: 55-8) terms is an abstract entity, whereas an instance is a more distinct reference. Scaling up this differentiation to account for literary constructions, a type would be something like a particular genre, whereas an instance would be a specific example within the genre. For example, The New York Trilogy would be an instance of the detective fiction type. Coraline similarly is a particular literary instance. It follows conventions of the fantasy fiction type - but this genre is in itself an anti-realist, hybrid genre and a superordinate term, including both fairy tales and Gothic fiction as sub-types (Herman, Jahn and Ryan 2005: 157). As a fantasy text, Coraline is therefore an example of a construction schema. As mentioned previously, in CG terms a construction schema is a template for particular linguistic constructions; one that 'captures a general pattern for the combination of smaller units into a larger assembly' (Taylor 2002: 589). Consequently Coraline is grounded in these three literary types, drawing on commonalities in 'global organization, more local structural properties, typical content, specific expressions employed, matters of style and register etc.' (Langacker 2008: 478) of fairy tale, fantasy and Gothic schemas.

Chapter 2 introduced the CDS and the idea of viewing frames, which provide a conceptual structure that outlines the way readers form expectations in the reading process. As will be observed in the following analysis, reviewers of Coraline discuss their levels of expectation regarding the narrative schemas upon which the text draws. The expectations that reading involves are created long before a reader begins to read, 
and particular expectations for a particular book form the common ground of the discourse event: the 'cultural expectations' and knowledge frames that are associated with fictional world-construction (Gavins 2007; see also Freeman 2007 and Rubba 1996 for further explications of grounded linguistic constructions).

In Coraline, the extralinguistic expectations are bound up in the cultural schemas upon which it draws, which are lexically signposted on the blurb:

'This book [has] the delicate horror of the finest fairy tales.'

Terry Pratchett

'I think this book will nudge Alice in Wonderland out of its niche at last.'

Diana Jones

These construals draw upon both general, genre-level schemas (FAIRY TALES and HORROR), as well as the more specific, profiled schemas as nominalised in the reference to ALICE IN WONDERLAND. The FAIRY TALE schema primes how, in the novel, as Kaveney (2009) observes in an online review, 'Gaiman is drawing on a variety of sources from fairy tale and literature [such as] Ibsen's Peer Gynt - whose eyes the trolls propose to slit, whom the Button Moulder proposes to melt down to buttons - because myths are the products of convergent evolution'.

Acknowledging these schemas prior to reading the story creates an 'environment of expectation', regarding both the linguistic and extra-linguistic contexts included in the common ground (Nahajec 2009: 111). Thus, readers expect a fairy tale, but one which is 'convergent' with other genres; one which is threaded with dark design. Expectation, or the lack of it, plays a key role in how readers process narratives, particularly in the creation of suspense, curiosity and surprise (Hoeken and van Vliet 2000; see also Rapp and Gerrig 2006; Tobin 2009). This is particularly true of postmodern fiction. As already observed, postmodernism famously subverts traditional 
notions of narrative development, and postmodern fictions are often fundamentally metatextual in that they are 'fictions about the order of things, discourses which reflect upon the worlds of discourse' (McHale 1989: 164).

The next section examines how these ideas and themes are apparent on a textual level. The analysis considers, in particular, the stylistic features that make up the fictional world in Coraline: its 'global organization, more local structural properties, typical content, specific expressions employed, matters of style and register etc.' (Langacker 2008: 478).

\subsection{Elaboration and world comparison: The 'other world' of Coraline}

This section offers a CG account of Gaiman's 'concrete prose' (Gooding 2008: 395) - his 'clear and effective prose style' (Pullman 2002) - and examines, in particular, how the varying levels of specific and schematic language work in a pivotal scene from the novel in which Coraline discovers the second fictional world the 'other world').

\section{Extract 5.1. Coraline}

She looked around the room. It was so familiar - that was what made it feel so truly strange. Everything was exactly the same as she remembered: there was all her grandmother's strange-smelling furniture, there was the painting of the bowl of fruit (a bunch of grapes, two plums, a peach and an apple) hanging on the wall, there was the low wooden table with the lion's feet, and the empty fireplace which seemed to suck the heat from the room.

But there was something else, something she did not remember seeing before. A ball of glass up on the mantelpiece.

She went over to the fireplace, went up on tiptoes, and lifted it down. It was a snow-globe, with two people in it. Coraline shook it and set the snow flying, white snow that glittered as it tumbled through the water. 
Then she put the snow-globe back on the mantelpiece, and carried on looking for her true parents and for a way out.

She went out of the flat. Past the flashing-lights door, behind which the other Misses Spink and Forcible performed their show for ever, and set off into the woods.

Where Coraline came from, once you were through the patch of trees, you saw nothing but the meadow and the old tennis court. In this place, the woods went on further, the trees becoming cruder and less tree-like the further you went.

Pretty soon they seemed very approximate, like the idea of trees: a greyishbrown trunk, below, a greenish splodge of something that might have been leaves above.

Coraline wondered if the other mother wasn't interested in trees, or if she just hadn't bothered with this bit properly because nobody was expected to come out this far.

She kept walking.

And then the mist began.

It was not damp, like a normal fog or mist. It was not cold and it was not warm. It felt to Coraline like she was walking into nothing.

I'm an explorer, thought Coraline to herself. And I need all the ways out of here that I can get. So I shall keep walking.

The world she was walking through was a pale nothingness, like a blank sheet of paper or an enormous, empty white room. It had no temperature, no smell, no texture and no taste.

'It certainly isn't mist,' thought Coraline, although she did not know what it was. For a moment she wondered if she might have gone blind. But no, she could see herself, plain as day. There was no ground beneath her feet, just a misty, milky whiteness.

(Gaiman 2002: 79-81)

\subsubsection{Elaborative relationships}

Coraline's perspective is focalised in this extract, and she is the figure and vehicle for the shifting perspective between the ontological levels in the narrative more generally. Her viewpoint therefore constitutes the viewing frame of the CDS.

Langacker (2008: 63) says that '[w]e sometimes need to distinguish between an expression's maximal scope in some domain, i.e. the full extent of its coverage, and a limited immediate scope, the portion directly relevant for a particular purpose'. If this idea is extended to fictional world processing, as readers we are often limited to the immediate scope of a focalised character's current perspective. Arguably, at the macrolevel of the narrative the maximal scope is the wider text world already established. This idea is relevant for this passage which, in the first four paragraphs, establishes a direct 
comparison between the present viewing frame in which Coraline describes the 'other living room', and the more 'familiar' parallel previous text world of Coraline's living room that readers would already have encountered in the text.

Initially, this world contrast is established through Coraline's process of comparison. She matches the features of this new world with the features of her own down to the exacting minutiae: '(a bunch of grapes, two plums, a peach and an apple)'. 'Everything' in this alternate world is the same as that in her world, a point compounded by the use of the definite article attached to the prominent world-builders: 'the painting', 'the low wooden table', 'the empty fireplace' and 'the mantelpiece'. Logically, choosing 'the implies that only one is visually evident' (Langacker 2008: 288); and here the definite article implies these world-builders have been directly transferred across from Coraline's world - they are not targets that refer back to previously mentioned salient reference points, they are, seemingly, the objects themselves. The definite article also focuses attention on each referent individually as the other-world world-builders are matched against the familiar-world world-builders, like a checklist. In this way, Coraline is assembling the composition of this new world, one world-builder at a time.

The only difference between this living room and Coraline's real-world living room is the ambiguous 'something', the elaborative features of which are identified incrementally. Firstly it is labelled as 'something else', then 'something she did not remember seeing before', and becomes more specific as an attentional zoom is instantiated and particular features become profiled. It is further identified as a 'ball of glass', a description which, finally, becomes occluded by the actual nominalisation of the object: a 'snow-globe'.

These comparatives continue through Coraline's attempt to make sense of her new surroundings and are marked lexically, for example through the choice of 
adjectives to describe specific reference points. She differentiates, for instance, between her 'true parents' and her 'other parents', and between 'Misses Spink and Forcible' and 'the other Misses Spink and Forcible'.

As Coraline leaves the other living room, however, and sets off 'into the woods' the language moves from the specific to the schematic. It also becomes more metaphorical. The comparisons continue, but in the latter half of the extract these become figurative constructions:

The world she was walking through was a pale nothingness, like a blank sheet of paper or an enormous, empty white room.

(Gaiman 2002: 80)

In this first clause, the proposition is positive and declarative; this is then qualified by the simile 'like a blank sheet of paper', which self-consciously references the writing process, as well as outlining a figurative point of comparison. This metaphor acts as a 'compositional deictic marker' (Stockwell 2002) that points to the physicality of the writing process and metatextually foregrounding the process of world-creation. Because there are no world-builders in 'the world she was walking through', then the attention reverts back to her previous location. The comparison of the 'mist' to 'an empty white room' elaborates the description further: this 'pale nothingness' is like the negative of the room previously outlined, and reflects Coraline's attempt to frame the nothingness in a recognisable form. This is something she also attempts earlier on in the story when she tries to draw mist (Gaiman 2002: 23-4). Furthermore, the fact that Coraline's walk into nothingness evokes a negated template of the previous location instantiates a reverse sequence scan. In other words, rather than an increasing list of world-builders as in the description of the living room, there is instead a progressive removal of them ('It had no temperature, no smell, no texture and no taste') (see Chapter 7 for a more detailed analysis of sequence scanning). 
These comparatives are also explicitly marked through negated structures in the latter half of the extract:

It was not damp, like a normal fog or mist. It was not cold and it was not warm [...] It had no temperature, no smell, no texture and no taste.

(Gaiman 2002: 80)

Here, the repetition of the negative particles 'not' and 'no' mirrors the earlier list-like description of the world-builders in the other living room. In this description, as well as discounting polar states, the graded states in between are also discounted. The temperature is 'not cold' or warm, thereby suggesting a state in between, but then the state is later qualified as having 'no temperature'. Further, all the senses are either explicitly cancelled ('no taste', 'no smell', 'no texture') or implicitly (Coraline wonders for a moment 'if she might have gone blind'). The references to the senses also create further parallelisms with the earlier living room schema, negating those already mentioned, albeit indirectly: the 'fireplace which seemed to suck the heat from the room'; the 'strange-smelling' furniture.

Other world-comparisons are made between Coraline's world and the other world in half of the extract. This is signposted here through the deictic underlay (Werth 1995): the rules that define the parameters of the deictic field ('Where Coraline came from' X happens; but, in 'this place' Y happens).

Where Coraline came from, once you were through the patch of trees, you saw nothing but the meadow and the old tennis court. In this place, the woods went on further, the trees becoming cruder and less tree-like the further you went.

Pretty soon they seemed very approximate, like the idea of trees: a greyishbrown trunk, below, a greenish splodge of something that might have been leaves above.

(Gaiman 2002: 79-80)

Here, the schema of the world-builders, such as the trees, is reduced to constituting only properties or basic semantic features. This is also explicitly mentioned in the 
comparative ('the trees becoming cruder and less tree-like the further you went'), which has the effect of foregrounding the negation, for '[m]entioning fading, even while negating it, creates a figural lacuna where [the figure] is faded from attention to a greater degree than if such a verb had not been used at all' (Stockwell 2009: 34). Additionally, the 'approximate' properties of trees become reduced to their more basic schematic visual traits. Like something a child might draw, the trees are reduced to their essential components, profiling the generic properties such as a 'greyish-brown trunk' and a 'greenish splodge'. These approximate qualities are also compounded by the use of modal language. For example, there is a lack of epistemic surety - the trees have a 'greenish splodge of something that might have been leaves' - as the identifiable features become 'cruder'.

In addition, the phrase '[y]ou saw nothing but the meadow and the old tennis court' (Gaiman 2002: 80) is interesting in terms of its negative scope. The explicit negative 'nothing' doubled with the adversative conjunction 'but' means that the meadow and the old tennis court are the visual focus. As Coraline walks away from the house in this scene, however, she sees 'nothing but' herself, and 'nothingness'. These salient world builders are missing from this current world, but their absence is nevertheless revoked.

Evidently, the viewing frames of Coraline's both elaborative and approximate description work together to build the fictional world of the text, and this shifting level of description sets up a comparison between this 'other' world and the initial text world presented in the novella. The further Coraline walks away from the house and the familiar world-builders, the more schematic the language becomes. Similarly, we become increasingly aware that we are moving away from a fictional world set-up that mirrors real-world world-builders. At this stage of the text we are required to acknowledge the fantastical foundations of this new text world, in which 'the idea of 
trees' is used in place of the actual objects. As such, the construction schema upon which Coraline is built becomes more prominent in this scene as the world-building elements of the Gothic and the fantastic - the strange fog that does not bear actually bear a resemblance to fog, and the schematisation of objects - similarly become progressively apparent.

Clearly, this world comparison/ mirror world set-up evokes the ALICE IN WONDERLAND schema (and also other children's texts that set up a division between a 'realistic' initial text-world and a more fantastic one, as often represented through a physical divide: the wardrobe in The Chronicles of Narnia (Lewis 1950-1956); the entrance through Diagon Alley or through Platform at $93 / 4$ s in the Harry Potter series (Rowling 1997-2007), and so on) at the micro-level of the text.

The second half of this chapter addresses how readers respond to these varying levels of specificity and schematicity at the macro-level of the text, and considers how the reception to the text has been divided - both in terms of readers acknowledging a difference in how children and adults would respond to the text, and also in regards to those who express identification with or resistance to its fictional world creation. Much of this division can be traced to schema recognition, as discussed in more detail in the latter sections of this chapter.

\subsection{Reading Coraline}

It could be argued that when reading texts - and particularly postmodern texts which are compositionally linked to a wider genre, readers automatically expect there to be reformulations of entrenched concepts. This next section considers the divided reader responses to Coraline, looking at, in particular, how readers construe intertextual schemas and composite reference points. 
Literary criticism on Coraline approaches the text in different yet connected ways. It is labelled as post-feminist (Parsons, Sawers and McInally 2008), or postmodern (Klapcsik 2008; Nikolajeva 2009); and it is discussed in terms of the themes of identity and existentialism (Rudd 2008), and the uncanny (Gooding 2008; Rudd 2008), which are concerns underpinning children's literature in general (Herman, Jahn and Ryan 2005: 470-474).

Following Freud, Gooding (2008) refers to the uncanny as something which is familiar, but unsettling; something which by its very deviance is foregrounded. In Coraline, the familiar here is the fairy tale construction schema; at the outset the discourse is construed as 'a familiar narrative pattern featuring a border between real and fantasy worlds' (2008: 393). Gooding argues, however, that the story does not proceed to follow normative patterns. He suggests that rather than having a clear separation of worlds as in other stories, the boundaries are blurred in Coraline. Although initially there is a physical boundary (which takes the form of a tunnel between the two worlds), the mirroring of the initial world and the fantasy world, and the similarities and duplications of entities and world-builders, complicates the separation of worlds (as observed in the analysis of Extract 5.1).

Observing reviews of the text, Gooding (2008: 390) also summarises the divided reception to the novella. He categorises the reviews into two groups: the first group, which constitute the first or earlier responses to the text, were characterised as responding primarily to the Gothic nature of the text, with evaluations of the story such as 'creepy' or 'unsettling' featuring most prominently (Gooding 2008: 390). The second group were said to respond to its age-appropriateness, and question whether a book labelled by many reviewers as 'creepy' or 'nightmarish' should be given to children. Gaiman himself claims 'double audience for the novel', something which likewise is applicable to Alice in Wonderland (see Tabakowska 2014), as well as many other 
examples of children's literature (for a further exposition of this 'divided' or 'second reading' process in response to children's and Young Adult fiction, see also Harrison and Mason: In preparation).

Gooding cites an online interview with Gaiman (2002) where the author defends these claims. In this interview Gaiman himself argues that this 'double audience' works differently. He suggests instead that children classify the text as an adventure story, whereas adults pick up on the 'scary and disturbing' elements of the narrative. Gaiman (2002; cited in Gooding 2008) also observes,

The thing that I find oddest...is those people who, after reading it, tell me that it seemed really familiar...familiar in that the shapes, once they've read them, just sort of assimilated into the way they saw the world. They felt they'd always known them.

In order to examine how readers respond to these 'familiar' components of the text's construction schema, the following sections explore reader reviews (for the full reviews, see RA-RJ in the Appendix) taken from Goodreads and Amazon to account for the various construals of the fictional world of Coraline.

\subsection{Resistance and identification}

\subsubsection{Reader response: Character}

Alongside the divided responses to the text, the reader reviews for Coraline can also be further categorised. The construals in the reviews analysed can broadly be defined into two approaches: those who view the text as representing a fully realised world with believable characters - in other words, those who identify or express attachment with the character and the fictional world (see Segal 1995; Kuiken and Miall 
1994; Kuiken, Miall and Sikora 2004; see also Stockwell 2009: 134-167) - and those who have more resistant responses (Whiteley 2014; Stockwell 2009).

Miall's (1990) study into reader response identifies a 'two-stage' process in the reading experience (following Iser 1978: 92-93). He argues that the first level involves the reader's recognition of a situation;

one with which they are likely to be familiar and for which an existing schema is available. But various points in the story also challenge the schema or fall outside it, requiring interpretive effort of the reader. How readers respond at the second level appears to depend to a significant degree on their individual experience and personality, since such textual features call for an evaluative response.

(Miall 1990: 328)

This idea of schema recognition and the 'interpretative effort' of the reader will be expanded on in this next section, and connections can be drawn between these ideas and Whiteley's classification of feelings of resistance and identification felt by readers in response to characters in texts.

In her 2014 chapter 'Ethics', Whiteley observes that the text worlds of the novel Never Let Me Go (Ishiguro 2005) establish different narrator and narratee 'roles', and through the analysis of reader response data it is seen that readers project themselves into these different narratee roles in order to resist or identify with the protagonist, Kathy. Whiteley further analyses how there are particular stylistic cues that can create clashes which obstruct or confuse this readerly process of projection (see also Martínez 2014 for an exposition of the role of 'storyworld possible selves' in narrative immersion).

More generally, reading group research suggests that '[e]motional proximity and distance from characters [...] form a crucial axis for moving through novels, and 'identification' often means not just recognition but closeness' (Long 2003: 153). Where these previous studies into identification have focused on attachment with characters, 
the following analysis also considers this phenomenon within the context of reader response to the fictional world more holistically.

A constant shared between Coraline and texts from the wider fairy tale genre is the exploration of identity, for 'all fairy tales tell the story of acquiring self' (Herman, Jahn and Ryan 2005: 158). The literary critical material on the text has made reference to this (see, for examples, Gooding 2008; Nikolajeva 2009; Rudd 2008). As we have seen in Chapter 4, salient reference points in narrative - such as literary characters - help to build or model readerly interpretation. Additionally, as in The New York Trilogy, characters in fairy tales are often considered 'types rather than individuals' (Herman, Jahn and Ryan 2005: 158; see also Propp 1968). Acknowledgement of Coraline as a target that evokes reference points - protagonists - from other texts is dependent on the individual reviewer and their relationship to the viewing frames of the narrative. In the story, Coraline and the cat are the only characters that remain constant reference points across the two worlds: they remain themselves, whereas all the other characters have 'other-world' targets.

Both readers and critics, for example, make the prototypical connection between Coraline and Alice in Wonderland (RF, RB; Pullman 2002; Rudd 2008) at the narrative level, and others break down the roles performed by the central characters even more specifically, as demonstrated in Table 5.1.

\begin{tabular}{l|l|l|l|l}
$\begin{array}{l}\text { Coraline } \\
\text { characters }\end{array}$ & $\begin{array}{l}\text { Alice in } \\
\text { Wonderland }\end{array}$ & $\begin{array}{l}\text { Other } \\
\text { Gaiman texts }\end{array}$ & $\begin{array}{l}\text { The Lion, The } \\
\text { Witch, and the } \\
\text { Wardrobe }\end{array}$ & Fairy tales \\
\hline Coraline & Alice (RD) & $\begin{array}{l}\text { Other Gaiman } \\
\text { protagonists } \\
\text { (RE; RJ) }\end{array}$ & $\begin{array}{l}\text { The Pevensie } \\
\text { children (RD) }\end{array}$ & --- \\
\hline The Cat & $\begin{array}{l}\text { The Cheshire } \\
\text { Cat (Rudd }\end{array}$ & --- & -- & $\begin{array}{l}\text { 'magical helper' } \\
\text { (Nikolajeva }\end{array}$
\end{tabular}




\begin{tabular}{l|l|l|l|l} 
& $\begin{array}{l}\text { 2008) } \\
\text { Humpty } \\
\text { Dumpty } \\
\text { (Nikolajeva } \\
\text { 2009) }\end{array}$ & & & 2009) \\
\hline $\begin{array}{l}\text { The Other } \\
\text { Mother }\end{array}$ & --- & -- & -- & $\begin{array}{l}\text { 'Fairytale villain' } \\
\text { (Nikolajeva } \\
\text { 2009) }\end{array}$
\end{tabular}

Table 5.1. Interrelated reference points in Coraline reviews.

The prototypical comparisons between the figure of Coraline and other similar literary figures can be perhaps explained through CG's entrenchment. Arguably the roles of some literary characters have become socio-culturally entrenched that they form a default reference point and accompanying dominion upon which readers can draw in order to conceptualise this new literary world. Those who mention the cat as a foregrounded figure, for example, speak about him in functional or Proppian (1968) terms (Gooding 2008; Nikolajeva 2009; Parsons et al. 2008). Gooding labels the cat as an instrumental agent, who allows us to access to Coraline's emotional state by acting as a translator of her emotions, whereas Nikolajeva (2009: 260) sees the cat as the 'magical helper' and as constituting part of a wider function of cats in contemporary fiction which is to "breach fluctuant boundaries between alternative worlds'. In turn, the protagonist Coraline is a schematic instance of the fairytale protagonist type, as observed in the interrelations between her character and Alice, other Gaiman protagonists and the Pevensie children from The Lion, the Witch and the Wardrobe (Lewis 1950) as shown in Table 5.1.

Following Propp's (1968) categorisation of functional characters in fairy tale narratives, it is said that ' $[\mathrm{w}]$ hile endowed with ordinary human qualities, fairy tale protagonists generally lack any psychological depth. They define themselves by means 
of their actions instead of their psychology' (Herman, Jahn and Ryan 2005: 158), which, as a psychonarrative strategy, 'allows readers greater interpretive latitude' (396).

Though built upon entrenched concepts, Coraline offers a different perspective to the traditional fairy tale and involves projecting the unfamiliar onto the familiar. One of the novel aspects of the text is that, actually, Coraline's character is considered more 'rounded' (Forster 1905) than other fairytale protagonists. Many of the reviewers, for example, comment upon Coraline's psychological role and perspective as a noteworthy part of the novella, as in the examples below:

I was surprised and pleased to discover that I enjoyed Gaiman's prose, and appreciated his perceptive depiction of the child's-eye view of the world around her

Coraline is a strong and inspirational character for children. She is intelligent and armed with streets-smarts but also a approachable character

Coraline is a modern gothic fairtale with a refreshingly active protagonist

Along with being an awesome adventure, the book focuses on Coraline's personality development through the novel. She doesn't gets all mature and serious (God gracious no! how dreadful would that be!) but finds courage and wisdom within her which she didn't know existed

(RB. All emphases and spelling as in the original reviews)

These examples all view Coraline positively, with other reviews in addition identifying particular personality traits ('she's smart, inquisitive, polite [and] brave', RA) that mark Coraline as a more rounded character. RB, quoted above, above even suggests that Coraline's character development is foregrounded as the main theme of the text ('[a]long with being an awesome adventure, the book focuses on Coraline's personality development through the novel', RB). This latter point is also supported by Rudd (2008: 2) who similarly states that 'Coraline is centrally concerned with how one negotiates one's place in the world'. 
Not all reviewers viewed Coraline's psychological perspective positively, however. RE, for example, describes how,

it's not frightening to simply show scary things. Hearing a strange noise in the woods is not the same as being told that a character hears a strange noise in the woods. It only becomes frightening when the vividness of the description or the realism of the character's psychology allows us to tap into that sense of fear.

Here, the reviewer is concerned with two aspects of the fictional world construction: the fact that a 'flat' character (Forster 1905) - in other words, a character that lacks psychological 'realism' - is represented as the protagonist, and the underspecified language (the lack of 'vividness of the description' in the text). This leads the reviewer to struggle to find the text 'frightening', which signposts another of the main divisions amongst reviewers of this text: the difference in reception between a child and adult audience - of whether readers identify the schematic cues that classify the text as a horror/ Gothic story, or not.

\subsubsection{Reader response: Fictional world}

It has been observed that Coraline is a fantasy text that is grounded in a mixture of genre sub-types, including fairy tales and the Gothic. Many readers acknowledge the younger readership of the book (7/10 of the reviews), and others are more specific in the genre templates they identify: for example, it is labelled as an adventure story (RB); as having 'magical' elements (RC); as a 'dark fairy tale' (RG), and as a 'modern gothic fairytale' (RH). It is also labelled as a horror story (RE; RF), as well as being a fantasy text but with 'no particular tradition' (RE). These construals will be discussed in more detail in the next section.

The language of Coraline is simple and direct, and primarily packaged as a children's book. In response to this, some reviewers argue that Coraline represents a 
fully-formed, detailed and vivid fictional world, and others conversely argue that Coraline 'sets a much barer stage' than Gaiman's other works and lacks sufficient specificity in its detail (such as RE's review here, and RC's review below). Feelings of identification or attachment to a text are therefore not only related to the affective response towards the character, but also pertain to a reader's response to the fictional world. This is supported by Long (2003: 151), who argues, based on evidence from reading group data, that characters are 'central' to a reader's attachment process, but that nevertheless 'believable settings and plots serve mainly to ground characters more fully in reality'.

The creation of the text world- and whether it is successful or unsuccessful - is frequently mentioned in the reviews. Indeed, the '[c]onstruction of a detailed fictional world is a key feature of most fantasy fiction' (Herman, Jahn and Ryan 2005: 161). Consider, for example, the following four review excerpts:

And what a world it is. "Other" parents in a house just like yours but better (and far worse) in the subtlest of ways. Keys, mists, a talking cat and ghosts... all done with a class and timelessness that others in the genre (that I'm familiar with anyway) have failed to pull off (but not to attempt).

Neil Gaiman creates an imaginary world here that still feels like it could exist. He doesn't explain away the differences between the book's world and ours with magic or science; his fantasy world exists in our world, and it doesn't feel like it couldn't or shouldn't.

It seemed to me that in creating a 'frighteningly' magical tale for a young reader, Coraline pulled back from a darker, profounder universe that was its provenance. I could sense that world behind the story, but the narrative seemed to simplify against it. This frustrated me, and I had a hard time believing and becoming engaged in the story. Even so, if being a child is not really LESS than being an adult, just a different way of understanding the world, then I think that the greatest books for children create worlds that are complete in and of themselves (and accessible to all readers AS SUCH), and do not feel like derivations of larger more 'adult' worlds.

His clear, unconvuluted style is really allowed to shine through here as this story is primarily for children, giving a wonderfully bleak, chilly feel. Also, Gaiman's 
masterful tendency of leaving much unexplained and not feeling the need to rationalise the extraordinary is, no doubt one that will appeal to children greatly.

My main criticism is that the narrative is a little distant - a bit movieish and The language is a little ambitious in part for children to read alone - I had to look up a few words myself! All in all a strong children book piece. A very dark fairy tale as all good fairy tales should be.

(RG. All spelling and emphases as original)

It was earlier mentioned that reading group research suggests that '[e]motional proximity and distance from characters [...] form a crucial axis for moving through novels, and 'identification' often means not just recognition but closeness' (Long 2003: 153). This idea of proximity is also discussed in Whiteley's (2014) chapter on identification and resistance, where she observed that some readers used a shift in pronouns (first person to second person forms) to align themselves more directly with the central character.

With the Coraline reviews, this process of readerly positioning can be observed in the responses to the style of the fictional world. RG, for example, describes the narrative as 'a little distant', whereas RA aligns their vantage point from a collective position: 'He doesn't explain away the differences between the book's world and ours with magic or science; his fantasy world exists in our world, and it doesn't feel like it couldn't or shouldn't', and also switches to a direct second person address ('a house just yours but better'). Apart from this proximal description, the other three reviewers here display a more distal position in relation to the text: they explicitly reference that the book is 'for children' (RF); and do not implicate themselves within the target audience.

Furthermore, some reviewers here argue that Coraline represents a fully specified fictional world, so successfully for one reviewer as to instantiate a 'believable' integration of real and fictional world: 'his fantasy world exists in our world, and it 
doesn't feel like it couldn't or shouldn't' (RA). Long (2003) argues that believability helps to ground characters in reality, but, equally, '[p]lausibility and authenticity do not depend upon realism or believability' (Stockwell 2009: 115). The text 'doesn't explain away the differences' (RA), but through the instantiation of entrenched literary templates, it becomes, for some readers (like RA and RF), 'plausible' and 'authentic', without necessarily having to be real, believable or having to 'rationalise the extraordinary' (RF). RF finds that the simplistic language contributes to the overall texture of the book, 'giving a wonderfully bleak, chilly feel' which works with the content rather than 'against' it, as argued by RC. RF's view is supported by other reviewers, such as RI who argues that Gaiman's 'writing is simple - he doesn't go overthe-top with adjectives, yet very effective and sets the scene well'. This is contrasted directly with the final review here, which conversely identifies the 'language [as] a little ambitious in part for children to read alone' (RG).

This response to the overall style of the text in these four reviews is considered a 'primary focus' (Kuiken and Miall 1994: 390) in reader reviews more generally. How readers judge the style of narrative, classing it as well written or too simple, can, like the text world analysis in the first section, be accounted for by the CG concept of lexical specificity. It is said that

[t]hose who have it that children's literature is characterised by nothing more than greater simplicity in all areas of narrative structure often argue that the genre is no less elegant or artistic for that simplicity - 'simple' doesn't mean 'simplistic"

(Herman, Jahn and Ryan 2005: 59).

As noted in Chapter 2, in CG linguistic specificity is paired with schematicity. In other words, linguistic choices can fall on a cline from specific at the one end to schematic at the other. In general, most written linguistic constructions show 'a mixture of schematic and specific description' (Langacker 2008: 56), and it seems that Coraline is no exception. 
Langacker (2008: 57) goes on to say that 'as representations of conventional patterns, schemas provide the basis for assessing linguistic well-formedness', and, consequently, '[a]n expression is judged well-formed to the extent that it bears relationships of elaboration (rather than extension) to the schemas invoked to categorize it'. When scaling these ideas to this discussion of Coraline, the relationship between narrative content and response can arguably be further explained in CDS terms. When a reader responds positively to the style or content of a literary text, this shows that the text satisfies or exceeds the expectations as outlined in the minus frame of the CDS. The minus frame lays the foundation for the unfolding discourse, and from this touchstone a reader can guess the plus frame of ongoing discourse - therefore outlining discourse expectation. Although Coraline immediately establishes links with other entrenched literary schemas, some reviewers feel that this is not pursued in the ongoing plus frames of discourse.

For RC, the well-formedness of the narrative is in question, because for her 'simplicity' does mean 'simplistic'. Equally, RE shares RC's view and says that Coraline does not 'explore its own origins'. Compared with the previous Gaiman texts RE has read which explore or adapt existing schemas, these readers argue that these expectations are not fulfilled in Coraline. That this leads to a negative construal of, and resistance to, the text. Because RE cannot relate Coraline to a particular pre-existing construction, 'the content has no discernible position in their mental universe and cannot be brought to bear on their situation. It simply floats unattached as an object of idle contemplation' (Langacker 2008: 259).

Generally it can be argued that there is difficulty with engaging with the reading material when there is a lack of detail, or if the schematic and specific description becomes unbalanced. The resolution of the narrative description therefore impacts upon the instantiation of schematised knowledge. Arguably, this level of schematisation 
is what Miall (1990) would label as a 'Level 2' feature of the text that impacts upon readerly 'interpretative effort':

Level 2 features of the text are indeterminate: their meaning is not given or obvious. Readers feel that the text is 'getting at' something, but cannot at first see what this is. In attempting to establish meaning readers focus on the same points in the text and tend to relate the same groups of points, but may place quite different valuations upon them.

(Miall 1990: 328-329)

For example, RC identifies problems between the recognition of grounded knowledge (she acknowledges 'the profounder universe that was its provenance'), but the low specificity caused problems with attachment ('the narrative seemed to simplify against it'). It is argued by RE, conversely, that the schematic template is missing from the text altogether:

By eschewing any particular tradition in Coraline, Gaiman has little to play with. He has nothing to subvert, nothing to vaguely reference. He cannot play upon our expectations.

The lack of discernible narrative template to compare against ('nothing to vaguely reference') has led to a resistant response to the fictional world construction for RE, to the extent that they finish the review by stating: 'This little story could have made a passable entry in a horror story collection, but is not original enough to stand on its own'.

It seems, therefore, that in both the areas of character- and world-attachment, recognition of schemas from intertextual knowledge, experiential memory and the process of narrative interrelation (Mason 2014) play important roles in reader responses to texts. Though the reader reviews here are commenting on 'the same points in the text', it is clear that they do 'place quite different valuations upon them' (Miall 1990: 329). 


\subsection{Conclusion: 'It was so familiar - that was what made it feel so truly strange'}

It has been discussed how Coraline is a complex construction in that it comprises elements of different narrative sources and schemas. Exploring construal's specificity and the associated concept of elaborative relationships, alongside world creation has proved an effective framework for accounting for fictional world-construction in this chapter: both regarding how this works within the text itself, where Coraline's physical perspective was outlined through changes in resolution of scene description, and in terms of how readers respond to the novella. Furthermore, it was seen that the lack of elaboration in Gaiman's simplistic writing style - in terms of the novella as a holistic linguistic construction - produces different degrees of attachment with both fictional character and world. Similarly, the prototypical comparisons between the figure of Coraline and other similar literary figures have been outlined through CG's idea of entrenched structures. In this way, CG's construal processes can be effectively used to describe how particular texts subvert or evoke traditional genre 'macro-designs' (Herman 2002).

As observed, recognition of the construction schema upon which Coraline is built is individual to the discourse participant, and can change a reader's overall construal of the text. As Miall (1990: 338) argues,

To the extent that valuations differ [...] so will construals of the story as a whole. Thus it is quite possible for two readers to make evaluative responses to the same phrases, see the same network of relationships across phrases, and make anticipations at the same moments, yet emerge with opposite readings of a text.

This division - these 'opposite readings' of the text - has been observed in the reader review data. The readers respond to the same textual cues (the intertextual references, the style of the language, the roles of the various characters), but where some have 
expressed attachment with the characters or fictional world creation, others have expressed resistance.

To extend this study in future it may be useful to further consider the role that the individual's CDS plays here. If the structure varies according to the individual reader, then tension between the minus and anticipated frames (in other words, whether a text fulfils a reader's extra-textual narrative expectations) can potentially provide an account for alternative construals of the same text.

\subsection{Review}

The first half of the analysis in this chapter considered text world creation through character construal, and centred on a clausal analysis of an extract from the text when Coraline walks through the 'other living room' (Extract 5.1). In this passage the description of the alternate reality profiles a comparison with Coraline's previous world knowledge, and through her perspective we see the visual scene directly compared with Coraline's corresponding room back home. This textual analysis further considered the construal concepts specificity and elaboration in text world creation.

The second half of this chapter explored readerly construal, and identified how the world-building information of Coraline is created through composite, intertextual reference points. The analysis observed how readers respond to Coraline as a character and the novella's text world creation more generally, and explored the important role that schema recognition plays in comprehending the narrative. It was noted that schema recognition impacts upon readers' construal of the text, and a 'divided reading' between an adult and children's audience is identified by many of the reviewers. Equally, a combination of schema recognition and acknowledgement of the levels of 
specificity/schematicity of the text appeared to cause further division amongst the reviewers; with some responding positively to the construction of the text - identifying with the character and fictional world construction - and others producing more resistant readings.

Discussed in Chapter 3 and briefly with Coraline's focalisation in this chapter, Chapter 6 focuses more specifically on how CG can be applied in a consideration of character perspective. In particular, the next analysis considers how attentional frames function in a multimodal text, and draws upon the cognitive semantic concepts of windowing, gapping and splicing (Talmy 2000a) in addition to a variety of perspectival CG terms to analyse how we mind-model perspective through multimodal constructions. 


\section{Chapter 6. Mind-modelling perspective in 'Great Rock and Roll Pauses'}

\subsection{Introduction: Visual attention in cognitive linguistics and CG}

Returning to the visual metaphor introduced in Chapter 2 (UNDERSTANDING LANGUAGE IS CONSTRUING A SCENE) there is said to be a strong relationship between linguistics and the visual or conceptual system (see Diack 1960; Doloughan 2011; Hamilton 2003; Jackendoff 1987; Köhler 1947; Mather 2006). Langacker (1993: 454) himself argues that some aspects of construal are universal and biologically grounded, whereas others are more idiosyncratic and that 'while space and vision must be accorded some kind of primacy, the exact nature of that primacy remains an open question'. This primacy is conceivably given greater emphasis in studies of multimodal texts (Forceville 1999, 2007, 2009; Gibbons 2008, 2012a, 2012b; Kress and Van Leeuwen 2006).

Styles (2006: 79) in turn argues that the spotlight metaphor is commonly used to explain visual attention, although it has been suggested that a zoom lens metaphor may be a more effective way of describing it (see also Laberge 1983). This zoom lens metaphor is relevant to the previous discussions of shifting levels of granularity in Chapters 3 and 5, where a zoom-effect in language represents the movement between the schematic and the specific (or vice versa) to achieve different means: for the subjectification of perspective (Chapter 3), for example, or to establish world comparison (Chapter 5).

This chapter refers to a range of cognitive linguistic ideas to explore how perspective is demonstrated throughout a multimodal text. Specifically, this chapter draws superordinately on CG's construal processes, profiling, grounding alterations, and Cognitive Semantics' attentional windowing (Talmy 2000a: 255-309) to explore how we 
mind-model (Stockwell 2009; Stockwell and Mahlberg 2015) perspective in Chapter 12, 'Great Rock and Roll Pauses', from A Visit from the Goon Squad (Egan 2011: 241-316). This analysis is centred on the idea of directed attention, which concerns how and where attention can be guided through linguistic and multimodal mechanisms (see Styles 2006; Talmy 2008. A stylistic account of attentional windowing in the representation of mind style (Fowler 1996; Semino 2002) is also considered in Harrison 2014. See also Nuttall 2015 for a CG account of perspective in fiction).

Since '[c]onstrual operations serve as prompts for the allocation of attention to a particular aspect of the cognitive representation evoked in the listener' (Pleyer and Schneider 2014: 39), a CG account of construal - and particularly profiling - is a logical starting point to explore how attention is directed in narrative discourse. A Visit from the Goon Squad as a whole comprises chapters that profile a part of the life of different characters, and a character that seems peripheral in one chapter often becomes the focal point of the next. Each chapter in the novel is written in a different style, including one that is written entirely in second person, one that is formatted as an interview written for a magazine article and one that is arranged as a PowerPoint slideshow but is in fact a journal of a twelve-year-old girl, which will form the focus of this analysis here.

\section{2. 'Great Rock and Roll Pauses'}

Egan is a contemporary American writer and the author of a collection of (some re-released) novels (1995, 2008, 2011, 2012) prior to A Visit from the Goon Squad, which was critically well-received and won the Pulitzer Prize for fiction in 2011. Her style in Goon Squad is more experimental than her previous novels, although the companion short story 'Black Box', which is written from the perspective of one of the 
minor characters in Goon Squad, similarly experiments with form and was published as a series of Tweets in 2012. The fact that the novel shows so much variation in style from chapter to chapter has meant that critics have argued whether Goon Squad can be labelled as a novel, a collection of interlinked short stories, or as a hybrid of the two (see Churchwell 2011; Martin 2011). A cohesive theme that ties these chapters together, however, is the representation of the music industry: the focus and orienting topic of each profiled story. 'Indeed, the novel could be Jennifer Egan's tribute to the scratchy old vinyl LP: it is divided into two 'sides' (A and B) and it's instructive to think of the chapters as tracks on an album' (Gibbs 2011).

'Great Rock and Roll Pauses' is the 'slide journal' (Egan 2011: 261) of Alison Blake. It is the penultimate chapter in the text, and represents a large jump in time from the setting of the previous chapter ('Goodbye, My Love') (Egan 2011: 215-241). It acquaints readers with Alison's family life, and her relationships with and between her mother (Sasha), father (Drew) and brother (Lincoln). Alison's mother, Sasha, is one of the most profiled characters in Goon Squad. She appears in many of the chapters prior to this point in the text, and her character is one of the most discussed by the reviewers (see Fulford 2010; Martin 2011). The familial relationships represented by Alison in her journal are complicated: she describes how her father (who is a surgeon) spends long hours working, the 'Waiting Chair' (Egan 2011: 272) regularly occupied by her mother, and her brother Lincoln who is 'slightly autistic' (Egan 2011: 241) and currently obsessed with pauses in rock songs - which Alison helps him to document on graphs in the PowerPoint. In particular, Lincoln is fascinated with the duration of these pauses, as well as when they appear in the song:

This is an excellent early pause. The voice tapers off, and then you've still got 1.5 seconds of total silence, from 2:38-2:395, before the chorus kicks back in. 
These 'rock and roll pauses' are seen to play a metaphorical role within the text:

Those pauses, like the spaces between the PowerPoint slides, become a metaphor for the gaps between what we mean and what we say, or the apparently unbridgeable distance between family members.

(Churchwell 2011)

The correspondence between the physical construction of texts and their emotional or aesthetic import has been explored in previous multimodal analyses (see, for example, Kress and van Leeuwen 1996, 2001; see also Baldry and Thibault 2006; Forceville 1999, 2007, 2 009; Gibbons 2008, 2012a, 2012b). In her 2008 study, for example, Gibbons argues that multimodal texts are 'polyphonic' (an idea particularly pertinent for this chapter, see Section 6.2.1); and also that a physical engagement with a book primes a reader's reception to the metaphorical movement within the text (Gibbons 2008: 114-118). Although monomodal literary texts elicit embodiment processes in their readers, arguably it is the strength of the relationship between linguistics and the visual or conceptual system which means that embodied human experience is felt to a greater degree in multimodal texts. 'Great Rock and Roll Pauses' is a chapter often identified in the critical material as the culmination of the novel's experimentation with form (as argued by Churchwell 2011), but it is simultaneously considered the most 'touching' narrative in the text (Fulford 2010).

\subsubsection{Mind-modelling perspective}

Among other uses for literary linguistic application, including metaphor, irony and versification, Hamilton (2003: 63) identifies how CG, and profiling, in particular, can be used to consider the representation of voice in fiction. 
This analysis aims to consider the voice of Alison, in particular, and argues that how the narrative directs a reader's attention (the object of conceptualisation) affects how we perceive the narrator (the conceptualiser). This process is an integral part of how we comprehend 'Great Rock and Roll Pauses', as well as how we comprehend the representation of narratorial voice in other texts. In Chapter 3, for example, it was shown how the various levels of objectivity and subjectivity in the Enduring Love scene represented the role and motivations of the intradiegetic narrator, Joe. He aimed to be omniscient, but the subjectification of language foregrounded his own uncertainty. It can therefore be argued that, in fiction, 'different degrees of attention can be assigned to the object and subject of conceptualisation and their relationship' (Pleyer and Schneider 2014: 38); and that this relationship impacts upon the representation of perspective in fiction.

The multimodal representation of Alison's perspective in this text creates a strong impression of her distinct view on the world; her individual 'mind style' (Fowler 1996; see also Palmer 2004; Semino 2008). Mind style is an applicable label for the stylistic representation of the narrative here, for as Semino (2008: 269) highlights, the term captures 'those aspects of world views that are primarily personal and cognitive in origin, and which are either peculiar to a particular individual, or common to people who have the same cognitive characteristics'. Furthermore, how this world view is framed becomes representative of 'an individual's characteristic cognitive habits, abilities and limitations' (Semino 2008: 269). As will be explored in the following analysis, one of Alison's most prominent characteristic habits is the way in which she presents the world around her.

Because of the high level of reader involvement in comprehending this chapter, however, it is also worth considering how the process of mind-modelling works in the reading of this text. Stockwell and Mahlberg (2014: 132) argue that this term, 
refers to the capacity that humans evidently have for imagining and maintaining a working model of the characteristics, outlook, beliefs, motivations and consequent behaviour of others. It is this fundamental cognitive capacity that allows us to understand that other people are people, and that they are in some ways similar to us and in some ways different.

In summary, mind-modelling is the method by which we perceive and understand minds other than our own.

The mind-modelling process in 'Great Rock and Roll Pauses' is a layered one, largely because of its 'polyphonic' (Gibbons 2008) construction. At the discourse level of the chapter we mind-model Alison principally because she is the author of the PowerPoint journal and the primary focal participant, but she is often off-stage in the slides. In other words, she is the conceptualiser, but frequently she is not the object of conceptualisation. Although the slides undergo subjectification through various (often multimodal) means, as the analysis will observe, we are also aware of how she mindmodels the other members of her family. Alison's brother Lincoln, in particular, is the focus and object of conceptualisation in most of the PowerPoint slides. We mind-model Lincoln through Alison's conceptualisation, but it is clear that he also displays a distinct mind style, which will be considered in more detail in the following analysis.

\subsection{CG and multimodality}

Put simply, multimodal texts entail the coexistence of more than one semiotic mode within a given context' (Gibbons 2012a: 41). It is said that CG is well suited for multimodal analyses as it 'sees visual processes of meaning construal as being founded on the same conceptual principles as linguistic construals of meaning and describes them with a common terminology' (Pleyer and Schneider 2014: 36). Previous applications of CG to point of view in multimodal fiction have focused on firstly graphic 
novels, and secondly on graphic novels that have a protagonist or focaliser who is clearly shown, in third-person terms, to be the construer of the scene (see, for examples, Herman 2009b; Pleyer and Schneider 2014).

'Great Rock and Roll Pauses' is evidently a multimodal text. In this chapter attention is directed through manipulations of font size or colour, through the use of 'text boxes' to foreground particular constructions, and through the general layout of the slide: where the linguistic construction is positioned on the page, how it corresponds with the rest of the text, how the space is structured, and so on. As well as being a multimodal text, Goon Squad can be classified even more specifically. Unlike the texts considered so far in this book, Goon Squad is an example of altermodernist fiction (Gibbons 2012b: 240). It fulfils the genre requirements in its use of form (often making references to contemporary culture), time (represented heterochronically) and identity (in the representation of 'a character whose movement through time and space traces out intersubjective memories and identities') (Gibbons 2012b: 240). These three preoccupations are recognised by the online newspaper reviews of the chapter. For example, the reviewer Gibbs (2011) comments that the text,

throws up perceptive theories of cultural consumption, and flatters the reader by presenting its characters as discrete slivers of personality to be pieced together, as if from a collection of different jigsaw puzzles.

This construal ties together two fundamental aspects of Gibbons' definition of altermodernist fiction. Firstly it acknowledges the relevance of 'motifs' from Western culture (through its mention of 'theories of cultural consumption', for example). Secondly this review notes the importance of the representation of identity in the text: namely, the 'discrete slivers' of personalities. These personalities are 'intersubjective', as they need to be 'pieced together, as if from a collection of different jigsaw puzzles'.

The third feature of altermodernism, the heterochronic representation of time, is also clearly observable in the text. Alongside music, a preoccupation with time is one of 
the central themes of Goon Squad, as well as in postmodern and contemporary fiction more generally (see Smethurst 2000). The representation of time, or of grounded events, is also integral to 'Great Rock and Roll Pauses' where it acts as a connective thematic device across and between attentional frames (see Churchwell 2011; Fulford 2010; Gibbs 2011; House 2011).

In 'Great Rock and Roll Pauses', the 'piecing together' of the jigsaw pieces of the fictional world occurs on a much more literal level than with the previous chapters of Goon Squad. PowerPoint slideshows are traditionally used to support a presentation: that is, they provide a visual means of accompanying an oral presentation, one that is usually delivered in front of a group of people. As such it is a very public mode of communication. It is clear from the outset, therefore, that this chapter does not present a straightforward writer/reader relationship. To accommodate this, at this stage of the novel a reader is required to update the current discourse space information: the relationship between reader and character/narrator alters, and we are instead invited to fulfil the role of an audience member (AM) who is viewing a presentation (see Figure 6.1).

In short, a reader is placed in the position of viewing a PowerPoint presentation without the physical presence of the presenter $(\mathrm{P})$ and consequently they are required to mind-model the protagonist differently than in a more standard prose format. This format means that readers are invited to respond to a different set of stylistic cues in order to follow the text, as explored in the following analysis. 


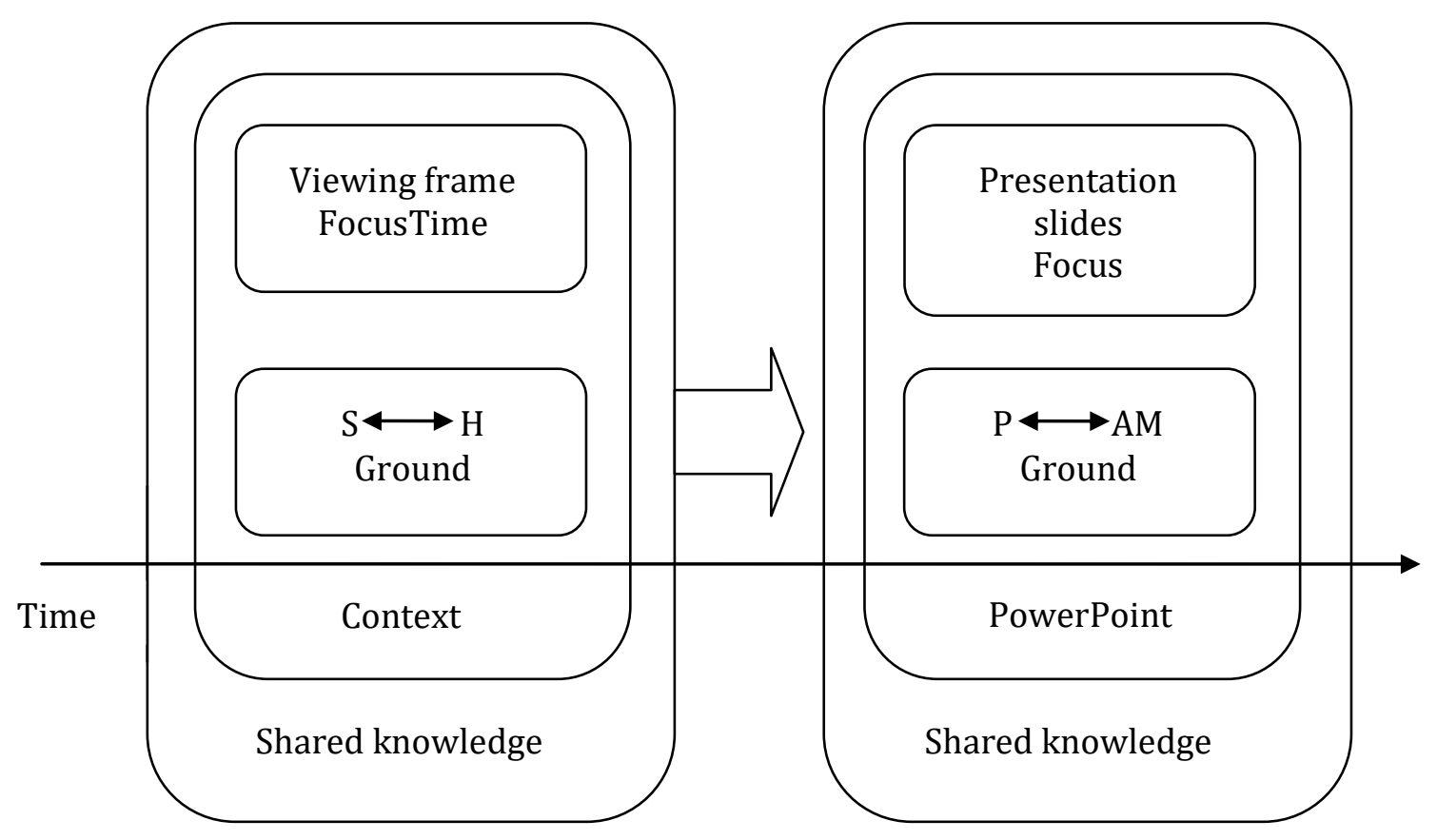

Figure 6.1. Updating the CDS of 'Great Rock and Roll Pauses'.

Of course, Alison's PowerPoint slideshow is actually her 'slide journal' (Egan 2011: 261). In contrast to a presentation, a journal is usually considered a private means of communication and one which represents someone's personal life and the details they wish to record. The conflict of modes here means that, interestingly, 'Great Rock and Roll Pauses' represents contrasting conceptualisations through one, contradictory, semiotic channel (see Herman 2009b, in which this idea is explored in more detail with another text). Consequently, this text represents a sort of 'ontological hoax' (Gibbons 2012b: 432). Multimodal texts in this category 'masquerade as something they are not' (Gibbons 2012b: 432), and in 'Great Rock and Roll Pauses', clearly, the form belies its content.

Some of the reviewers have remarked upon this ontological hoax format. Churchwell (2011), for example, contends that the mode of communication is a sort of 'trick' that 'feels appropriate in a book preoccupied throughout by the effects of technology on our lives'. In choosing this form Egan shows 'a profound interest in the 
metaphorical implications of technology' (Martin 2011); a point further supported by the fact that Egan has made an online version of this chapter available through her website, complete with the relevant songs - and their pauses - to accompany the slides. 


\section{Walking to the Car}

- My arm around my brother's neck, skipping in the desert night.

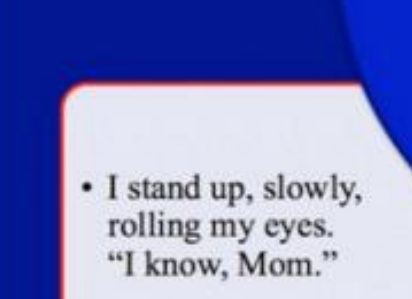

rolling my eyes.

"I know, Mom."
Cool air, but you feel heat coming up from the earth like from behind a person's skin.

I was right: the ground is warm.
- When kids say "Good game, Linc," I answer for him.

I think I feel it

through my

shoes, but do I?

When I crouch

to touch the

parking lot, it

glitters like

coal in the

streetlight.

"Alison, cars!" Mom yells, overreacting as usual (Annoying Habit \#81).

Figure 6.2. 'Walking to the Car' (Egan 2011: 246).

Figure 6.3. 'Lincoln Wants to Say/ Ends Up Saying' (Egan 2011: 257).

\section{Lincoln Wants to Say/Ends Up Saying:}

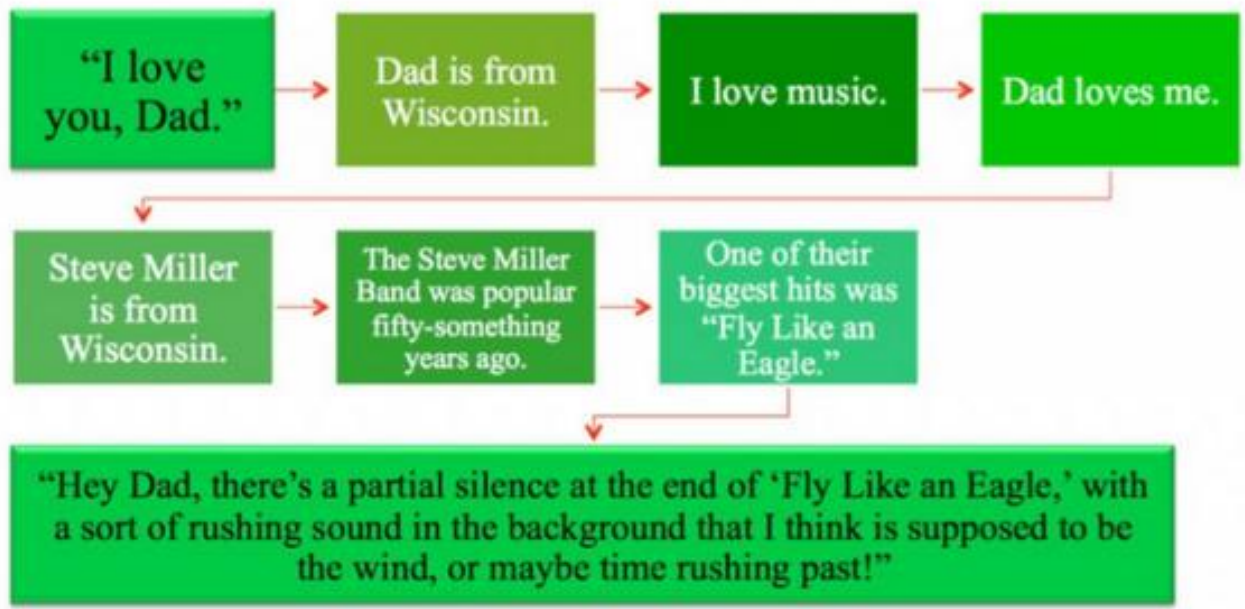




\section{"What is going on in here?"}

\begin{tabular}{|c|c|}
\hline $\begin{array}{c}\text { Mom, in the } \\
\text { doorway. }\end{array}$ & $\begin{array}{c}\text { "Bedtime, } \\
\text { kittens," she } \\
\text { says. }\end{array}$ \\
\hline $\begin{array}{c}\text { She's holding a } \\
\text { handful of the } \\
\text { little papers she } \\
\text { makes into } \\
\text { collages after } \\
\text { we're asleep } \\
\text { (Annoying Habit } \\
\text { \#22). }\end{array}$ & $\begin{array}{c}\text { She collages in her } \\
\text { Waiting Chair, in } \\
\text { the living room. }\end{array}$ \\
\hline $\begin{array}{c}\text { I don't know why } \\
\text { she loves junk so } \\
\text { much. }\end{array}$ & $\begin{array}{c}\text { Usually when } \\
\text { Dad's not home } \\
\text { yet. }\end{array}$ \\
\hline
\end{tabular}

Figure 6.4. "'What is going on in here?"' (Egan 2011: 272).

Figure 6.5. 'Mom's “Art”' (Egan 2011: 273).

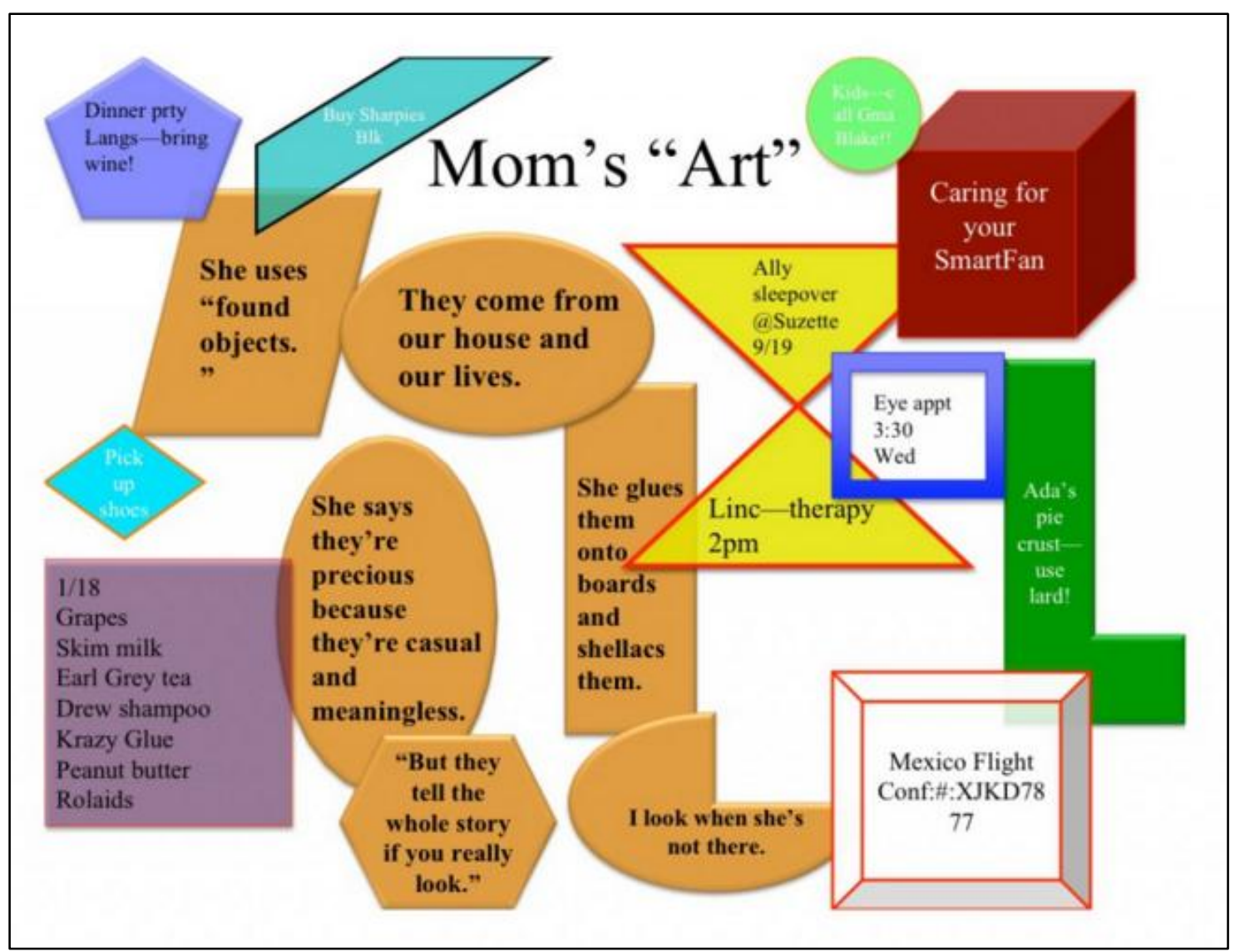




\section{What I'm Afraid Of}

\section{That the solar panels were a time machine.}

That I'm a

grown-up

woman

coming

back to

this place

after many

years.
That my parents are gone, and our house isn't ours anymore.

It's a brokendown ruin with no one in it.
Living here all together was so sweet.

\section{Even when} we fought.

It felt like it would never end. miss it.

Figure 6.6. 'What I'm Afraid Of' (Egan 2011: 307).

\subsection{Event frames}

As observed in Harrison (2014), Langacker's profiling system is strengthened when considered alongside a Cognitive Semantic account of attentional windowing as it helps to provide a more holistic account of how attention is directed in discourse. Talmy (2000: 255-309) describes the windowing of attention as the process where one or more portions of an event frame - the trajectory of a particular action - is placed in the foreground of attention while the remainder of the scene is backgrounded (Talmy 2000a: 258). Briefly put, attentional- or path-windowing in Cognitive Semantics is 'a way of focusing attention on a particular subpart of a path of motion' (Evans and Green 2006: 198) and falls within Talmy's broader attentional system. In Talmy's terms, an 
event frame describes a path of motion, outlining a trajector's movement through space from point A to point C.

In an event frame, which is 'the coherent referent situation with respect to which the windowing must take place', initial, medial or final gapping or windowing can exist (Talmy 2000a: 257). This means that some of the sections of the scene are mentioned (windowed) or excluded (gapped).

5. The book flew through the room and out of the window.

6. The book flew through the room.

7. The book flew out of the window.

In the sentence above, the same event ('flew') is described but framed differently in each construction. Sentence (5), for example, delineates a full event frame (SOURCE PATH - GOAL), with each portion of the path fully windowed. Sentence (6), on the other hand, shows gapping of the final portion of the path. Simply put, attentional windowing outlines how our attention can be drawn from the SOURCE to the GOAL (which represent particular locations).

Typically, however, the medial section of a sentence is often not as attentionally foregrounded as the other two sections, which can result in conceptual splicing (Talmy 2000a: 270). Rather than outlining the full path of the trajectory (SOURCE - PATH - GOAL), an event frame with a conceptual splice omits the medial portion of the path (SOURCE GOAL), as seen in sentence (7). When compared to sentence (5), it can be observed that the path 'through the room' is gapped. This conceptual splice means that the construction moves from the SOURCE to the GOAL, with a windowed agent ('the book') but a gapped (i.e. omitted) path of movement. It is this gapping process that CG's equivalent - profiling - does not account for (see Harrison 2014 for a summary and further comparison).

Like the CG terms applied thus far, all of the definitions outlined above are applied originally by Talmy to the trajectories of events at the sentence-level of 
language. This means that much of his original discussion of the effects of attentional windowing also centres on the problems caused by those elements of syntax such as complements and adjuncts (Talmy 2000a: 262). In line with the rest of the analyses in this book, these cognitive-semantic terms are applied to linguistic units above the clausal level in the following analysis. Consequently the term event frame here is used in relation to the development and progression of the narrative, as 'narrative events' (Dancygier 2007). This is in line with Text World Theory's definition of functionadvancers, which are propositional phrases that 'propel a discourse forwards' (Gavins 2007: 56).

As in comic strips and graphic novels, time is represented in a more physical way in 'Great Rock and Roll Pauses' than in a traditional prose narrative. Both the absences and attentional frames - the text world elements that are given prominence - between and across the pages represent and accentuate different phenomena: pauses in conversation, the boundaries of turn-taking, topic switching, and the representation of sound (or, rather, the lack of it). In this way the gaps and windows are used alternately to make connections as well as disjunctures (Talmy 2000a) between the event frames of the narrative; and across the presentation slides themselves. The physical space and construction of the multimodal text (its form) is thus incorporated into the meaning (its function) and becomes an even more integral part of the linguistic construction.

At the macro-level of the text, Goon Squad spans two generations of the characters' lives, and often much of the narrative arc of a particular character's life is gapped; either entirely, or windowed off-stage. For instance, although Sasha's narrative is one of the more prominent in the text, the disjuncture between her previous chapter ('Goodbye, My Love') (Egan 2011: 215-241), in which she appeared as a teenager in Naples, and the present day as represented in 'Great Rock and Roll Pauses', indicates a conceptual splice in terms of both time and location. The gap is addressed by a simple 
summary scan offered by Alison in one of the slides in this chapter: 'After Dad and Mom found each other again, she packed up her life in New York and met him overseas' (Egan 2011: 263), which completes some of the medial portion of Sasha's narrative trajectory. We can also retrospectively window other gapped information from Sasha's narrative trajectory through other facts mentioned. We know, for example, that the family lived in Pakistan for a time (Egan 2011: 263), that Sasha moved in with and had children with her boyfriend Drew who appears once in the previous chapter 'Out of Body' (Egan 2011: 244), and that she has turned her addiction to stealing into a career of making art using 'found objects' (Egan 2011: 273).

Fittingly, in the course of the text many of the characters do discuss their own movement through time: how they move from A to B. In an earlier chapter, for example, a character demands: 'I want to know what happened between $\mathrm{A}$ and $\mathrm{B}[\ldots] A$ is when we were both in the band, chasing the same girl. $B$ is now' (Egan 2011: 106). Although some of the reviewers equate this simply with the A/B side on a record (see Gibbs 2011), 'A to B' also colloquially expresses a passing of time or location; the idiomatic phrase getting from $A$ to $B$ ).

\subsection{Multimodal perspective in 'Great Rock and Roll Pauses'}

\subsubsection{Attentional windowing}

The organising structure of the slide journal in 'Great Rock and Roll Pauses' - the event frames that form the focus of attention - is made explicit at the beginning of the chapter. The first slide provides a contents page, which outlines the four episodic components of the chapter's construction: 

1) After Lincoln's Game
2) In My Room
3) One Night Later
4) The Desert

Portions of these superordinate narrative event frames are windowed linguistically in the slide, as in the above summary scan that provides 'snapshot' locations ('My Room'; 'The Desert') and specific times ('After Lincoln's Game'; 'One Night Later') of each of the forthcoming scenes.

While there are many implied portions of event frames that present macroevents in the narrative, in 'Walking to the Car' (Figure 6.2) a reader is presented with a micro-event frame (SOURCE - GOAL) as summarised by the title. The medial portion of this event frame path, in which Alison kneels down to check whether the ground is warm, is omitted from the title, but windowed in the slide itself. The event is presented in a clockwise circular format, with arrows guiding the direction of reading. The differentiation between the outer circle and inner circle on this slide represent the difference in the events, and what they mean to Alison. The outer circle represents what is literally occurring around Alison ('My arm around my brother's neck, skipping in the desert night'), whereas the inner circle represents an internal monologue that provides more information about the event PATH; what happens while Lincoln and Alison are walking to the car ('cool air, but you feel heat coming up from the earth like from behind a person's skin'). The fact that the medial portion of the event is windowed in more detail than the rest of the event frame backgrounds the importance of the SOURCE - GOAL portions of the frame (the event of walking to the car itself), and also functions to create a feeling of disconnection. Alison's thoughts ('I think I feel it through my shoes, but do I?') are represented as isolated from the external description of what is going on around her. 
The disconnection between these windows is further emphasised through other stylistic choices. For example, the language of the medial frame is much more metaphorical ('Cool air, but you feel heat coming up from the earth like from behind a person's skin' and 'When I crouch to touch the parking lot, it glitters like coal in the streetlight') as compared to the more literal lexical choices and dialogue as represented in the other portions of the path ("'Alison, cars!" Mom yells, overreacting as usual (Annoying Habit \#81)'). That attention is directed to these emotive portions of the event fractures the superordinate ontological hoax structure of the chapter. In other words, it exposes the 'masquerade', and it fulfils our CDS expectations about what a journal should include: personal thoughts and reflections. Despite the overall frame of the PowerPoint format, the underlying 'slide journal' aims of the chapter are nevertheless discernible.

As mentioned previously, the visual construal of each slide often reinforces or provides extra information about the text represented. Figure 6.5 entitled 'Mom's "Art"' (Egan 2011: 273), in particular, is a microcosm for the structure of the rest of the chapter. It comprises circles, squares and frames of 'found objects', which 'come from our house and our lives' (Egan 2011: 273). The text inside these shapes are lists ('1/18: Grapes; Skim milk; Earl grey tea'), memos (Eye appt 3:30 Wed), recipe notes ('Ada's pie crust - use lard!') and receipts ('Mexico Flight Conf:\#:XJKD7877'), as well as unattached quotations ('But they tell the whole story if you really look"') and personal comments from Alison ('I look when she's not there'). This format windows portions of the Blake family's life, and emphasises, in particular, the domestic concerns of the family. This contrasts with the windowed event frames from Sasha's previous chapters, in which her lifestyle as a personal assistant to a rock star takes centre focus. The idea that these windowed events 'tell the whole story if you really look' is suggestive of the structure of the novel as whole, and furthermore ironically parallels Alison's own methods of 
communicating. Finally, the fact that Alison's statement ('I look when she's not there') is given the same attentional focus as the other windowed parts of this slide functions to bury (Emmott and Alexander 2014: 329) the admission. It emphasises that this is something she does surreptitiously; a process she does not necessarily wish to highlight or draw attention to.

Forceville (2009) observes how the visual representation of language often contributes to its metaphorical meaning, and this is evidently applicable to the constructions of 'Great Rock and Roll Pauses'. Directed attention - windowing and gapping - functions on a multimodal level to create a figurative construal of particular constructions or frames. In the slide 'Ways It Can Be When Dad Comes Back' (Egan 2011: 274), for example, the world-building information is listed in boxes on a set of scales, with the positive 'Ways It Can Be' piled up on one side, and the negative 'Ways It Can Be' on the other side. These positive world-builders are matched directly with their negative counterparts on the other side of the scales: 'Wine Cork Popping' vs. 'Gin Pouring'; 'Laughing' vs. 'Angry'; 'Kissing Mom' vs. 'Hugging Mom' (Egan 2011: 274). However, the balance is tipped in favour of the negatives rather than the positives, as the negative 'ways' are stacked higher and more precariously than the positive 'ways'. This multimodal construction foregrounds the conceptual metaphor of NEGATIVITY IS WEIGHT, and further directs emphasis towards the one extra negative 'Way': 'Sits in Car Before Coming In' is not balanced out by a positive counterpart construction. Again, as in the 'Mom's Art' slide, the overall structure of the slide represents splices of other habitual event frames - and, more specifically, ones that construe an underlying unhappiness in their home life as a family. 


\subsubsection{Speech presentation}

The format of 'Great Rock and Roll pauses' means that it is an illustrative example of 'fractured episodic fiction': 'humanity in all its grime and glory is captured in clipped fashion' (House 2011). This 'clipped fashion' is suggested through different kinds of attentional gapping, rather than simply through straightforward lexical negation at the clausal level. There is gapping on a physical, multimodal level (as in the slide where Alison has drawn an empty box to signify what a rock and roll pause sounds like) (Egan 2011: 246) but this also occurs in the represented dialogue in the chapter.

In many of the slides just one half of a conversation is represented (see, for examples, Figure 6.3 and 6.4). Attentional frames in CG were originally applied in the context of conversation constructions, which Langacker argues we process as 'successive windows of attention' (2008: 482). This original application is particularly pertinent for 'Great Rock and Roll Pauses', which frequently foregrounds dialogue constructions. In fact, arguably most of the function-advancing information in this chapter is contained within the extracts of dialogue or isolated reflective statements or quotations that Alison includes in her slides. In terms of the overall form of 'Great Rock and Roll Pauses', PowerPoint presentations are typically accompanied by an oral commentary, which potentially gives primacy to the representations of speech in general. The examples of direct speech and spoken discourse therefore become profiled by the very fact that we missing the accompanying spoken commentary for this presentation.

Gavins (2007: 50) asserts that '[e]ach time an enactor speaks, a world-switch transports readers of the text directly to that enactor's origo for as long as the speech is ongoing'. Like Dancygier and Vandelanotte's (2009) notion of 'prompts' for space which create distanced mental spaces in hypotheticals, direct speech functions as a prompt, or 
an anchor, that aligns the reading perspective with the origo of the speaker. The fact that 'Great Rock and Roll Pauses' often only provides conversational splices (initial, medial or final portions of a conversation), however, is significant. Evidently the text focalises Alison's perspective throughout, and although deictic shifts to other character perspectives are initiated through her inclusion of direct speech, what she decides to window in terms of spoken discourse again carries further implicative weight. Like with Joe's perspective in Chapter 3, Alison's viewing platform is displayed even when the grounding shifts to other characters. In other words, we are always aware that a selection process, and therefore a subjectification, has occurred: we are only reading the constructions she chooses to highlight and not the full conversation - the full scope of the scene.

While some roles in the dialogue are gapped, information that we think might be entirely gapped (such as the aim of the conversation, or the response from the other conversation participant) is supplied in a later slide. In the previous example of 'Mom's Art' (Figure 6.5), for instance, only Sasha's discourse is explicitly windowed ("They tell the whole story if you really look"), although Alison's gapped contribution to the conversation is implied through Sasha's response in Figure 6.4. ("Not junk', Mom will say. 'Tiny pieces of our lives."). In this way, alternating slides window different parts of the conversation.

As a result of this, different characters are placed as the object of conceptualisation in alternating attentional frames, and we are often required to 'fill in the gaps' of the dialogue - often by returning to previous slides. The slide 'Dad vs. Mom' (Egan 2011: 253), for example, follows on from the slide 'Songs with Lincoln's Comments', which lists Lincoln's descriptions of 'early pauses' in the songs "Bernadette" (Four Tops), "Foxey Lady" (Jimi Hendrix) and "Young Americans" (David Bowie) (Egan 2011: 241). Lincoln's obsession with these pauses, and the fact that all of his 
represented dialogue is focused on describing them, appears to be one of his 'characteristic cognitive habits' (Semino 2014) of interactional behaviour. We know therefore, through following the 'successive windows of attention' (Langacker 2008: 482) that Lincoln is implied off-stage as an addressee in 'Dad vs. Mom'. The slide lists three examples of direct speech in response to 'Lincoln's comments' from both Dad and Mom, respectively. The slide is represented with Mom's utterances listed on the left hand side of the page, and Dad's utterances listed on the right. The 'versus' format also means that a direct comparison between the statements (like with the previously mentioned 'Ways It Can Be When Dad Comes Back' slide), and consequently between the characters, is instantiated. The quotations from Dad are summative and declarative statements such as 'Wow, you've really analyzed those songs, Linc', as compared with Sasha's more reflective and questioning statements: 'I don't think of Bowie as a chicken, so there must be some reason he opted not to pause there'.

In Werth's original text world model, indirect speech suggests greater epistemic distance from direct speech (Werth 1999; see also Gavins 2005: 84). Here, however, the use of direct speech both shows different deictic parameters, but simultaneously also emphasises epistemic distance because of the high level of subjectification. In other words, because Dad's utterances are framed by the modal construction ('What Dad Would Say (if he were here)' makes the grounding of the other statements unclear. Is Alison quoting something he has said, either once or frequently, before? Conversely, are the statements simply hypothetical? (This idea of conceptual distance is returned to in the next section).

In the slide "What is going on in here" (Figure 6.4), the direct speech also acts as a reference point for particular world-building information. Included in two out of the three visual frames are quotations from direct speech: 'Bedtime, Kittens' and 'Back to your room, Linc. It's a school night' (Egan 2011: 272). These are consequently attached 
to descriptive information that creates a sense of routine and habitual action: 'She collages in her waiting chair [...] [u]sually when Dad's not home yet' (Egan 2011: 272). Additionally, the detail of the 'waiting chair' here acts as a salient and orienting reference point: it connects with the previously discussed slide, 'Dad vs. Mom', in which Alison's father's regular absence from home is implied. The pairing of world-building information with dialogue in this way creates an oscillation between grounded viewpoints: between specific times in which these conversations occurred, as well as more habitual exchanges between the family.

\subsubsection{Viewing arrangements and conceptual distancing}

In addition to the discrete attentional frames of each slide, many of the slides also comprise hypothetical structures, such as examples of utterances people would say ('What Dad Would Say (if he were here))' (Egan 2011: 253), how people would behave ('If my friends are around, I ignore Lincoln's music') (Egan 2011: 254), or what Alison or the other characters want ('She looks like someone I want to know, or maybe even be') (Egan 2011: 266). These splices often contribute extra world-building information for the narrative attentional frame currently in focus.

Hypothetical constructions are a source of interest in recent research in cognitive linguistics. They have been studied within mental space theory (Dancygier and Sweetser 2005; Dancygier and Vandelanotte 2009) and Text World Theory (Werth 1995a, 1995b, 1999; Gavins 2007) and are beginning to be considered through a CG perspective (see Hamilton 2014). As observed in Chapter 3, hypotheticals are said to create epistemic distance in literary texts (Gavins 2007: 118). This idea of distance is explored by Dancygier and Vandelanotte (2009: 362), who in turn maintain that such distanced discourse can be encoded in a text through many different linguistic means, 
such as spatial, temporal, epistemic and social deictic markers, amongst others. They further argue that such distance phenomena are created through the spatiotemporal displacement of mental spaces, with two separated spaces 'and the speaker's deictic alignment with one of them' (Dancygier and Vandelanotte 2009: 327). This sense of 'distancing' is described in CG in terms of latent energy (Langacker 2008).

It has been observed that, as the narrator and conceptualiser of the chapter, Alison's viewing arrangement is particularly prominent in this text. Like Joe's perspective in Enduring Love (explored in Chapter 3 of this book), one of the stylistic cues for Alison's vantage point is her modalisation of language. In the slide 'Lincoln Wants to Say/Ends Up Saying' (Figure 6.3), for example, there is another instance of represented spoken discourse, except that here the construction comprises modalised structures relating to projected desires (specifically, what Lincoln 'Wants to Say' to their Dad). This slide is represented as a flow diagram, with the boulomaic construction 'What Lincoln Wants to Say' heading the text, and then a sequence of attentional frames that show a chain of reasoning, made literal through the connecting arrows between statements. The chain of thought (from the initial, unsaid speech event, through the medial thought processes behind it, to the actual speech event) is clearly windowed in this format. In other words, in this frame Lincoln's emotional prompts for the unsaid statement ("I love you, Dad") become serially displaced from what he actually says “Hey Dad, there's a partial silence at the end of 'Fly Like an Eagle,' with a sort of rushing sound in the background that I think is supposed to be the wind, or maybe time rushing past!" - and this is shown both visually and linguistically. The sequence scans of facts ('Dad is from Wisconsin'; 'I love music'; 'Dad loves me', etc.) are made cohesive through overlapping locatives (both Dad and The Steve Miller Band are 'from Winconsin') and clear target-/ reference-point relationships ('I love music'; 'Dad loves me'). 
Though Lincoln's speech and thoughts are the objects of conceptualisation here, this slide portrays how Alison imagines Lincoln's thought processes: it demonstrates how she is mind-modelling the motivations behind his speech - the connections he makes between ideas. The direct speech ('What Lincoln Ends Up Saying') is the speech construction that grounds Lincoln's perspective, but the medial windowing between SOURCE and GOAL is projected by Alison as a translation of his utterances.

Hypotheticals are also used in 'Great Rock and Roll Pauses' to create conceptual remoteness, as can be seen in the slide 'What I'm Afraid Of' (Figure 6.6). This slide appears in the chapter after an argument between Alison's parents, and when Alison has gone for a walk with her father at night to the solar panels that are in the desert near to their house ('Three steps down from our deck, the desert surrounds us: Mountains like cutout paper shapes. Big-top sky full of stars') (Egan 2011: 283). This slide is grounded, in particular, in the event frame of Alison walking back from the solar panels with her father; an event windowed in the previous slide ('We Walk for Several Years' [...] 'When our house finally comes into view, the windows are dark' (Egan 2011: 294).

'What I'm Afraid Of' details a shift in grounding as initiated through a change in temporal parameters. Alison imagines a future point in time in which their family home becomes a 'broken down ruin', and pictures what it would be like returning to it. In the current text world, she is returning home with her father, so the spatial coordinates remain the same. Like the other slides that foreground Alison's thoughts rather than pieces of dialogue, the language becomes more emotive. Grammatically, 'That', which bridges between the protasis and the apodoses of the first three statements, acts as a point of attachment between the initial attentional frame ('What I'm Afraid Of') and the constructions of the imagined attentional frames: 
What I'm Afraid of

$>$ That the solar panels were a time machine.

$>$ That I'm a grown-up woman coming back to this place after many years.

$>$ That my parents are gone, and our house isn't ours anymore.

(From Figure 6.6. Egan 2011: 307)

The hypothetical frame becomes backgrounded as we read through the slide, however. In the second nested text box on this slide, the declarative construction instantiated through 'It's' shows a shift in perspective as Alison's deictic alignment becomes grounded in that of the imagined attentional frame:

It's a broken-down ruin with no one in it.

$>$ Living here together was so sweet.

$>$ Even when we fought.

$>$ It felt like it would never end.

$>$ I'll always miss it.

(From Figure 6.6. Egan 2011: 307)

The grounding then shifts again in the next sentence as Alison undergoes a temporal shift forward, and looks back on her childhood in the house, using past tense constructions: 'Living here all together was so sweet. Even when we fought. It felt like it would never end. I'll always miss it.' The frames in this slide therefore show a complex series of grounding alterations: Alison firstly imagines a point in the future, and then from that grounded viewing platform she reflects on the past and on how she will miss it in the future. This complex shift in perspective is further emphasised through the visual structure of the slide. Like many of the previous slides mentioned, the visual structure of the slide helps to emphasise the stylistic choice in language. Here, the nested box structures of the constructions become smaller and more 'nested' the more conceptually remote the statements become. 
It was observed earlier in this chapter that one of the features of altermodernist texts is the representation of 'pluralized accounts' of time. In altermodernist texts these accounts are realised through a 'spatialized landscape, whereby past, present and future can be woven together into a complex network' (Gibbons 2012b: 240). In this final slide, the 'complex network' or pluralized accounts can clearly be seen. We mind-model Alison's various perspectives successively by following the linguistic cues - here, specifically, the grounding alterations invited by the change in temporal coordinates in the slide. Further, the world-building information in this chapter is framed by an overarching 'spatialized landscape' in a literal sense, with the 'woven' components of temporal splices joined and made coherent by the manipulation of visual structures. Consequently, both the visual and linguistic parts of the attentional frames combine in the production of meaning; both here, and in the chapter more generally.

\subsection{Conclusion: 'Music first, and then the pause'}

The chapter 'Great Rock and Roll Pauses' from Goon Squad windows attention through two semiotic channels: through both linguistic and visual constructions - or, rather, through constructions that combine the two channels. In summary, it could be argued that these constructions work metonymically: they profile smaller sections of wider parts of conversations and events that combine to form an impression of the overall fictional world. This is particularly important in reference to how perspective is represented through the text, as the choices of what is windowed and what is gapped through the linguistic and the visual constructions, directly impact on how we mindmodel Alison's perspective. All constructions superordinately undergo subjectification through the PowerPoint format, as observed in Figure 6.1. As the conceptualiser of the 
discourse, but also the creator of the PowerPoint slide journal, Alison retains a prominent position within our construal of the fictional world.

Gibbons (2012a) argues that there is a consistency of 'cognitive operations' across different modes: that is, she contends that image and text can provide equivalent constructions which in turn elicit simultaneous construal processes. This certainly appears to be the case in 'Great Rock and Roll Pauses', as many of the PowerPoint stylistic features used are iconically representative of the content. If the visual elements of the text align with the linguistic constructions and form part of the construal, then this analysis has shown that there is a strong symbolic correspondence between the two poles of form and meaning in this text. This is made prominent more explicitly in the slides that foreground metaphorical content, but this also functions on a more implicit level in many other slides discussed in this analysis: in the representation of dialogue, of turn-taking boundaries, of internal commentary vs. external description, and in the representation of conceptual distancing, among other examples.

In summary, 'Great Rock and Roll Pauses' has been shown to be representative of the wider genre of altermodernist fiction to which Goon Squad belongs. It meets Gibbons' (2012b: 240) features of the genre with regard to form (being 'formally experimental'), identity (representing 'pluralized accounts' of the characters, despite being focalised through one character's perspective) and time. It is also clearly polyphonic (even in a metatextual sense, as it references real-world rock and roll songs throughout): we mind-model Alison, and mind-model how she mind-models other characters.

There are many stylistic cues that signal how we should mind-model the polyphonic perspective in this chapter. As mentioned in the analysis, these include: hypothetical structures (in the slide entitled 'Dad vs. Mom', what 'Mom Says' is pitched against what 'Dad Would Say (if he were here)') or constructions that alter the 
grounding of the spatiotemporal parameters ('What I'm Afraid Of'); modalised structures relating to projected desires ('Lincoln Wants to Say/Ends Up Saying') and temporal jumps that initiate gapping of the medial portion of the narrative and therefore reveal a conceptual splice ('One Night Later') - as well as many others in the text.

This chapter has shown firstly that an analysis using CG's construal works successfully for exploring how meaning is constructed in multimodal texts. Secondly, it has shown that an analysis that draws on CG construal concepts can be useful to explore texts that are complexly structured in terms of relationships between multiple discourse attentional frames. In 'Great Rock and Roll Pauses', for example, one of the more complex structures was the representation of perspective, but also the ontological hoax format: the contradictory public vs. private modes of communication. Thirdly it has observed that conceptual splicing and ideas from Talmy's (2000a, 2000b) Cognitive Semantics work successfully alongside CG in application to a literary text. Finally, such an analysis helps to explore how perspective is represented through linguistic - or, in this instance, multimodal - cues within the text.

\subsection{Review}

So far in Cognitive Grammar in Contemporary Fiction various central components of Langacker's CG model have been applied for literary linguistic analysis: namely, action chains and grounding (Chapter 3), reference points (Chapter 4 and 5), schematicity and elaboration (Chapter 5) and attentional profiling and perspective (Chapter 6). All of these CG concepts have been shown to account for interesting and diverse interpretations of contemporary literature, and have cumulatively provided a 
working model for the experiential processes of reading; the exploration of literary texture (Stockwell 2009).

The next and final analysis extends the ideas of 'dynamic meaning construction' (Pleyer and Schneider 2014: 38), in particular, even further and draws together the concepts covered in this book holistically. 


\section{Chapter 7. Scanning the compositional path of 'Here We Aren't, So Quickly'}

\subsection{Introduction}

This final analysis explores Jonathan Safran Foer's (2010) short story 'Here We Aren't, So Quickly', and brings together the concepts discussed under an account of CG's compositional path. This account also draws upon scanning, in particular, alongside a text world analysis to investigate how the fictional world in this short story is both built and fragmented by its composition of sequence scans; how, like in many postmodern narratives, it is built but, simultaneously, destabilised (McHale 1992; for another account of sequence scanning in reading paths see also Nuttall 2014).

\subsubsection{Scanning paths}

By its own nature, a short story has constraints as to the amount and choice of detail of the fictional world and characters (see Head 1992, 2002; March-Russell 2009). The analysis in this chapter offers a stylistic account of how CG's compositional path helps to delineate the chronology of world-building information, and to describe exactly how the fictional world is created and built up of micro-structures that combine to form a holistic world-construction. This was mentioned briefly in relation the text analysis of Coraline in Chapter 5, but will be considered in more detail here.

Introduced in Chapter 2, the compositional path is one of the main substructures of the construal process focusing. Langacker (1987: 292) refers to how compositional paths can be scaled across different levels of language and identifies three 'facets', which are 'functionally and experientially distinguishable', of how we distinguish the relationship between semantic components and the composite expression they combine 
to create (in other words, the holistic conceptualisation of a narrative): (1) analysable (micro-), (2) component (meso-) and (3) composite (macro-) linguistic structures. Linguistic constructions have been defined as any 'linguistic structure, whether phonological, semantic, or symbolic, that can be analysed into component parts' (Taylor 2002: 589). All constructions are therefore analysable (or are said to have analysability). This is a process that describes how we make connections between these 'component parts'; how 'meaning chunks' in language lead to the production of 'higher levels of meaning' (Taylor 2002: 589).

Of course, when scaling up these ideas, reading is a process that requires the sequential assembly of 'building blocks' to create the fictional world of a text. The relationship between these structural levels is said to form a 'foreground/background relationship' (Langacker 2008: 60), with the macro-, composite structure forming the primary focus of attention, and the component structures together forming the background of the linguistic construction.

In theory, an analysis of a text's compositional path is a fairly simple premise that involves the exploration of fictional world creation at the different levels of the text. In a scaled up application such as the one presented in this book, this idea is broadly comparable with Doloughan's (2011: 135) concept of a reading path; 'a term which points to the ways in which different texts suggest, if not require, different modes of apprehension and negotiation, as the reader or viewer attempts to navigate through them'. Like CG's 'compositional path', this label is similarly based on the same underlying metaphor: that TEXT COMPREHENSION (or in this context, more specifically, READING) IS A JOURNEY. The mental construction of a text is a path that is followed at each successive level of the reading process; a dynamic process that requires the 'apprehension' and 'negotiation' of the reader with the text. 
The sequence scanning process essential to 'Here We Aren't, So Quickly' - most notably signposted through the 'attentional pauses' (Kuiken and Miall 1994) instantiates experiential iconicity (Tabakowska 1993) in the experience of reading of this story. Iconicity occurs when there is a strong relationship between the form and meaning of a linguistic construction. In semiotics, it is a term used to 'characterize the relationship of similarity between a sign and the object it represents' (Ljungberg 2015: 476). Simply put, all '[l]iterature, in fact, can be regarded as iconic in the sense that its form may strive to imitate in various ways the reality it presents' (Wales 2001: 193). The analysis in the next few sections will return to these ideas, and address how the 'imitation' of reality works in this short story.

\section{2. 'Here We Aren't, So Quickly'}

Foer is a contemporary American writer who has written two acclaimed novels, Everything Is Illuminated (2002a) and Extremely Loud and Incredibly Close (2005), as well as a few short stories (2002b, 2006, 2010) and a work of non-fiction (2011). Experimentation is a hallmark of Foer's writing style. Extremely Loud and Incredibly Close, for example, is a multimodal novel that includes photographs throughout the text as well as the manipulation of font size, colour and density (see Gibbons 2012a: 127166 for a discussion of multimodality in the text).

Foer's short stories are also highly experimental, and often adopt and manipulate different genres and styles. The short story 'A Primer for the Punctuation of Heart Disease' (2002b), for example, rethinks and re-writes grammatical knowledge in the format of a primer: an elementary text book for teaching language learners the rules of grammar, or which outlines the basic elements of a particular subject. Primer in medicine, however, also can be defined as a segment of DNA that is used for replication, 
which evidently has resonance within this particular narrative. 'A Primer for the Punctuation of Heart Disease' principally concerns the difficulty of familial communication, and sets up a series of complicated familial relationships contextualised against the family's genetic background of developing heart disease. This layering of meaning is therefore prevalent in this text, as it is a story that plays with 'the material production of fiction' (Gibbons 2008: 179). It uses semantic definitions to rupture knowledge systems of grammar, words, and ultimately, communication.

Unlike the historical events that form the centre of other Foer narratives (the 9/11 attacks in Extremely Loud and Incredibly Close; and the Holocaust in Everything Is Illuminated, for examples), 'Here We Aren't, So Quickly' is similar to 'A Primer for the Punctuation of Heart Disease' in that it is conversely centred on more domestic themes. The short story summarises the married life spent between two people, the experience of parenthood and all the small events, expressions and routines that make up a shared life. The structure is complex, for the short story is composed of a series of 'nonsequitur' statements that connect only at times (as the following analysis shall detail). The 'destabilisation' (McHale 1992) of the text is therefore signposted through the way in which it represents the parameters of the fictional world. Reference points and their targets chained across attentional frames help to make the story cohere as a sequence but these are linked only tenuously at times, as each micro-construction presents a temporally anchored splice of domestic life. Foer said that the inspiration for this story was narratives that 'experimented with voice in similar ways - shifting rapidly between perspectives, using pronouns rhythmically, condensing time into details' (Knox 2010); and it is these features that are particularly distinctive in the text, and which cause such disruption in the reading process.

A CG study that explores shifting perspectives and 'condensed viewpoints' is Nuttall's (2014) chapter 'Constructing a text world for The Handmaid's Tale'. Nuttall's 
study provides a detailed frame-by-frame analysis of a descriptive scene from The Handmaid's Tale, in which readers are required to sequentially scan individual parts of the scene in order to create a holistic conceptualisation of the room being described. Nuttall (2014: 89) argues that a combined text world and CG analysis means that 'the readerly construction of text worlds can be modelled in terms of an imposition of structure through dynamic processes of conceptualisation', which scales from 'conceptual integration at the lowest levels of grammatical composition to apprehension of the global import of entire texts' (Langacker 2008: 486).

Nuttall (2014: 94) further argues that the sequential structuring of text world components in The Handmaid's Tale means that the holistic conception becomes disrupted and that, consequently,

emphasis is placed instead upon the sequential processing of these conceptions as they emerge in the mind of the narrator, foregrounding the movement between memories, direct speech, beliefs and possibilities of which [the] narrative is composed.

The narrative of 'Here We Aren't, So Quickly' is similarly structured. The narrator's memories are also foregrounded, and a list of possible scenarios about what may or may not have happened is presented to us. Equally, the conceptions in this story are both positively and negatively conceived, and alternately framed as categorical and modalised structures. Like another of Foer's short stories, 'If the Aging Magician Should Begin to Believe' (2006), which is framed entirely through conditional constructions, these hypothetical and negated structures are an analysable component of the fictional world of 'Here We Aren't, So Quickly'. They play an integral role in both the composition and, conversely, the destabilisation, of the fictional world.

The study of negation is a developing area of research within cognitive poetics and cognitive linguistics more widely (Giora et al. 2007, 2009; Hidalgo-Downing 2000a, 2000b; Hoeksema 2001; Horn 1989, 2010; Leinfeller 1994; Nahajec 2009; Nørgaard 
2007; Stockwell 2009). Negation automatically presupposes the process of focusing and of figure and ground differentiation, for it 'evokes as background the positive conception of what is being denied' (Langacker 2008: 59).

Observing the effects of negation across an entire narrative or discourse is a useful endeavour. Giora (2007) conducts a study that monitors the effects of negationretention/suppression. Giora discusses how previous studies into negation and the effects of suppression have focused on isolated sentences, rather than observing the effects of context and how this affects the way negated sentences are processed, when in fact research suggests that 'how negation is processed depends on global discourse considerations' (Giora 2007: 169). In turn, Nørgaard (2007: 41) studies Joyce’s 'Two Gallants', despite negation not being a 'prominent feature' in the story.

In 'Here We Aren't, So Quickly', however, negation is a prominent feature. The counterbalance of negative constructions alongside positive conceptualisations establishes a pattern of oppositions that run throughout the narrative (for an overview of how oppositions work in the text, see Gibbons and Whiteley: Forthcoming; and for a consideration of how opposition works in Foer's other writing, see Atchison 2010). Additionally, as the following analysis observes, the constructions move between declarative statements and modalised constructions. The movement between these two types of construction creates a sense of specific indefiniteness that characterises the entire story.

\section{Extract 7.1. 'Here We Aren't, So Quickly'}

I was not good at drawing faces. I was just joking most of the time. I was not decisive in changing rooms or anywhere. I was so late because I was looking for flowers. I was just going through a tunnel whenever my mother called. I was not able to make toast without the radio. I was not able to tell if compliments were backhanded. I was not as tired as I said.

You were not able to ignore furniture imperfections. You were too light to arm the airbag. You were not able to open most jars. You were not sure how you should 
wear your hair, and so, ten minutes late and halfway down the stairs, you would examine your reflection in a framed picture of dead family. You were not angry, just protecting your dignity.

I was not able to run long distances. You were so kind to my sister when I didn't know how to be kind. I was just trying to remove a stain; I made a bigger stain. You were just asking a simple question. I was almost always at home, but I was not always at home at home. You were not able to cope with a stack of more than three books on my bedside table, or mixed currencies in the change dish, or plastic. I was not afraid of being alone; I just hated it. [...]

I counted the seconds backward until he fell asleep, and then started counting the seconds backward until he woke up. We took the same walks again and again, and again and again ate at the same easy restaurants. They said he looked like them. I was always watching movie trailers on my computer. You were always wiping surfaces. I was always hearing my father's laugh and never remembering his face. You broke everyone's heart until you suddenly couldn't. He suddenly drew, suddenly spoke, suddenly wrote, suddenly reasoned. One night I couldn't help him with his math. He got married. [...]

And here we aren't, so quickly: I'm not twenty-six, and you're not sixty. I'm not forty-five or eighty-three, not being hoisted onto the shoulders of anybody wading into any sea. I'm not learning chess, and you're not losing your virginity. You're not stacking pebbles on gravestones; I'm not being stolen from my resting mother's arms. Why didn't you lose your virginity to me? Why didn't we enter the intersection one thousandth of a second sooner, and die instead of die laughing? Everything else happened - why not the things that could have?

I am not unrealistic anymore. You are not unemotional. I am not interested in the news anymore, but I was never interested in the news. What's more, I am probably ambidextrous. I was probably meant to be effortless. You look like yourself right now. I was too slow to change, but I changed. I was probably a natural tennis player, just like my father used to say over and over and over.

I changed and changed, and with more time I will change more. I'm not disappointed, just quiet. Not unthinking, just reckless. Not wilfully unclear, just trying to say it as it wasn't. The more I remember, the more distant I feel. We reached the middle so quickly. After everything it's like nothing. I have always never been here. What a shame it wasn't easy. What a waste of what? What a joke. But come. No explaining or mending. Be beside me somewhere: on the split stools of this bar, by the edge of this cliff, in the seats of this borrowed car, at the prow of this ship, on the all-forgiving cushions of this threadbare sofa in this one-story copper-crying fixer-upper whose windows we once squinted through for hours before coming to our senses: "What would we even do with such a house?"

(Foer 2010: 139-144)

\subsection{Analysability ('I counted the seconds backward')}

The salient reference point in this opening paragraph is the speaking 'I' persona.

The speaker remains an object of conceptualisation throughout this first paragraph; and 
the grounding throughout is overt - more so in this text than in any of the others analysed so far in this book - because ' $\mathrm{I}$ ' is continuously revivified as the head of each respective sentence. Equally, the clausal grounding is also clear: each verb process in this first paragraph is framed in either the simple past or in the past progressive, which makes it clear that the speaker is grounded from a retrospective position - describing both (negated) statements of fact and habitual occurrences.

The structural and semantic foregrounding of 'Here We Aren't, So Quickly' creates an unusual reading process in that the reader is required to 'discern, delimit, or develop the novel meaning suggested by the foregrounded passage' (Kuiken and Miall: 1994: 394). The foregrounding occurs through its atypical construction; mainly that the list-like structure creates 'attentional pauses' (Kuiken and Miall: 1994: 394) at each sentence boundary. In the opening sentences of the first paragraph, for instance, apart from the speaking 'I' persona who remains onstage, there is little thematic or topical connection between and across the sentences that would justify their grouping as a portion of the composite meaning. Instead, the connections between sentences here is predominantly syntactic rather than semantic, as the cohesion occurs mainly through the parallel syntax constructions ('I was not X' / 'I was Y' and 'I was just Z'):

I was not good at drawing faces. I was just joking most of the time. I was not decisive in changing rooms or anywhere. I was so late because I was looking for flowers. I was just going through a tunnel whenever my mother called. I was not able to make toast without the radio. I was not able to tell if compliments were backhanded. I was not as tired as I said.

(Foer 2010: 139)

This disjuncture means that a list of fleetingly mentioned past events and routines is presented: a 'collage' (Nuttall 2014: page) of attentional frames that splice between different spatiotemporal parameters. This can be conceptually represented in text 
world terms as in Figure 7.1, where each sentence evokes a particular instance; its own momentary text world.

Figure 7.1 represents the analysable text world structures of the first paragraph of the story. Each analysable construction displays a transitory mention of a past event or habit; presented as a series of splices as the full information of each event is never given. Arguably, each new sentence creates a new text world, as the parameters of time and space change in each micro-construction. However, although each attentional frame opens up a new scenario, there are connections across the text worlds. Each text world contains the speaking 'I' narrator, and as the story progresses, semantic connections are drawn between and across the events so that, cumulatively, component patterns begin to emerge (this is returned to in the analysis of the next section). These connections mean that the frames are not entirely disparate; rather, a chain of 'nested narratives' (Talmy 2000a: 84) is formed instead. This is conceptually represented in Figure 7.1 through the overlapping text world boxes.

These momentary text worlds are formed of declarative constructions that are either a statement of fact ('I was late')(TW4), a negated statement of fact ('I was not good at drawing faces')(TW1) or a statement qualified with a modal adverb ('I was just joking')(TW2). Each sentence sets up a new attentional frame that shifts in time and space from the previous sentence. This is either marked explicitly through the identification of a particular locative world-builder ('in changing rooms', 'going through a tunnel') or else is an offstage location. The reference to 'looking for flowers' (TW4), for example, suggests either a shop or an outside location. Similarly, the construction 'I was not able to make toast', indicates a kitchen setting through the inclusion of salient world builders that profile small portions of an overall scene ('toast', 'radio') (TW6). 


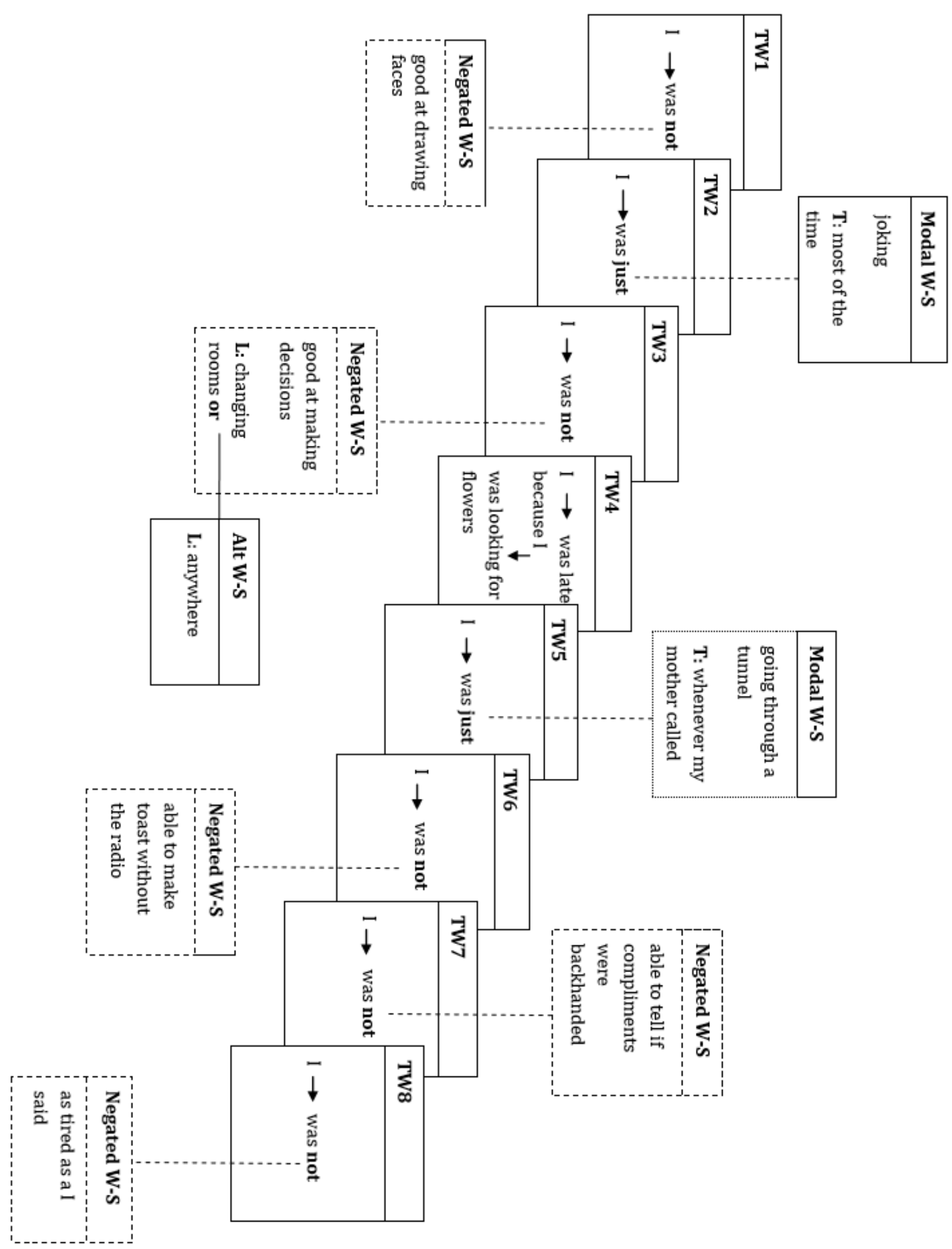

Figure 7.1. The analysable text world structures of 'Here We Aren't, So Quickly', paragraph one. 
The negated sentences are filters, which in CG terms 'are negative statements indicating that a particular configuration of elements is not permitted' (Langacker 2001: 2). In text world terms, negation sets up a world-switch, requiring a reader to conceptualise the positive statement first in order to evoke the negative. Similarly, CG observes that,

[w] hile any linguistic usage event involves two conceptualizers as part of its ground, sentential negation (as well as a phrase such as on the contrary in English) actually profiles two viewpoints being brought into coordination in the linguistic material.

(Verhagen 2007: 68)

Consequently, a 'doubling up' process happens in negated constructions whereby attentional frames are automatically layered.

The repeated negative constructions lead us to mind-model the narrator in a particular way. He appears defensive, or as if he is trying to excuse or mitigate his actions. Equally, these statements in isolation lend themselves to a comparison. The defensive tone, coupled with the negated structures, means that in addition to a negated world-switch these statements seem like a defence presented to someone else; someone who possibly is able to do or has done these things. Arguably, despite the fact that, in this very first paragraph, the fleeting text worlds are populated by only the speaking 'I' persona (and his mother in TW5), an off-stage character is being addressed. Who was good at drawing faces, or more decisive? This acts as a precursor to the introduction of the protagonist-addressee at the component level of the narrative, as considered in more detail in the next section. The modal adverb 'just' here further contributes to this tone of defence. Additionally, the statement 'I was just joking most of the time' also implies a negative self-evaluative stance: 'I was just joking' often collocates as a postmodification of an offensive statement in direct speech, usually directed at a listener who has potentially been offended. 
It is generally agreed upon that negative expressions take longer to process than positive expressions (see Clark and Clark 1977; Giora 2007, 2009). What problematises the processing of this short story further, however, is that readers are additionally required to infer and create their own cohesive ties between the analysable structures. As mentioned previously, the foregrounded structure of this story creates a series of attentional pauses where we are required to form inferential connections between the various attentional frames. If the reading path is considered as sequential and consequently a paragraph as a guide for composite expressions, then readers could spend some time bridging the gaps between sentences here. 'I was not good at drawing faces' because 'I was just joking most of the time'? 'I was not decisive' because 'I was so late'?

At the component level of this story's path it becomes apparent that another cohesive device of the story is the oscillation between character profiles, as referenced through the second person pronouns in the second paragraph.

You were not able to ignore furniture imperfections. You were too light to arm the airbag. You were not able to open most jars. You were not sure how you should wear your hair, and so, ten minutes late and halfway down the stairs, you would examine your reflection in a framed picture of dead family. You were not angry, just protecting your dignity.

(Foer 2010: 139)

The analysable or cohesive structures shift in this second paragraph to incorporate the deviation in person address: 'You were not $\mathrm{X}$ ' and 'You were too $\mathrm{Y}$ '. This style shift is what Richardson (2006: 19) identifies as the 'standard' mode of second person narration, in which another protagonist is designated as 'you', and the 'narratee is quite distinct from the "you" protagonist'. In CG terms, therefore, the grounding remains overt throughout the story: the speaker's role as the conceptualiser is continuously 
foregrounded, while the addressee's role as the object of the conceptualisation is similarly given attention at alternating points in the discourse.

What also impedes world-construction in reading this text is that the statements seem conversely both simple in form (declarative, factual and mainly simple sentences) and yet simultaneously specific in the details they describe. For example, the second paragraph quoted above describes how 'You were not sure how you should wear your hair, and so, ten minutes late and halfway down the stairs, you would examine your reflection in a framed picture of dead family' (Foer 2010: 139). Here there is a high level of lexical specificity: the evocative information presented about the 'you' character - the process of checking your hair in 'your reflection in a framed picture of dead family' - is both everyday and mundane, and simultaneously, conversely, evocative and poignant.

\subsection{Components ('Not wilfully unclear, just trying to say it as it wasn't')}

The first two paragraphs begin to build composite character profiles for the two protagonists. The perspective shifts then become more frequent and begin to occur within the paragraphs themselves, where both 'you' and 'I' are profiled in relation to one another.

I was not able to run long distances. You were so kind to my sister when I didn't know how to be kind. I was just trying to remove a stain; I made a bigger stain. You were just asking a simple question. I was almost always at home, but I was not always at home at home. You were not able to cope with a stack of more than three books on my bedside table, or mixed currencies in the change dish, or plastic. I was not afraid of being alone; I just hated it.

(Foer 2010: 139)

At first this occurs as an elaboration of a negative statement ('You were so kind to my sister when I didn't know how to be kind') and then finally the inclusion of first 
person plural grounds the addressee in the same viewing arrangement as the speaking 'I' narrator: 'We went to the Atacama. We went to Sarajevo. We went to Tobey Pond every year until we didn't'. Here, there is an obvious shift in grounding, where the addressee 'you' is situated from the same vantage point as the speaking conceptualiser. This cumulative viewing position is signposted through the use of first person plural at this point in the story, but the two characters are also subsequently paralleled syntactically. At the end of this paragraph, for example, there are pairings of double negative constructions in reference to the two characters: 'I am not unrealistic anymore. You are not unemotional', which oscillate between placing the conceptualiser and the addressee as the object of attention.

Additionally, these double negations complicate the world construction further: if a negative statement profiles two viewpoints (Verhagen 2007), then a double negative arguably profiles multivalent viewpoints. We must conceptualise a situation where the addressee is both emotional and unemotional, but also contemplate the meaning behind this particular configuration. Describing someone as 'not unemotional' suggests, of course, that the addressee is emotional; but again, this construction subjectifies the statement, and further suggests a wider context for this statement. Is this part of a conversation, a re-phrasing of what the addressee once said?

In other words, the reverse of these negative statements does not always suggest a polar opposite meaning. In this text, often the story behind what is not explicitly described seems to imply more than what is stated positively. For example, the statements 'You were not angry, you were just protecting your dignity' and 'You were just asking a simple question' could, similarly, be read as examples of indirect speech that suggest there was a particular situation in which the 'You' character was defensive about her actions. This occurs throughout the entire short story, in which what is not 
said - but specifically, much more than what is not said - constitutes the world-building information.

In the previous section of analysis it was mentioned how the processing time of 'Here We Aren't, So Quickly' is affected by its structure. The representation of conceived time functions differently. In this story, time is conceived through abrupt leaps in time ('He suddenly drew, suddenly spoke, suddenly wrote, suddenly reasoned') (Foer 2010: 142), which creates conceptual splicing of attentional frames. Langacker (2008: 79) argues that,

[t]here is a natural tendency for conceived time and processing time to be coaligned, such that the order in which events are conceived as occurring dovetails with the order in which they are conceptualized and described.

This is a process known as temporal iconicity. The co-alignment of conceived time and processing time is problematic in 'Here We Aren't, So Quickly', however. It takes time to read and process the text, but simultaneously the representation of time within the story is hastened as the narrative progresses. Furthermore, the lack of connection between statements means that often the sequential order of events feels like the temporal iconicity is disrupted, even if it is not. This occurs through the seemingly disparate order of events at a clausal level ('I was so tired of being alone; I just hated it. You were just admiring the progress of someone else's garden. I was so tired of food'). This disruption also occurs through the focus on habitual actions rather than more macro-events, as signposted through the repetition of 'always' and direct phrasal repetition ('I was always at home, but I was not always at home at home'; 'We took the

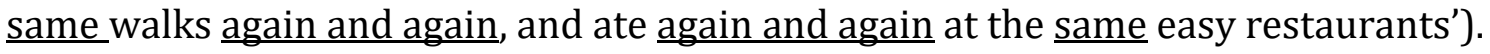

Once a third character is introduced, their son, the conceived time is disrupted even further: 
He suddenly drew, suddenly spoke, suddenly wrote, suddenly reasoned. One night I couldn't help him with his math. He got married.

(Foer 2010: 142)

The events here are represented chronologically but there are still leaps in time (he 'suddenly spoke, suddenly wrote [...] He got married'). From a mind-modelling perspective, it can be said that this representation suggests an emotional evaluation of the passing of time in how the narrator has conceptualised these events: retrospective accounts of a happy time period are often described as passing swiftly.

Towards the end of the story, the grounding alters when there is a shift to the present tense (and back to the title) with the sentence: 'And here we aren't, so quickly'. This revoked viewing platform is continued in the subsequent analysable structures of this paragraph ('You look like yourself right now'; 'I am not unrealistic anymore. You are not unemotional'); and there is also a reference to the future, as signposted through epistemic modality ('I changed and I changed, and with more time I will change more').

Similarly, the spatial parameters of each attentional frame change at this point in the story. Like 'To his lost lover' (Armitage 1993), 'Here We Aren't, So Quickly' begins by suggesting deictic proximity between the world of the text ('here') and the deictic position of its reader ('we') (see Gavins and Stockwell 2012). 'Here' is particularly grounded within the final paragraph in which ' $\mathrm{I}$ ' asks 'you' to '[b]e beside me somewhere: on the split stools of this bar, by the edge of this cliff, in the seats of this borrowed car'. The emphasis on 'this' in each attentional frame further compounds the sense of deictic proximity connecting speaker and addressee. Following this list of spliced locations, the 'here' finally settles in the 'fixer-upper' of what is presumably 'their' marital home:

We reached the middle so quickly. After everything it's like nothing. I have always never been here. What a shame it wasn't easy. What a waste of what? 
What a joke. But come. No explaining or mending. Be beside me somewhere: on the split stools of this bar, by the edge of this cliff, in the seats of this borrowed car, at the prow of this ship, on the all-forgiving cushions of this threadbare sofa in this one-story copper-crying fixer-upper whose windows we once squinted through for hours before coming to our senses: "What would we even do with such a house?"

(Foer 2010: 144)

Here an inventory of contextual anchors in their shared life is shown, presented as a scan of past locations:

\begin{tabular}{r|l|l} 
on the split stools of & this & bar \\
\hline by the edge of & this & cliff \\
\hline in the seats of & this & borrowed car \\
\hline at the prow of & this & ship \\
\hline on the all-forgiving cushions of & this & threadbare sofa \\
\hline$>$ in & this & $\begin{array}{l}\text { one-story copper-crying fixer- } \\
\text { upper }\end{array}$
\end{tabular}

Table 7.1. Sequentially accessed locations in 'Here We Aren't, So Quickly'

This list is framed by the imperative 'Be beside me somewhere'; and here the speaking I, the 'me', increasingly becomes backgrounded as a reference point for these expressions. Sequentially, the conceptualiser retreats and the objects of conception - in this instance, the text world locations - take centre focus.

By contrast the 'you' is even further offstage as they are not referenced explicitly in this sentence. This arguably causes a shift in how the reader is addressed in this construction. Arguably at this point the second person form changes from Richardson's (2006: 30) 'standard form' (that identifies the 'you' as protagonist) to the 'autotelic form' ('the direct address to a "you" that is at times the actual reader of the text and whose story is juxtaposed to and can merge with the characters of the fiction'). The 'you' is offstage and so a reader instead becomes more implicitly conceptualised as the addressee - or, at least, they are placed in a position to become more immersed in each 
respective site of the fictional world. Typically, first person deictic markers (such as here, now, this, these) encode 'different distances between the conceptualizer and the object of conceptualization' (Verhagen 2007: 65). Here, the conceptualiser encodes a proximal distance with these situations, and the sequence scan structure and shift to more direct reader involvement similarly invites the reader to be closer to the object of conceptualisation; to the situations presented in this fictional world.

In short, these few sentences present a list of image-schematic relationships where the reader is required to imagine a set of 'sequentially accessed possibilities' (Nuttall 2014: 93), spatially encoded through the prepositions (on (x2), by, in (x2), at). Sequentially, a reader encounters many shifts in the spatiotemporal parameters of the scene through a list of contrasting locations: inside ('fixer upper') and outside ('this cliff'); those that are more personal ('this threadbare sofa') or less familiar ('this borrowed car'). Equally, the conceptualiser moves from sitting on a 'threadbare' sofa 'in this [...] fixer-upper', described in a way which suggests the longevity of its existence ('threadbare'), and yet the conceptualisation concludes by outlining a previous attentional frame that is grounded in an earlier time: when 'they' are just outside the house and considering buying it. It ends by being grounded in a hypothetical rhetorical question, represented through direct speech ("What would we even do with such a house?"). This displacement in spatiotemporal parameters further complicates the fictional world construction: we are positioned close to the narrator's memories, and yet simultaneously distanced from them. This is a destabilisation mechanism highlighted by the narrator himself: 'The more I remember, the more distant I feel' (Foer 2010: 144). 


\subsection{Composition ('Everything else happened - why not the things that could have?')}

Progressively the life, marriage and habits of 'I' and 'you' are sequentially represented. Despite the disjointed structure at the analysable level of this story, however, it appears that in terms of the component structure of the text there is an approximate chronological order to the events. Even though there is temporal and thematic disconnection between consecutive sentences (as seen in the opening paragraphs), the connections between the linguistic constructions become more prominent as the narrative progresses. The high level of inferences required to scan this story, however, means that a large number of potential interpretations is generated, some of which were identified by an undergraduate seminar group with whom I shared this text.

One of the more prominent interpretations of the text was that the narrator is addressing his late wife. This construal is arguably reinforced through the inclusion of excuses in the story, which often involve projected, or imagined, scenarios: 'I was just going through a tunnel whenever my mother called' (Foer 2010: 169). The students argued that these excuses, or defensive statements, means that the overall tone of the text feels like an apology: the statements associated with 'you' are more positive and complimentary ('you were so kind') as compared to the more self-deprecating statements relating to the 'I' narrator ('I was too slow to change'). For the students, this meant that the story was re-framed as a love letter, or an apology written to a partner after her death. Another popular construal mentioned in the group was that they drew a parallel between this story and the Armitage (1993) poem 'To his lost lover', which similarly generates feelings of loss in groups of readers (see Gavins and Stockwell 2012: 40). 
Some students were even more specific in their interpretation of the story, and inferred that the narrator's wife was involved in a car accident. The constructions they identified that suggested this particularly were:

- 'You were too light to arm the airbag' (Foer 2010: 139);

- 'Why didn't we enter the intersection one thousandth of a second sooner, and die instead of die laughing?' (Foer 2010: 143);

Even though the sequential structure of the narrative means that attention is equally placed on each construction, these inferences cumulatively direct attention to parts of the text more than others, and to constructions that are potentially more prominent on a re-reading of the text (see Harrison and Nuttall: Forthcoming for an account of CG, reader response and re-reading). Arguably, it is the constructional filter invited by the alternative 'instead' that verifies this response to the latter sentence. In a similar way to how negative constructions are processed through the conceptualisation of their positive counterpart, this 'conceptual alternativity' (Talmy 2000a, 2000b) outlines another potential event alongside the actual event presented ('die instead of die laughing'). World-builders that appeared earlier in the story - such as the reference to 'gravestones', of looking for 'flowers', the 'framed picture of dead family' and the location of the 'tunnel' in the first two paragraphs - then become more prominent as a result of this reconstrual, and act as textual placeholders for this interpretation. This construal is reinforced again through implications generated by negated, or gapped, structures. For instance, the question 'What a waste of what?' generates the necessity to complete the idiomatic phrase. In this instance, possible collocates include the idiomatic expressions what a waste of time/life; and both are inferences supported by the text.

Like responses to 'To His Lost Lover' in Gavins and Stockwell's (2014) study, this text similarly divided interpretations. A small group of students discussed the 
possibility of the speaker of 'Here We Aren't, So Quickly' as representing a life and a relationship that never happened. In this construal the text becomes a lament over a life missed out on. The repetition of negated and hypothetical scenarios was cited as the textual cue for this interpretation, as well as the use of rhetorical questions:

Why didn't you lose your virginity to me? Why didn't we enter the intersection one thousandth of a second sooner, and die instead of die laughing? Everything else happened - why not the things that could have?

Oakley (2014: 234) argues that '[w]ith rhetorical questions, a question scenario is embedded in a declarative scenario, such that the declarative scenario gains prominence'. With this in mind, these rhetorical questions again place the addressee as the object of conceptualisation, but without the expectation of a direct response. He presents these scenarios both declaratively (as dictated by the rhetorical format), and yet these scenarios are still intangible and conceptually remote ('Everything else happened - why not the things that could have?').

The final construal of the text was that the narrator is a forgetful old man who is simply recounting his memories. This interpretation was traced to those constructions where the disjunction between the semantic content of two statements occurs within the same construction, as signposted, for example, through the coordinating conjunction 'what's more' in the following two sentences:

I am not interested in the news anymore, but I was never interested in the news. What's more, I am probably ambidextrous.

(Foer 2010: 143)

The cohesive 'What's more' typically bridges between statements by providing further (related) information. In this construction, however, it ironically functions to create disconnection. This disconnection leads us to mind-model the narrator in a particular way. In the above quotation, it is possible to perceive the narrator as an older character, 
forgetful of what has just been said, or perhaps as someone delivering a rambling anecdote. Either way, attention is directed and diverted, and the lack of focus is both bewildering and simultaneously evocative (a similar process is identified in the reading of David Foster Wallace’s 'The Soul Is Not a Smithy’; see Harrison 2014).

\subsection{Conclusion: 'We reached the middle so quickly'}

Overall, the collage structure of 'Here We Aren't, So Quickly' is characterised by the impression of what I have called 'specific indefiniteness'. Readers are left with certain facts and scenarios about the life of 'you' and 'I', but it is a life characterised by events that did or did not happen. The 'here' of the title is revoked in all subsequent spatiotemporal locations listed in the analysable constructions across the story, but the 'here', in the end, is actually the 'middle' of the story. It suggests a particular point in 'their' life, and strongly evokes the LIFE IS A JOURNEY conceptual metaphor.

A text world analysis of this short story can certainly help describe the world switching/toggling that occurs between the attentional frames of the story. What is also important to the reading of this short story, however, that CG is able to account for, is the experiential involvement required by the reader in the fictional world construction: how the connections between these constructions work at the micro-, meso- and macrolevels of the text. Equally, certain world-builders seem more prominent than others, and therefore CG's reference points - the idea that certain elements of a scene are particularly salient - and the targets/dominions evoked and maintained through them work as placeholders for fictional world construction. 
In summary, this short story represents a set of 'sequentially accessed possibilities' (Nuttall 2014: 93). The opening invites us to scan the text sequentially; using each new sentence as a building block to create a more holistic conceptualisation of the narrative. This process of sequence scanning was also seen, to a lesser extent, in the Enduring Love analysis of Chapter 3, where each label of the 'event' and each displaced viewing point created a new attentional frame, which contributed to form the full scope of the scene in the field. It was observed that, as the narrative progressed, the micro structures present more and more cumulative world-building information, and this is also applicable to 'Here We Aren't, So Quickly'. Connections between world builders become easier to discern as more semantic connections are made between and across the attentional frames, and as salient reference points are evoked and then reinstated.

The micro-structures of this short story were further complicated, however, by the prevalence of non-sequiturs, oppositions and negated structures. Describing a scene by describing what is not there (as seen in the fictional world comparison of the Coraline analysis, as well as in the analysis of 'Here We Aren't, So Quickly' in this chapter), can be the conceptual equivalent of describing what is there, except it reframes or profiles the negative stance while simultaneously offering disparate construals of what is actually present.

This analysis has also enabled a description of how readers can create the fictional world at each successive level of organisation; how the holistic fictional world is composed of a series of 'snapshots' of a shared domestic life. I argue here that in reading 'Here We Aren't, So Quickly', how the world is constructed seems equally if not more important than the impression of the holistic fictional world itself. The attentional effects of the structure of this short story are therefore inherently connected with its 
fragmented organisation. Approaching this fragmented world creation through CG's compositional path, attentional frames and filters, and specificity and focusing more generally, has enabled a description of the experiential iconicity (Tabakowska 1993) involved in reading this story. In other words, the analysis has demonstrated how the structure of the text reflects how we perceive memories or past experiences: as a series of fleeting moments.

\subsection{Review}

As much as possible, all the analyses in this book have moved between the hierarchical structures of language, and the final analysis, in particular, has shown how CG can be applied to account for linguistic constructions at all levels of the text. Certainly more work needs to be carried out on the relationship between CG concepts and text world analysis, but an account of CG's compositional path here arguably helps to explore the experiential process of moving from analysable language levels to the composite structure (macro-level) of the fictional world. Such an account alongside a text world analysis helps to generate a discussion of the text that is fine-grained and nuanced (see Nuttall 2014).

The next and final chapter summarises the main findings of the volume and outlines directions for future research. 


\section{Chapter 8. Conclusion}

\subsection{Introduction}

Cognitive Grammar in Contemporary Fiction has taken the first steps to demonstrate CG's potential as a scalable stylistic model. Following Stockwell (2014), the aim has been to show that 'Cognitive Grammar offers a seamlessly principled treatment of text, textuality and texture' (Stockwell 2014: 33). The analysis overall has demonstrated how a cognitive discourse grammar can offer new insights into how readers think and talk about contemporary literature, and because CG models language 'in terms of well-attested mental capacities that are not unique to language' (Nesset 2008: 477), this has allowed an exploration of language that is essentially a disassembling of intuitive conceptual processes.

In 'Engaging the World' (2008: 500-540), Langacker argues that one of the guiding principles behind the relationship between cognition and grammar is fictivity. Introduced in Chapter 2, this process explains how readers understand fictional narratives, or virtual instances, through processes of embodiment. Drawing on existing stylistic frameworks alongside the application of CG concepts here has enabled a discussion of these processes, whist retaining a strong focus on the language - the textual mechanisms - that create such 'virtual instances'. Further, although Langacker purports that CG is a usage-based theory, the literary applications of the theory presented in Cognitive Grammar in Contemporary Fiction have analysed and explored these virtual instances within the context of language in use, thus making the 'usagebased' label much more pertinent and deserved. 
Consequently, this volume has presented an exploratory account of how CG ideas can be scaled up and applied for literary analysis - but to say there is scope for development would, certainly, be an understatement.

\subsection{Overview}

As previously observed, Langacker's (2008: 43) model of construal describes how the meaning of an utterance comprises both conceptual content and a particular construal of that content, and therefore is essentially 'our manifest ability to conceive and portray the same situation in alternate ways'.

CG's construal processes have formed the base of all the analyses in Cognitive Grammar in Contemporary Fiction. Many of CG's processes, and sub-processes, of construal have been applied for stylistic analysis in this study, and seem particularly useful when considered alongside existing cognitive-poetic frameworks. Crucially, the analyses in this book have shown that CG can be applied to account for the stylistic structure of a text, but also as a model to account for readerly interpretations. As such, it is a concept that can be used at both the production and reception ends of linguistic construction: for the analysis of literary texture, and the choices made by authors and narrators, but also for considering the attentional choices made by readers themselves, as observed in the analysis of reader reviews. This versatility as a model makes it wellsuited as a means of exploring reader-response (see Harrison and Nuttall: In preparation).

One of the more prominent aspects of construal that was considered in the analyses was the difference between objective and subjective construal. It was observed 
that all linguistic constructions display subjectification/ objectification of language to a greater or lesser extent, but that these levels revealed the role that narrator plays in how the language is framed. Chapter 3, for example, noted the conflict between objective and subjective interpretation, and how the clash between the two created a narrative 'rupturing effect' (Cobley 2001: 239), whereas Chapter 6 noted how subjectification of discourse can also occur through multimodal mechanisms.

Reference points and the scanning of them is an integral part of reading comprehension and consequently fictional world-construction. The analysis of The New York Trilogy (Chapter 4) used the RPM, specifically, to account for how readers can track the changing character roles within a text. This analysis differs from other applications of the model (Giovanelli 2014; Stockwell 2009) but offers a useful, dynamic model for how readers scan entire narratives. Following on from this, reconceptualisation or backtracking was also seen to be an important process: targets became revivified or revoked upon a re-reading of the text.

Furthermore, observing conceptual archetypes alongside reference points has allowed a more detailed exploration of the model. This has helped to describe the type (or instance) of the particular reference point involved in the discourse, situating the referent in relation to its associated textual actions. For example, it was found that the three protagonists in The Trilogy could be identified or paralleled with other referent roles based on their associated actions: being superordinate agents in one instance, and patients in another, thereby equating their roles with detectives/criminals and reader/writers, respectively.

Once a reference point and its subsequent targets have been evoked and sanctioned by the narrative, a more fully realised fictional world can be generated. Construal's cline of lexical schematicity and lexical specificity is a simple concept, but 
certainly one that has proven useful in the analyses in this book. Chapter 3 , for example, observed how movement from descriptions that are more granular to those that are more fully specified (and vice versa) can disrupt the 'narrative urgency' (Simpson 2014) of a text. This movement displayed the subjectivity of the conceptualiser, and, of course, their lack of objectivity; the fact that they were not privy to the full scope of the scene. Specificity was also explored briefly alongside elaborative relationships in the world comparison of Coraline in Chapter 5. The analysis here observed that readers can respond negatively or positively to granular (or, 'simpler')/ more highly specified narratives, and this is in part dependent on schema recognition and whether the narrative in question fulfils the narrative expectations of the individual reader. It was observed that this generated both identification and resistance amongst the reviews.

Finally, the dynamicity of construal was explored in Chapter 7. Through the analysis of a highly fragmented short story, it was demonstrated how holistic fictional world structures are both built and destabilised throughout the reading process. The compositional path of 'Here We Aren't, So Quickly' was noted to be particularly complex, requiring readers to make connections between the layers of narrative and succession of non-sequitur attentional frames in order to build a complete text world. The relationship between the conceptualiser and the addressee, and at what points the reader is invited to interact more fully with the text, means that the story is a 'collage' (Nuttall 2014: 98) that needs to be processed and assembled by the reader at each stage of reading. The construal of this text invites experiential iconicity (Tabakowska 1993). In other words, the way the text is constructed directly impacts upon how we experience the fictional world.

The next and final two sections outline the key benefits of and questions for applying CG for stylistic analysis, and gesture towards future directions of research. 


\subsection{Suitability for stylistics: Scalability and rigour}

It has been observed earlier that CG 'diverges from standard assumptions in two fundamental respects: (1) its claim that grammar is symbolic (i.e. 'inherently meaningful') in nature, and (2) its focus on constructions (rather than 'rules') as the primary objects of description' (Langacker 2009: 1). With these ideas underpinning any account of CG, this book has provided a means of observing the interpretations and stylistic designs of a diverse group of texts, arguably without being too prescriptive or making categorical generalisations about each text type or genre. In other words, this approach has enabled analyses that are centred on the respective text's overall 'construction' and the experience of reading it. It has also allowed a discussion of the linguistic constructions and patterns individual to each text, while simultaneously positioning the particular text within the wider literary field. Most importantly, each stylistic analysis has argued that the CG concepts under consideration in this book are flexible in terms of application to micro-, meso- and macro-areas of language.

In using CG for stylistic application, such literary linguistic analyses are departing from the original use of the model. This seems a caveat that stylisticians who research this area cannot ignore, but which I hope, with continued application, will not need such qualification. Indeed, stylistics' reputation as a tool-kit discipline means that it has borrowed models that were originally intended for other uses for purposes of literary linguistic analyses: schema theory, pragmatics, conceptual metaphor theory, corpus methods, amongst others. Such models are now well established within the discipline, and do not need the same disclaimers in their practical applications for literary analysis. 
The application of CG in this book is centred on the idea of linguistic constructions, and specifically the observation that a narrative text - that stretches of text above the clausal level - can be treated as an entire linguistic unit or construction (Langacker 2008). This is not a new idea necessarily; although championed more recently by cognitive narratologists Dancygier (2012) and Herman (2002), it is an idea also expounded in the original work of Halliday and Hasan (1976).

All the texts used for analysis in Cognitive Grammar in Contemporary Fiction have been challenging examples - complex constructions - of literature. As postmodern texts, each extract has shown manipulation of form and self-conscious narration, in some instances, and the destabilisation of fictional world construction has been observed across all of the texts - albeit through the disrupting presence of a prominent narrator (Chapter 3), an either explicit or implicit layering of fictional identities (Chapters 4 and 5), or through the disruption of narrative modes (Chapters 6 and 7).

A few of the contemporary texts used here have also been classed as interactive, either based on their template form ('Great Rock and Roll Pauses'), or their complex structure that invites a high level of reader involvement (such as The New York Trilogy and 'Here We Aren't, So Quickly'). This is a label often underpinned by particular conceptual metaphors drawn upon in the reading process, such as READING IS A GAME or READING IS A PUZZLE (Ryan 1998). These can be seen as metaphors that underlie contemporary or postmodern fiction as a whole; and they certainly relate to the selfconsciousness of form that many critics ascribe to postmodern fiction.

The analyses in this book have demonstrated that parts of CG can be applied in support of existing cognitive stylistic approaches. Each chapter has presented a stylistic analysis of the respective text by positioning a CG account alongside existing literary or cognitive linguistic concepts or models. Certain ideas have been particularly useful in 
supporting or scaffolding a CG account (namely, deixis, mind-modelling, schema theory and Text World Theory). Rather than as a replacement for these frameworks, this book has suggested that a consideration of CG offers a fine-grained, text-driven and construalbased model for investigating the reading experience that enriches and supplements these existing stylistic tools.

Dabrowska and Divjak (2015) argue that, in previous applications of CG for stylistics (see Harrison et al 2014; Stockwell 2009), the 'main concern is not meaning but emotional effect'. Although the analyses in Cognitive Grammar in Contemporary Fiction have looked at situated reader responses, this has not been so much a study on emotional effect but rather on the holistic reading experience: the experiential processes of reading, and of how text constructions impact on how we comprehend textual meaning.

For the purposes of this preliminary investigation, the inclusion of reader reviews as qualitative data here has yielded sufficient and pertinent data to help consider these experiential processes more holistically. These data have made it possible to qualitatively observe patterns of construal and scanning processes, and their impact upon the individual, situated reading experience. Using qualitative reader response data has certainly been useful to explicate these construal processes, but going forward this methodology would need to be elaborated on using larger data sets, and possibly using empirical methods of data collection. An investigation incorporating corpus stylistic methods (Semino and Short 2004; Thomas and Short 1996), for example, may be beneficial to observe constructions at the macro-level of the text, in particular.

Empirical methods to verify or provide evidence for particular aspects of the CG model are also needed. As mentioned in Chapter 2, CG is based on universal cognitive 
linguistic principles, many of which have shown to be psychologically grounded through empirical testing (foregrounding, for example, has been explored in Hakemulder 2007; van Peer, Hakemulder and Zyngier 2007; Zwann 1993). There has been speculation, however, whether all of the CG components are needed or indeed useful (see, for example, Broccias and Hollman's 2007 exposition of summary and sequence scanning). Many researchers, including Langacker himself (2007), identify that more empirical support for its central claims is still needed (see, for examples, Bennett 2014; Bielak and Pawlak 2013; Hollmann 2013). This is something that, going forward, stylistic applications of CG would need to address.

\subsection{Replicability}

Of course CG's application for stylistic analysis has been, up until this point, fairly limited (Dabrowska and Divjak 2015). CG itself is a 'work in progress' (Langacker 2006; Bennett 2014), which means that, by extension, its application for literary linguistic research is likewise in its infancy. Cognitive Grammar in Contemporary Fiction has outlined just some of the potential for CG for stylistic analysis, but this is far from providing an exhaustive overview. The accounts in each chapter have drawn on some of the more accessible and central concepts of CG, but other parts of the model (such as the phonological or morphological aspects) have not yet been trialled in literary-linguistic contexts.

Arguably there are some difficulties in adapting CG for stylistic application that hinder researchers. Firstly, there is a lack of accessible guides for the model. Although a prolific writer, Langacker's original accounts of the model are notoriously complex, 
complicated in part through his reliance on abstract diagrams to explain specific concepts (Pincombe 2014: 174). This is a criticism that the volume (Giovanelli and Harrison: Forthcoming) Cognitive Grammar in Stylistics: A Practical Guide aims to address. To compound this difficulty further, there is also the complexity of the model itself. Put simply, '[d]espite many of its intuitive foundational concepts, Cognitive Grammar is not an easy theory to master and apply' (Oakley 2014: 232).

Another potential obstacle for CG analyses in stylistics is that, due to the size and complexity of the model, it is not simple to isolate sections for practical use. It is my intention that the accounts offered in this book will help those interested in using CG for stylistics an overview of the more accessible and practical applications of the model. Certainly, some of the more central CG components - such as construal, action chains, reference points and fictive simulation - are easier to use (and hopefully also to comprehend) as stylistic tools in isolation.

Despite these challenges, CG allows an account of language structures that helps to explain the inseparable and interdependent connections between linguistic form and literary effect. As Hamilton (2003: 62) argues, a CG analysis

may be hard to appreciate but if language is a window onto the human mind, it is a window because it reflects cognitive structures. Those structures exist in the mind of the writer and the mind of the reader, which is the necessary condition for communication to occur.

The capacity for CG to help consider cognitive structures of both writer and reader means that it is ideally placed for cognitive poetic analysis, as it offers a clear 'reconnection of literary scholarship with natural readers' (Harrison and Stockwell 2014: 218-219); a concern at the heart of the subject. 
As a discipline, stylistics openly acknowledges that it is a progressive field; one that aims 'for a better account of things' (Carter and Stockwell 2008: 301). As acknowledged earlier in this book, CG is similarly a 'work in progress' (Bennett 2014: 47).

This process of road testing CG's capacity for the analysis of literature - or for style patterns in situated examples of any text - is therefore a necessary one at this stage. Until these ideas have been discussed and considered in literary linguistic contexts, it is unclear just how much they can offer the stylistics tool-kit. Of course, this means that such applications are, currently, still largely exploratory. Nevertheless, the results of these initial analyses offer new and innovative insights into the cognitive mechanisms - the experiential processes - of reading. 


\section{References}

Alford, S. 1995. Spaced-out: Signification and space in Paul Auster's The New York Trilogy. Contemporary Literature 36(4): 613-632.

Allington, D. 2007. "How come most people don't see it?": Slashing The Lord of the Rings. Social Semiotics 17(1): 45-64.

Allington, D. \& Swann, J. 2009. Researching literary reading as social practice. Language and Literature 18(3): 219-230.

Allington, D. \& Swann, J. 2011. Reading and social interaction: A critical approach to individual and group reading practices. In The History of Reading, Vol 3: Methods, Strategies, Tactics, R. Crone and S. Towheed (eds), 247-264. London: Palgrave Macmillan.

Arnett, C. \& Jernigan, H. 2014. A Cognitive Grammar account of case for L2 students of German. GFL: 68-93.

Atchison, T. 2010. "Why I am writing from where you are not": Absence and presence in Jonathan Safran Foer's Extremely Loud and Incredibly Close. Journal of Postcolonial Writing 46(3): 359-368.

Atwood, M. 1985[1996]. The Handmaid's Tale. London: Vintage.

Auster, P. 1987[2004]. The New York Trilogy. London: Faber and Faber.

Bakhtin, M. 1973. Questions of Literature and Aesthetics. London: Equinox.

Baldry, A. \& Thibault, J. 2006. Multimodal Transcription and Text Analysis: A Multimedia Toolkit and Coursebook. London: Equinox.

Bartlett, F. 1932. Remembering: A Study in Experimental and Social Psychology. Cambridge: Cambridge University Press.

Belmonte, M. K. 2008. Does the experimental scientist have a "Theory of Mind"? Review of General Psychology 12(2): 192-204.

Bennett, P. 2014. Langacker's Cognitive Grammar. In The Bloomsbury Companion to Cognitive Linguistics, J. Littlemore \& J.R. Taylor (eds), 29-48. London: Bloomsbury.

Bergen, B. \& Chang, N. 2005. Embodied construction grammar in simulation-based language understanding. In Construction Grammars: Cognitive Grounding and Theoretical Extensions, J. Östman and M. Fried (eds), 147-190. Amsterdam: John Benjamins.

Bergs, A. 2009. Contexts and Constructions. Amsterdam: John Benjamins.

Berry, M., Butler, C., Fawcett, R. \& Huang, G. (eds). 1996. Meaning and Form: Systemic Functional Interpretations. Stanford: Ablex.

Bielak, J. \& Pawlak, M. 2013. Applying Cognitive Grammar in the Foreign Language Classroom: Teaching English Tense and Aspect. New York: Springer.

Birkerts, S. 1998. Grand Delusion. The New York Times, 25 January 1998, <https://www.nytimes.com/books/98/01/25/reviews/980125.25birkert.html> (30 April 2016).

Broccias, C. \& Hollman, W. 2007. Do we need summary and sequential scanning in (cognitive) grammar? Cognitive Linguistics 18(4): 487-522.

Browse, S. 2014. Resonant Metaphor in Never Let Me Go. In Cognitive Grammar in Literature, C. Harrison, L. Nuttall, P. Stockwell, \& W. Yuan. (eds), 69-82. New York: John Benjamins.

Burke, M. 2011. Literary Reading, Cognition and Emotion: An Exploration of the Oceanic Mind. London: Routledge. 
Burke, M. 2014. Rhetoric and poetics: The classical heritage of stylistics. In The Routledge Handbook of Stylistics, M. Burke (ed), 11-30. London: Routledge.

Burton, D. 1982. Through glass darkly: Through dark glasses. On stylistics and political commitment - via a study of a passage from Sylvia Plath's The Bell Jar. In Language and Literature: Reader in Stylistics, R. Carter (ed), 195-214. London: George Allen \& Unwin.

Butler, C.S. \& Gonzálvez-García, F. 2005. Situating FDG in functional-cognitive space: An initial study. In Studies in Functional Discourse Grammar, J.L. Mackenzie \& M. de los Ángeles Gómez-González (eds), 109-158. Bern: Peter Lang.

Carter, R. \& Stockwell, P. 2008. Stylistics: Retrospect and prospect. In The Language and Literature Reader, R. Carter and P. Stockwell (eds), 291-302. London: Routledge.

Carroll, L. 1865. Alice in Wonderland. London: Macmillan.

Chatman, S. 1978. Story and Discourse. Ithaca: Cornell University Press.

Childs, P. 2007. Adaptations. In Ian McEwan's Enduring Love: A Routledge Study Guide, P. Childs (ed), 123-136. London: Routledge.

Churchwell, S. 2011. A Visit from the Goon Squad by Jennifer Egan - Review. The Guardian, 13 March 2011, <http://www.guardian.co.uk/books/2011/mar/13/jennifer-egan-visit-goon-s quad $>$ (15 March 2012).

Clark, H. H. \& Clark, E.V. 1977. Psychology and Language: An Introduction to Psycholinguistics. New York: Harcourt Brace Jovanovich.

Cobley, P. 2001. Narrative. London: Routledge.

Cobley, P. 2012. The reactionary art of murder: Contemporary crime fiction, criticism and verisimilitude. Language and Literature 21(3): 286-298.

Cockcroft, R. \& Cockcroft, S. 1992[2014]. Persuading People: An Introduction to Rhetoric. $3^{\text {rd }}$ edn. London: Palgrave Macmillan.

Cook, G. 1994. Discourse and Literature. Oxford: Oxford University Press.

Crisp, P. 2008. Between extended metaphor and allegory: Is blending enough? Language and Literature 17(4): 291-308.

Croft, W. 2001. Radical Construction Grammar: Syntactic Theory in Typological Perspective. Oxford: Oxford University Press.

Croft, W. \& Cruse, D. A. 2004. Cognitive Linguistics. Cambridge: Cambridge University Press.

Currie, M. 1995. Metafiction. London: Longman.

Dabrowska, E. \& Divjak, E. 2015. Handbook of Cognitive Linguistics. Berlin: Mouton De Gruyter.

Dancygier, B. 2007. Narrative Anchors and the processes of story construction. Style 41(2): 133-152.

Dancygier, B. 2008. The text and the story: Levels of blending in fictional narratives. In Mental Spaces in Discourse and Interaction, T. Oakley \& A. Hougaard (eds), 51-78. Amsterdam: John Benjamins.

Dancygier, B. 2012. The Language of Stories: A Cognitive Approach. Cambridge: Cambridge University Press.

Dancygier, B. \& Sweetser, E. 2005. Mental Spaces in Grammar: Conditional Constructions. Cambridge: Cambridge University Press.

Dancygier, B. \& Vandelanotte, L. 2009. Judging distances: Mental spaces, distance and viewpoint in literary discourse. In Cognitive Poetics: Goals, Gains and Gaps, G. Brône \& J. Vandaele (eds), 319-369. Berlin: Mouton de Gruyter.

Diack, H. 1960. Reading and the Psychology of Perception. Nottingham: E. H. Lee \& Co. Ltd. 
Dickens, C. 1852-1853[1994]. Bleak House. Harmondsworth: Penguin.

Dimovitz, S. 2006. Public personae and the private I: De-compositional ontology in Paul Auster's The New York Trilogy. Modern Fiction Studies 52(3): 613-633.

Dirven, R. \& Pörings, R. 2002. Metaphor and Metonymy in Comparison and Contrast. Berlin: Mouton de Gruyter.

Dodge, E. \& Lakoff, G. 2005. From linguistic analyses to neural grounding. In From Perception to Meaning: Image Schemas in Cognitive Linguistics, B. Hampe \& J. Grady (eds), 57-92. Berlin: Mouton de Gruyter.

Dolezel, L. 1995. Fictional worlds: Density, gaps and inference. Style 29(2): 201-214.

Doloughan, F. 2011. Contemporary Narrative: Textual Production, Multimodality and Multiliteracies. London: Continuum.

Dowty, D. 1991. Thematic proto-roles and argument selection. Language 67: 574-619.

Duchan, J. F., Bruder, G. A. \& Hewitt, L. E. (eds). 1995. Deixis in Narrative: A Cognitive Science Perspective. Hillsdale: Lawrence Erlbaum.

Egan, J. 1995. Invisible Circus. London: Corsair, Constable \& Robinson Ltd.

Egan, J. 2008. The Keep. London: Abacus.

Egan, J. 2010. A Visit from the Goon Squad. London: Corsair, Constable \& Robinson Ltd.

Egan, J. 2011. Look at Me. London: Corsair, Constable \& Robinson Ltd.

Emmott, C. 1992. Splitting the referent: An introduction to narrative enactors. In Advances in Systemic Linguistics: Recent Theory and Practice, M. Davies \& L. Ravelli (eds), 221-228. London: Pinter.

Emmott, C. 1995. Consciousness and context-building: Narrative inferences and anaphoric theory. In New Essays in Deixis, K. Green (ed), 81-97. Amsterdam: Rodopi.

Emmott, C. 1997. Narrative Comprehension: A Discourse Perspective. Oxford: Oxford University Press.

Emmott, C. 2003. Reading for pleasure: A cognitive poetic analysis of 'twists in the tale' and other plot reversals in narrative texts. In Cognitive Poetics in Practice, J. Gavins \& G. Steen (eds), 145-160. London: Routledge.

Emmott, C. and Alexander, M. 2014. Foregrounding, burying and plot construction. In The Cambridge Handbook of Stylistics, P. Stockwell \& S. Whiteley (eds), 329-343 Cambridge: Cambridge University Press.

Emmott, C., Sanford, J.A. \& Morrow, L.I. 2006. Capturing the attention of readers? Stylistic and psychological perspectives on the use and effect of text fragmentation in narratives. Journal of Literary Semantics 35: 1-30.

Evans, V. \& Green, M. 2006. Cognitive Linguistics: An Introduction. Edinburgh: Edinburgh University Press.

Fauconnier, G. 1985. Mental Spaces. Cambridge: Cambridge University Press.

Fauconnier, G. 1997. Mappings in Thought and Language. Cambridge: Cambridge University Press.

Fillmore, C. 1985. Frames and the semantics of understanding. Quaderni di Semantica 6(2): 222-254.

Fillmore, C. 1992. Toward a frame-based lexicon: The semantics of RISK and its neighbours. In Frames, Fields and Contrasts: New Essays in Semantic and Lexical Organization, A. Lehrer \& E. Kittay (eds), 75-102. Hillsdale: Lawrence Erlbaum Associates.

Fitzpatrick, J. 2010. Five best book recommendation services. Lifehacker, 25 July 2010, <http://lifehacker.com/5595842/five-best-book-recommendation-services> (1 December 2010). 
Foer, J. S. 2002a. Everything Is Illuminated. New York: Penguin.

Foer, J. S. 2002b. 'A Primer for the Punctuation of Heart Disease'. In The Unabridged Pocketbook of Lightning, J.S. Foer (ed), 1-9. London: Penguin.

Foer, J. S. 2005. Extremely Loud and Incredibly Close. New York: Penguin.

Foer, J. S. 2006. 'If the Aging Magician Should Begin to Believe'. In A Convergence of Birds: Original Fiction and Poetry Inspired by Joseph Cornell, J.S. Foer (ed), 203222. London: Hamish Hamilton.

Foer, J.S. 2010. 'Here We Aren't, So Quickly'. In 20 under 40: Stories from the New Yorker, D. Treisman (ed), 139-144. New York: Farrar, Strauss \& Giroux.

Fokemma, A. 1991. Postmodern Characters: A Study of Characterization in British and American Postmodern Fiction. Amsterdam: Rodopi.

Forceville, C. 1999. Educating the eye? Kress and van Leeuwen's Reading Images: The Grammar of Visual Design (1996). Language and Literature 8 (2): 163-178.

Forceville, C. 2007. Pictorial and multimodal metaphor in commercials. In Go Figure! New Directions in Advertising Rhetoric, E. McQuarrie, \& B. Phillips (eds), 178-204. Armonk: M.E. Sharpe.

Forceville, C. 2009. Multimodal Metaphor. Berlin: Mouton de Gruyter.

Forrest, L. B. 1996. Discourse goals and attentional processes in sentence production: The dynamic construal of events. In Conceptual Structure, Discourse and Language, A. Goldberg (ed), 149-161. Stanford: CSLI Publications.

Forster, E.M. 1905. Aspects of the Novel. Cambridge: Hodder Arnold.

Fowler, R. 1986[1996]. Linguistic Criticism. $2^{\text {nd }}$ edn. Oxford: Oxford University Press.

Frank, A. 2010. Letting Stories Breathe: A Socio-Narratology. Chicago: University of Chicago Press.

Freeman, M. 1995. Metaphor making meaning: Dickinson's conceptual universe. Journal of Pragmatics 24(6): 643-666.

Freeman, M. 1997. Grounded spaces: Deictic-self anaphors in the poetry of Emily Dickinson. Language and Literature 6(1): 7-28.

Freeman M. 2006. The fall of the wall between literary studies and linguistics: Cognitive poetics. In Cognitive Linguistics: Current Applications and Future Perspectives, G. Kristiansen, M. Achard, R. Dirven \& F. Ruiz de Mendoza Ibáñez (eds), 403-428. Berlin: Mouton de Gruyter.

Freeman, M. 2007. Cognitive linguistic approaches to literary studies: State of the art in cognitive poetics. In The Oxford Handbook of Cognitive Linguistics, D. Geeraerts \& H. Cuyckens (eds), 1175-1202. Oxford: Oxford University Press.

Fulford, R. 2010. Jennifer Egan's A Visit from the Goon Squad is all about the timing. National Post, 1 December 2010, <http://arts.nationalpost.com/2012/01/10/jennifer-egans-a-visit-from-thegoon-squad-is-all-about-the-timing/> (15 October 2012).

Fuller, D. 2008. Reading as social practice: The beyond the book research project. Journal of Popular Narrative Media 1(2): 211-217.

Gaiman, N. 2002. Coraline. London: Bloomsbury.

Gavins, J. 2000. Absurd tricks with bicycle frames in the text world of The Third Policeman. Nottingham Linguistic Circular 15: 17-33.

Gavins, J. 2003. Too much blague? An exploration of text-worlds of Donald Barthelme's Snow White. In Cognitive Poetics in Practice, J. Gavins \& G. Steen (eds), 129-144. London: Routledge.

Gavins, J. 2005. (Re)thinking modality: A text-world perspective. Journal of Literary Semantics 34(2): 79-93. 
Gavins, J. 2007. Text World Theory: An Introduction. Edinburgh: Edinburgh University Press.

Gavins, J. \& Stockwell, P. 2012. About the heart, where it hurt exactly, and how often. Language and Literature 21(1): 33-50.

Genette, G. 1980. Narrative Discourse: An Essay in Method. Ithaca: Cornell University Press.

Genette, G. 1988. Narrative Discourse Revisited. Ithaca: Cornell University Press.

Genette, G. 2002. Order, duration and frequency. In Narrative Dynamics: Essays on Time, Plot, Closure and Frame, B. Richardson (ed), 25-34. Columbus: Ohio State University Press.

Gibbons, A. 2008. Multimodal literature 'moves' us: Dynamic movement and embodiment in VAS: An Opera in Flatland. Hermes 41: 107-124.

Gibbons, A. 2012a. Multimodality, Cognition and Experimental Literature. London: Routledge.

Gibbons, A. 2012b. Altermodernist fiction. In Routledge Companion to Experimental Literature, J. Bray, A. Gibbons \& B. McHale (eds), 238-252. London: Routledge.

Gibbons, A. \& Whiteley, S. (eds) Forthcoming.

Gibbs, J. 2011. A Visit From the Goon Squad, by Jennifer Egan. The Independent, 8 April 2011,

<http://www.independent.co.uk/arts-entertainment/books/reviews/a-visitfrom-the-goon-squad-by-jennifer-egan-2264678.html> (15 October 2012).

Gibbs, R. 2002. Feeling moved by metaphor. In Textual Secrets: The Message of the Medium, S. Csabi \& J. Zerkowitz (eds), 13-28. Budapest: Eötvös Loránd University.

Giora, R., Fein, O., Aschkenazi, K. \& Alkabets-Zlozover, I. 2007. Negation in context: A functional approach to suppression. Discourse Processes 43: 153-172.

Giora, R., Heruti, V., Metuki, N. \& Fein, 0. 2009. 'When we say no we mean no': Interpreting negation in vision and language. Journal of Pragmatics 41(11): 2222-2239.

Giovanelli, M. 2013. Text World Theory and Keats' Poetry: The Cognitive Poetics of Desire, Dreams and Nightmares. London: Bloomsbury Academic.

Giovanelli, M. 2014. The 'missive from the trench': Conceptual proximity and the experience of war in Siegfried Sassoon's 'A Working Party'. In Cognitive Grammar in Literature, C. Harrison, L. Nuttall, P. Stockwell \& W. Yuan (eds), 145-159. New York: John Benjamins.

Giovanelli, M. \& Harrison, C. Forthcoming. Cognitive Grammar in Stylistics: A Practical Guide. London: Bloomsbury.

Goldberg, A. 1995. Construction: A Construction Grammar Approach to Argument Structure. Chicago: Chicago University Press.

Goldberg, A. 1996. Conceptual Structure, Discourse and Language. Stanford: CSLI Publications.

Gooding, R. 2008. "Something very old and very slow": Coraline, uncanniness, and narrative form. Children's Literature Association Quarterly 33(4): 390-407.

Green, K. (ed). 1995. New Essays in Deixis: Discourse, Narrative, Literature. Amsterdam: Rodopi.

Green, M., Strange, J. \& Brock, T. 2002. Narrative Impact: Social and Cognitive Foundations. Mahwah: Lawrence Erlbaum Associates.

Gregoriou, C. 2012. 'Times like these, I wish there was a real Dexter': Unpacking serial murder ideologies and metaphors from TV's Dexter internet forum'. Language and Literature 21(3): 274-285. 
Greimas, A. J. 1971. Narrative Grammar: Units and Levels. Modern Language Notes 86: 793-806.

Greimas, A. J. 1973. Les actants, les acteurs et les figures. In Semiotique Narrative et Textuelle, C. Chabrol (ed), 161-176. Paris: Larousse.

Greimas, A. J. 1977. Elements of a Narrative Grammar. Diacritics 7: 23-40.

Hakemulder, J. 2004. Foregrounding and its effects on readers' perception. Discourse Processes 38: 193-208.

Halliday, M. A. K. 1971. Linguistic function and literary style: An inquiry into the language of William Golding's The Inheritors. In Literary Style: A Symposium, S. Chatman (ed), 330-365. Oxford: Oxford University Press.

Halliday, M. A. K. 1973. Explorations in the Functions of Language. London: Edward Arnold.

Halliday, M. A. K. 1978. Language as Social Semiotic. London: Edward Arnold.

Halliday, M. A. K. 1985. An Introduction to Functional Grammar. London: Edward Arnold.

Halliday, M. A. K. \& Hasan, R. 1976. Cohesion in English. London: Longman.

Halliday, M. A. K. \& Martin, J. 1993. Writing Science: Literacy and Discursive Power. London: Falmer Press.

Halliday, M. A. K. \& Matthieson, C. 1985[2004]. An Introduction to Functional Grammar. $3^{\text {rd }}$ edn. London: Edward Arnold.

Hamilton, C. 2003. A cognitive grammar of 'Hospital Barge' by Wilfred Owen. In Cognitive Poetics in Practice, J. Gavins \& G. Steen (eds), 55-65. London: Routledge.

Hamilton, C. 2014. The cognitive poetics of if. In Cognitive Grammar in Literature, C. Harrison, L. Nuttall, P. Stockwell \& W. Yuan (eds), 195-212. New York: John Benjamins.

Hampe, B. \& Grady, J. 2005. From Perception to Meaning: Image Schemas in Cognitive Linguistics. Berlin: Mouton de Gruyter.

Harrison, C. 2014. Attentional windowing in 'The Soul Is Not a Smithy'. In Cognitive Grammar in Literature, C. Harrison, L. Nuttall, P. Stockwell \& W. Yuan (eds), 5367. New York: John Benjamins.

Harrison, C. In preparation. Finding Elizabeth: Scanning text worlds in Elizabeth Is Missing by Emma Healey.

Harrison, C. \& Mason, J. In preparation. 'Reimagining innocence? "You read it back when you're older, you're like, oh my god!".

Harrison, C. \& Nuttall, L. In preparation. Re-reading Margaret Atwood's 'The FreezeDried Groom'.

Harrison, C., Nuttall, L., Stockwell, P. \& Yuan, W. (eds). 2014. Cognitive Grammar in Literature. New York: Benjamins.

Harrison, C. \& Stockwell, P. 2014. Cognitive poetics. In The Bloomsbury Companion to Cognitive Linguistics, J. Littlemore \& J. Taylor (eds), 218-233. London: Bloomsbury.

Hart, C. 2014a. Construal operations in online press reports of political protests. In Contemporary Critical Discourse Studies, C. Hart \& P. Cap (eds), 167-188. London: Bloomsbury.

Hart, C. 2014b. Discourse, Grammar and Ideology: Functional and Cognitive Perspectives. London: Bloomsbury.

Head, D. 1992. The Modernist Short Story: A Study in Theory and Practice. Cambridge: Cambridge University Press.

Head, D. 2002. The Cambridge Introduction to Modern British Fiction, 1950-2000. Cambridge: Cambridge University Press.

Head, D. 2007. Ian McEwan. Manchester: Manchester University Press. 
Healey, E. 2014. Elizabeth Is Missing. New York: Harper Collins.

Heine, B. 1997. Cognitive Foundations of Grammar. Oxford: Oxford University Press.

Herman, D. 2002. Story Logic. Nebraska: University of Nebraska Press.

Herman, D. 2003. Stories as a tool for thinking. In Narrative Theory and the Cognitive Sciences, D. Herman (ed), 163-192. Stanford: CSLI Publications.

Herman, D. 2009a. Beyond voice and vision: Cognitive Grammar and focalization theory. In Narratology: Point of View, Perspective, and Focalization: Modeling Mediation in Narrative, P. Hühn, W. Schmid \& J. Schönert (eds), 119-142. Berlin: Mouton de Gruyter.

Herman, D. 2009b. Cognitive approaches to narrative analysis. In Cognitive Poetics: Goals, Gains and Gaps, G. Brône \& J. Vandaele (eds), 79-118. Berlin: Mouton de Gruyter.

Herman, D. 2009c. Basic Elements of Narrative. Oxford: Wiley-Blackwell.

Herman, D. 2011. The Emergence of Mind: Representations of Consciousness in Narrative Discourse in English. Lincoln: University of Nebraska Press.

Herman, D., Manfred, J. \& Ryan, M.-L. (eds). 2007. The Routledge Encyclopedia of Narrative Theory. London: Routledge.

Hidalgo-Downing, L. 2000a. Negation, Text Worlds and Discourse: The Pragmatics of Fiction. Stanford: Ablex.

Hidalgo-Downing, L. 2000b. Negation in discourse: A text world approach to Joseph Heller's Catch-22. Language and Literature 9(3): 215-240.

Hoeken, H. \& van Vliet, M. 2000. Suspense, curiosity and surprise: How discourse structure influences the affective and cognitive processing of a story. Poetics 27(4): 277-286.

Hoeksema, J. 2001. Perspectives on Negation and Polarity Items. Amsterdam: John Benjamins.

Hoekstra, T. \& Sybesma, R. 2004. Arguments and Structure: Studies on the Architecture of the Sentence. Berlin: Mouton de Gruyter.

Hollman, W. B. 2013. Nouns and verbs in Cognitive Grammar: Where is the 'sound' evidence? Cognitive Linguistics 24(2): 275-308.

Horn, L. 1989. A Natural History of Negation. Chicago: University of Chicago Press.

Horn, L. 2010. The Expression of Negation. Berlin: Mouton de Gruyter.

House, C. 2011. A Visit from the Goon Squad, by Jennifer Egan: Ambitious dispatches from America's nattiest frontier. The Independent, 13 March 2011, <http://www.independent.co.uk/arts-entertainment/books/reviews/a-visit-fr om-the-goon-squad-by-jennifer-egan-2240306.html> (15 October 2012).

Iser, W. 1974. The Implied Reader: Patterns of Communication in Prose Fiction from Bunyan to Beckett. Baltimore: Johns Hopkins University Press.

Ishiguro, K. 2005. Never Let Me Go. London: Faber and Faber.

Jackendoff, R. 1987. On beyond zebra: The relation of linguistic and visual information. Cognition 26(2): 89-114.

Ji, Y. \& Shen, D. 2004. Transitivity and mental transformation: Sheila Watson's The Double Hook. Language and Literature 13(4): 335-348.

Jones, G. \& Ells, K. 2011. Chaos and complexity in Paul Auster's The New York Trilogy. In Restoring the Mystery of the Rainbow: Literature's Refraction of Science, C. Barfoot \& V. Tinkler (eds), 627-640. Amsterdam: Rodopi.

Kamp, H. \& Reyle, U. 2003. From Discourse to Logic. Dordrecht: Kluwer.

Kaveney, R. 2009. Mother Shudder. The Times Literary Supplement, 5 June 2009, <http://entertainment.timesonline.co.uk/tol/arts_and_entertainment/the_tls/ar ticle 6437999.ece> (28 April 2009). 
Kay, P. \& Fillmore, C. 1999. Grammatical constructions and linguistic generalisations: The what's doing $X$ to $Y$ ? construction. Language 75(1): 1-33.

Kennedy, C. 1982. Systemic grammar and its use in literary analysis. In Language and Literature: An Introductory Reader in Stylistics, R. Carter (ed), 82-99. London: George Allen \& Unwin.

Kimmel, M. 2011. From text-linguistics to literary actants - the force dynamics of (emotional) vampirism. Language and Cognition 3(2): 235-282.

Klapcsik, S. 2008. Neil Gaiman's irony, liminal fantasies, and fairy tale adaptations. Hungarian Journal of English and American Studies 14(2): 317-334.

Knox, J. 2010. Jonathan Safran Foer. The New Yorker, 14 June 2010, <http://www.newyorker.com/magazine/2010/06/14/jonathan-safran-foer> (27 May 2015).

Köhler, W. 1947. Gestalt Psychology. New York: New American Library.

Kövecses, Z. 2002. Metaphor: A Practical Introduction. Oxford: Oxford University Press.

Kress, G. R. \& van Leeuwen, T. 2006. Reading Images: The Grammar of Visual Design. London: Routledge.

Kristeva, J. 1981. A Semiotic Approach to Literature and Art. Oxford: Blackwell Publishers.

Kuiken, D. \& Miall, D. S. 1994. Foregrounding, defamiliarisation and affect: Response to literary stories. Poetics 22: 389-407.

Kuiken, D., Miall. D. \& Sikora, S. 2004. Forms of self-implication in literary reading. Poetics Today 25(2): 171-203.

Laberge, D. 1983. Spatial extent of attention to letters and words. Journal of Experimental Psychology: Human Perception and Performance 9(3): 371-379.

Labov, W. 1972. Language and the Inner City: Studies in the Black English Vernacular. Philadelphia: University of Pennsylvania Press.

Lahey, E. 2004. All the world's a subworld: Direct speech and subworld creation in 'After' by Norman MacCaig. Nottingham Linguistic Circular: 21-28.

Lakoff, G. 1987. Women, Fire and Dangerous Things: What Categories Reveal about the Mind. Chicago: University of Chicago Press.

Lakoff, G. \& Johnson, M. 1980. Metaphors We Live By. Chicago: Chicago University Press.

Langacker, R. 1982. Space Grammar, analysability, and the English passive. Language 58(1): 22-80.

Langacker, R. 1987. Foundations of Cognitive Grammar, Volume 1, Theoretical Prerequisites. Stanford: Stanford University Press.

Langacker, R. 1990. Concept, Image, and Symbol: The Cognitive Basis of Grammar. Berlin: Mouton de Gruyter.

Langacker, R. 1991. Foundations of Cognitive Grammar, Volume 2, Descriptive Application. Stanford: Stanford University Press.

Langacker, R. 1993a. Universals of construal. Proceedings of the Annual Meeting of the Berkeley Linguistics Society 19: 447-463.

Langacker, R. 1993b. Grammatical traces of some 'invisible' semantic constructs. Language Sciences 15(4): 323-355.

Langacker, R. 1999a. Virtual reality. Studies in the Linguistics Sciences 29(2): 77-103.

Langacker, R. 1999b. Grammar and Conceptualization. Berlin: Mouton de Gruyter.

Langacker, R. 2001. Discourse in Cognitive Grammar. Cognitive Linguistics 12(2): 143188.

Langacker, R. 2007. Cognitive Grammar. In The Oxford Handbook of Cognitive Linguistics, D. Geeraerts \& H. Cuyckens (eds), 421-462. Oxford: Oxford University Press. 
Langacker, R. 2008. Cognitive Grammar: A Basic Introduction. Oxford: Oxford University Press.

Langacker, R. 2009. Cognitive Linguistics Research: Investigations in Cognitive Grammar. Berlin: Mouton de Gruyter.

Lavender, W. 1993. The novel of critical engagement: Paul Auster's City of Glass. Contemporary Literature 34(2): 219-239.

Lehrer, A. \& Kittay, E. (eds). 1992. Frames, Fields and Contrasts: New Essays in Semantic and Lexical Organization. Hillsdale: Lawrence Erlbaum Associates.

Leinfeller, E. 1994. The broader perspective of negation. Journal of Literary Semantics 13(2): 77-98.

Lewis, C.S. 1950-1956. The Chronicles of Narnia. London: Harper Collins.

Little, W. 1997. Nothing to go on: Paul Auster's City of Glass. Contemporary Literature 38(1): 133-163.

Littlemore, J. \& Taylor, J. R. 2014. Introduction. In The Bloomsbury Companion to Cognitive Linguistics, J. Littlemore \& J. R. Taylor (eds), 1-26. London: Bloomsbury.

Ljungberg, C. 2015. Iconicity. In The Bloomsbury Companion to Stylistics, V. Sotirova (ed), 476-489. London: Bloomsbury.

Long, E. 2003. Book Clubs - Women and the Uses of Reading in Everyday Life. Chicago: University of Chicago Press.

March-Russell, P. 2009. The Short Story: An Introduction. Edinburgh: Edinburgh University Press.

Mars-Jones, A. 1999. I think I'm right, therefore I am. The Guardian, 7 September 1999, <http://www.theguardian.com/books/1999/sep/07/fiction.reviews> (30 April 2016).

Martin, T. 2011. Jennifer Egan: Profile. The Telegraph, 25 March 2011, <http://www.telegraph.co.uk/culture/books/bookreviews/8403574/JenniferEgan-Profile.html> (15 October 2012).

Martínez, M. A. 2014. Storyworld possible selves and the phenomenon of narrative immersion: Testing a new theoretical construct. Narrative 22: 110-131.

Mason, J. 2014. Narrative. In Cambridge Handbook of Stylistics, P. Stockwell \& S. Whiteley (eds), 179-195. Cambridge: Cambridge University Press.

Mason, J. Forthcoming. Intertextuality in Practice. New York: John Benjamins.

Mather, G. 2006. Foundations of Perception. London: Psychology Press.

Matlock, T. 2004. Fictive motion as cognitive stimulation. Memory and Cognition 32(8): 1389-1400.

Matlock, T. 2010. Abstract motion is no longer abstract. Language and Cognition 2(2): 243-260.

Matsumoto, N. 2008. Bridges between cognitive linguistics and second language pedagogy: The case of corpora and their potential. SKY Journal of Linguistics 21: 125-153.

McEwan, I. 1997. Enduring Love. London: Vintage.

McHale, B. 1989. Postmodernist Fiction. Cambridge: Cambridge University Press.

McHale, B. 1992. Constructing Postmodernism. London: Routledge.

McHale, B. 2012. Postmodernism and experiment. In Routledge Companion to Experimental Literature, J. Bray, A. Gibbons \& B. McHale (eds), 141-153. London: Routledge.

McIntyre, D. 2006. Point of View in Plays. Amsterdam: John Benjamins.

Miall, D. S. 2006. Literary Reading: Empirical and Theoretical Studies. New York: Peter Lang. 
Miall, D. S. 1990. Readers' responses to narrative: Evaluating, relating, anticipating. Poetics 19: 323-339.

Miall, D. S. \& Kuiken, D. 1999. What is literariness? Three components of literary reading. Discourse Processes 28(2): 121-138.

Miall, D. S. \& Kuiken, D. 2002. A feeling for fiction: Becoming what we behold. Poetics 30(4): 221-241.

Mills, S. 2002. Feminist Stylistics. London: Routledge.

Nahajec, L. 2009. Negation and the creation of implicit meaning in poetry. Language and Literature 18(2): 109-127.

Nesset, T. 2009. Review of Cognitive Grammar: A Basic Introduction (2008), R. Langacker. Journal of Linguistics 45(2): 477-480.

Nicol, B. 2009. The Cambridge Introduction to Postmodern Fiction. Cambridge: Cambridge University Press.

Nikolajeva, M. 2009. Devils, demons, familiars, friends: Toward a semiotics of literary cats. Journal of Fairy-Tale Studies 23(2): 248-267.

Nørgaard, N. 2007. Disordered collarettes and uncovered tables: Negative polarity as a stylistic device in Joyce's “Two Gallants”. Journal of Literary Semantics, 36(1): 3552.

Nuttall, L. 2014. Constructing a text world for The Handmaid's Tale. In Cognitive Grammar in Literature, C. Harrison, L. Nuttall, P. Stockwell, \& W. Yuan. (eds), 8399. New York: John Benjamins.

Nuttall, L. 2015. Attributing minds to vampires in Richard Matheson's I Am Legend. Language and Literature 24(1): 23-39.

Nuyts, J. 2007. Cognitive linguistics and functional linguistics. In The Oxford Handbook of Cognitive Linguistics, D. Geeraerts \& H. Cuyckens (eds), 543-565. Oxford: Oxford University Press.

Oakley, T. 2005. Force-dynamic dimensions of rhetorical effect. In From Perception to Meaning: Image Schemas in Cognitive Linguistics, J. Hampe (ed), 443-473. Berlin: Mouton de Gruyter.

Oakley, T. 2014. Afterword: From Cognitive Grammar to systems rhetoric. In Cognitive Grammar in Literature, C. Harrison, L. Nuttall, P. Stockwell, \& W. Yuan. (eds), 231236. New York: John Benjamins.

Oatley, K. 2002. Emotions and the story worlds of fiction. In Narrative Impact, T. Brock, M. Green \& J. Strange (eds), 36-69. Mahwah: Erlbaum.

Oatley, K. 2003. Writingandreading: The future of cognitive poetics. In Cognitive Poetics in Practice, J. Gavins \& G. Steen (eds), 161-173. London: Routledge.

Östman, J. \& Fried, M. (eds). 2005. Construction Grammars: Cognitive Grounding and Theoretical Extensions. Amsterdam: John Benjamins.

Padley, S. 2006. Key Concepts in Contemporary Literature. London: Palgrave Macmillan.

Palmer, A. 2004. Fictional Minds. Lincoln: University of Nebraska Press.

Palmer, A. 2009. Attributions of Madness in Ian McEwan's Enduring Love. Style 43(3): 291-308.

Paradis, C. 2005. Ontologies and construals in lexical semantics. Axiomathes 15(4): 541573.

Parsons, E., Sawers, N. \& McInally, K. 2008. The Other Mother: Neil Gaiman's postfeminist fairytales. Children's Literature Association Quarterly 33(4): 371389.

Pavel, T. 1973. Some remarks on narrative grammars. Poetics 2(4): 5-30. 
Peplow, D. 2012. 'Oh, I've known a lot of Irish people': Reading groups and the negotiation of literary interpretation. Language and Literature 20(4): 295-315.

Pleyer, M. \& Schneider, C. 2014. Construal, cognition, and comics: Analysing the multimodal construction of a Gothic autobiography in Alison Blechdel's Fun Home. In Cognitive Grammar in Literature, C. Harrison, L. Nuttall, P. Stockwell, \& W. Yuan. (eds), 35-52. New York: John Benjamins.

Prince, G. 1973. A Grammar of Stories. The Hague: Mouton.

Propp, V. 1968. Morphology of the Folktale. Austin: University of Texas Press.

Pullman, P. 2002. The other mother. The Guardian, 31 August 2002, <http://www.guardian.co.uk/books/2002/aug/31/booksforchildrenandteenage rs.neilgaiman> (8 March 2013).

RA-RE. 2008-2012. Goodreads: Coraline reviews, December 2008 - January 2012, <http://www.goodreads.com/book/show/17061.Coraline> (15 February 2012).

RF-RJ. 2006-2012. Amazon: Coraline reviews, April 2006 - April 2012, <http://www.amazon.com/Coraline-Neil-Gaiman/dp/0061649694> (17 April 2012).

R1-R6. 2008-2012. Goodreads: The New York Trilogy reviews. February 2008 - April 2012, <http://www.goodreads.com/book/show/431.The_New_York_Trilogy> (15 February 2012).

R7-R11. 2005-2012. Amazon: The New York Trilogy reviews, September 2005 September 2012, <http://www.amazon.co.uk/New-York-Trilogy-Paul-Auster/dp/0571276652> (17 April 2012).

Rapp, D. N. \& Gerrig, R. J. 2006. Predilections for narrative outcomes: The impact of story contexts and reader preferences. Journal of Memory and Language 54: 5467.

Rice, C. 2012. Fictive motion and perspectival construal in the Lyric. In Cognitive Literary Studies: Current Themes and New Directions, I. Jaén \& J. Simon (eds), 183198. Austin: University of Texas Press.

Richardson, B. 2002. Beyond story and discourse: Narrative time in postmodern and nonmimetic fiction. In Narrative Dynamics: Essays on Time, Plot, Closure and Frames, B. Richardson (ed), 47-63. Columbus: Ohio State University Press.

Richardson, B. 2006. Unnatural Voices: Extreme Narration in Modern and Contemporary Fiction. Columbus: Ohio State University Press.

Ridley, M. 2009. Foreword: Ian McEwan and the Rational Mind. In Ian McEwan Contemporary Critical Perspectives, S. Groes (ed), vii-xii. London: Continuum.

Rowen, N. 1991. The detective in search of the lost tongue of Adam: Paul Auster's City of Glass. Critique 32(4): 224-234.

Rowling, J. K. 1997-2007. The Harry Potter series. London: Bloomsbury.

Rubba, J. 1996. Alternate grounds in the interpretation of deictic expressions. In Spaces, Worlds, and Grammars, G. Fauconnier \& E. Sweetser (eds), 227-261. Chicago: University of Chicago Press.

Rudd, D. 2008. An eye for an I: Neil Gaiman's Coraline and questions of identity. Children's Literature in Education 39: 159-168.

Russell, A. 1990. Deconstructing The New York Trilogy. Critique: Studies in Contemporary Fiction 31(2): 71-84.

Ryan, M. L. 1998. The text as world versus the text as game: Possible worlds semantics and postmodern theory. Journal of Literary Semantics 27(3): 137-163. 
Sánchez-García, J. 2007. Toward a cognitively-oriented discourse analysis: Framing, construal and violence-related emotional meaning. In Cognitive Linguistics in Critical Discourse Analysis, C. Hart \& D. Lukeš (eds), 207-231. Cambridge: Cambridge Scholars Press.

Schank, R. 1982. Reading and Understanding. Hillsdale: Erlbaum.

Schank, R. \& Abelson, R. 1977. Scripts, Plans, Goals and Understanding. An Inquiry into Human Knowledge Structures. Hillsdale NJ: Lawrence Erlbaum Associates.

Schemberg, C. 2004. Achieving 'at-one-ment': Storytelling and the concept of the self in Ian McEwan's The Child in Time, Black Dogs, Enduring Love and Atonement. Anglo-American Studies, 26: 106.

Segal, E. 2010. Closure in detective fiction. Poetics Today 31(2): 153-215.

Segal, E. 1995. Narrative comprehension and the role of deictic shift theory. In Deixis in Narrative: A Cognitive Science Perspective, J. F. Duchan, G. A. Bruder and L. E. Hewitt (eds), 3-17. Hillsdale, NF: Lawrence Erlbaum.

Semino, E. 1995. Schema theory and the analysis of text worlds in poetry. Language in Literature 4(2): 79-108.

Semino, E. 2008. A cognitive stylistic approach to mind style in narrative fiction. In The Language and Literature Reader, R. Carter \& P. Stockwell (eds), 268-277. London: Routledge.

Semino, E. 2014. Pragmatic failure, mind style and characterisation in fiction about autism. Language and Literature 23(2): 141-158.

Semino, E. \& Short, M. 2004. Corpus Stylistics: Speech, Writing and Thought Presentation in a Corpus of English Writing. London: Routledge.

Shiloh, L. 2002. Paul Auster and the Postmodern Quest: On the Road to Nowhere. New York: Peter Lang.

Shiloh, L. 2010. Double, the Labyrinth, and the Locked Room: Metaphors of Paradox in Crime Fiction and Film. New York: Peter Lang.

Short, M. \& van Peer, W. 1989. Accident! Stylisticians evaluate: Aims and methods of stylistics analysis. In Reading, Analysing and Teaching Literature, M. Short (ed), 22-71. London: Longman.

Simpson, P. 1993. Language, Ideology and Point of View. London: Routledge.

Simpson, P. 2004. Stylistics: A Resource Book for Students. London: Routledge.

Simpson, P. 2014. Just what is narrative urgency? Language and Literature 23(1): 3-22.

Simpson, P. \& Canning, P. 2014. Action and event. In The Cambridge Handbook of Stylistics, Stockwell, P. \& Whiteley, S. (eds), 281-299. Cambridge: Cambridge University Press.

Smethurst, P. 2000. The Postmodern Chronotype: Reading Space and Time in Contemporary Fiction. Amsterdam: Rodopi.

Steen, G. 1989. Metaphor and literary comprehension: Towards a discourse theory of metaphor in literature. Poetics 18(1-2): 113-141.

Steen, G. 1991. The empirical study of literary reading: Methods of data collection. Poetics 20(5-6): 559-575.

Stockwell, P. 2000. The Poetics of Science Fiction. London: Longman.

Stockwell, P. 2002. Cognitive Poetics: An Introduction. London: Routledge.

Stockwell, P. 2007. (Sur)real stylistics: From text to contextualising. In The Language and Literature Reader, R. Carter \& P. Stockwell (eds), 198-208. London: Routledge.

Stockwell, P. 2009. Texture: A Cognitive Aesthetics of Reading. Edinburgh: Edinburgh University Press. 
Stockwell. P. 2014. War, worlds and Cognitive Grammar. In Cognitive Grammar in Literature, C. Harrison, L. Nuttall, P. Stockwell \& W. Yuan (eds), 17-34. New York: John Benjamins.

Stockwell, P. \& Mahlberg, M. 2015. Mind-modelling with corpus stylistics in David Copperfield. Language in Literature 24(2): 129-147.

Styles, E. 2006. The Psychology of Attention. New York: Psychology Press.

Swann, J. \& Allington, D. 2009. Reading groups and the language of literary texts: A case study in social reading. Language and Literature 18(3): 247-264.

Tabakowska, E. 1993. Cognitive Linguistics and Poetics of Translation. Tübingen: Gunter Narr Verlag.

Tabkowska, E. 2014. Point of view in translation: Lewis Carroll's Alice in grammatical wonderlands. In Cognitive Grammar in Literature, C. Harrison, L. Nuttall, P. Stockwell \& W. Yuan (eds), 101-116. New York: John Benjamins.

Talmy, L. 1988. Force dynamics in language and cognition. Cognitive Science 12(1): 49100.

Talmy, L. 2000a. Towards a Cognitive Semantics. Vol. 1: Concept Structuring Systems. Cambridge: Cambridge University Press.

Talmy, L. 2000b. Towards a Cognitive Semantics. Vol. II: Typology and Process in Concept Structuring. Massachusetts: Massachusetts Institute of Technology Press.

Talmy, L. 2008. Aspects of attention in language. In The Handbook of Cognitive Linguistics, P. Robinson (ed), 27-38. London: Routledge.

Talmy, L. 2011. Cognitive Semantics: An overview. In Semantics: An International Handbook of Natural Language Meaning. C. Maienborn, K. von Heusinger \& P. Portner (eds), 622-642. Berlin: Mouton de Gruyter.

Taylor, J. 2002. Cognitive Grammar. Oxford: Oxford University Press.

Thomas, J. \& Short, M. (eds). 1996. Using Corpora for Language Research. Studies in Honour of Geoffrey Leech. London: Longman.

Tobin, V. 2009. Cognitive bias and the poetics of surprise. Language and Literature 18(2): 155-172.

Todorov, T. 1977. The Poetics of Prose. Oxford: Blackwell.

Tomashevsky, B. 2002. Story, plot and motivation. Narrative Dynamics: Essays on Time, Plot, Closure and Frames. In B. Richardson (ed), 164-178. Columbus: Ohio State University Press.

Toolan, M. 1988[2001]. Narrative: A Critical Linguistic Introduction. $2^{\text {nd }}$ edn. London: Routledge.

Traugott, E. \& Pratt, M. 2008. Language, linguistics and literary analysis. In The Language and Literature Reader, R. Carter, \& P. Stockwell (eds), 39-48. London: Routledge.

Tsur, R. 1992. Towards a Theory of Cognitive Poetics. Amsterdam: Elsevier.

Uspensky, B. 1973. A Poetics of Composition [trans. V. Zavarin and S. Wittig]. Berkeley. University of California Press.

van Peer, W. \& Chatman, S. (eds). 2001. New Perspectives on Narrative Perspective. New York: State University of New York Press.

van Peer, W. Hakemulder, J. \& Zyngier, S. 2007. Lines on feeling: Foregrounding, aesthetics and meaning. Language and Literature 16(2): 197-213.

van Vliet, S. 2009. Reference points and dominions in narrative: A discourse level exploration of the reference point model of anaphora. In New Directions in Cognitive Linguistics, V. Evans \& S. Pourcel (eds), 441-464. New York: John Benjamins. 
Verhagen, A. 2007. Construal and perspectivization. In The Oxford Handbook of Cognitive Linguistics, D. Geeraerts \& H. Cuyckens (eds), 48-81. Oxford: Oxford University Press.

Wales, K. 1990[2001]. A Dictionary of Stylistics. $2^{\text {nd }}$ edn. London: Longman.

Wales, K. 2014. The stylistics tool-kit: Methods and sub-disciplines. In The Cambridge Handbook of Stylistics, P. Stockwell \& S. Whiteley (eds), 13-31. Cambridge: Cambridge University Press.

Waugh, P. 2002. Metafiction: The Theory and Practice of Self-Conscious Fiction. London: Routledge.

Wells, H.G. 1898. The War of the Worlds. London: William Heinemann.

Werth, P. 1995a. How to build a world (in a lot less than six days, using only what's in your head). In New Essays in Deixis: Discourse, Narrative, Literature, K. Green (ed), 49-80. Amsterdam: Rodopi.

Werth, P. 1995b. 'World enough and time': Deictic space and the interpretation of prose. In Twentieth Century Fiction: From Text to Context, P. Verdonk \& J. Weber (eds), 181-205. London: Routledge.

Werth, P. 1999. Text Worlds: Representing Conceptual Space in Discourse. London: Longman.

Whiteley, S. 2011. Text World Theory, real readers and emotional responses to The Remains of the Day. Language and Literature 20(1): 23-42.

Whiteley, S. 2014. Ethics and alternativity. In The Cambridge Handbook of Stylistics, Stockwell, P. \& Whiteley, S. (eds), 393-407. Cambridge: Cambridge University Press.

Wójcik-Leese, E. 2000. Salient ordering of free verse and its translation. Language and Literature 9 (2): 170-181.

Yuan, W. 2014. Fictive motion in Wordsworthian nature. In Cognitive Grammar in Literature, C. Harrison, L. Nuttall, P. Stockwell \& W. Yuan (eds), 177-194. New York: John Benjamins.

Zunshine, L. 2006. Why We Read Fiction: Theory of Mind and the Novel. Columbus: Ohio State University Press.

Zwann, R. 1993. Aspects of Literary Comprehension. Amsterdam: John Benjamins. 


\section{Appendix}

\section{The New York Trilogy reviews}

The following anonymised reviews are taken from www.goodreads.com (R1-R6) [retrieved 15th February 2012], and amazon.co.uk (R7-R11) [retrieved 17th April 2012]. All reviews are reproduced as they appear in the original context.

\section{R1}

I think this was my first encounter with Paul Auster, a man who I met through the cult of the 1001 books to read before you die list. Prior to that I was vaguely aware of Auster and his peculiar brand of love/loath inciting literature which had friends alternatively raging or swooning, but had never bothered my arse to go and see what all the fuss was about.

Turns out I rather loved this - once I had progressed beyond the first forty pages. For the first forty pages I'd already rather rudely pigeon-holed the book as "arty-wank", thinking to myself, Oh dear this looks like it is entering into pretentious toss territory. When I say entering I mean approaching the door marked pretentious toss and busting its way in using a battering ram made out of glued together copies of The Body Artist by Don DeLillo, then stepping over the wreckage of the door and striding to the middle of the room to stand on the podium of arty-toss-bollocks while waving its arms over its head.... but nope, turns out it's all good.

Excellent trilogy, a study on the watched and the watcher in a sort of claustrophobic ever decreasing circles format which made my tiny mind spin, but in a good way, like the literary equivalent of an MC Escher drawing. In a complete about turn I then had to remove the book from the arty-wank pigeon hole and give it a little hug. This was followed by me then going out to purchase pretty much all of Paul Auster's books. Can't think for the life of me why I've not bothered to review more of them on Goodreads either. This one is deserving of a place on the 1001 books to read before you die list just don't let the first forty pages fool you.

Life is too short to re-read a book, but someday I will give time for this one. The reason is that I assumed that the book being a trilogy is composed of 3 totally unrelated stories since I read in the write up that the stories were published one at a time in a weekly magazine in the 80s. However, to my surprise, at the end of the 3rd story - The Locked Room (which by itself was the best among the 3) - it was revealed that the detective looking for Fanshawe was the main character in the first story, The City of Glass. So, I had to think back on how the three stories relate to each other but I could not really figure out how the second - Ghosts - fit into the whole story as the main characters were named after colors - Blue, Black, Brown and White. I agree with what they say that Paul Auster contributed to American literature by having a totally different writing style - the mixed up identities, the infusion of psychological insights into the narratives (Don Quixote for example in the second story) and even witty practical advises to the reader (you have to slow down to appreciate literature - to which I am a bit guilty because I 
have been reading books one after the other). If you want to read a intelligent yet entertaining book, make it this one!

R2

City of Glass (1985), Ghosts (1986) and The Locked Room (1986): Meta as in metafiction, also metaphysics and metaphor. This is fiction about fiction, writing about the writer. Who's writing whom? Who's the author and who's the imagined character? Auster's characters aren't "real" people (even when they are autobiographical) in the sense that you might invite one over for dinner, but are real in the sense that you might imagine yourself dissolving into fiction, or have the sense that the self is fiction.

These are stories that demand that the reader NOT check her brain at the door: disquieting, self-weary perhaps, not particularly plot-driven. They include elements of detective fiction, of mysteries and thrillers. Detective stories in the sense that characters follow one another around and spy on one another. Characters disappear and/or mirror one another: one "self" becomes the "other." Everyone here is lost and almost no one is found. Who is trailing whom becomes undecidable or indecipherable. Characters disappear. We don't know where they go and neither does the author.

R3

This is my first experience with Paul Auster and I have to say that I am impressed. The three novellas included in this book are not difficult reads, but they have so much meat to them they aren't easy reads either. I found them to be very thought provoking. Is this kind of obsession or sense of duty really possible in the non-fiction world?

I started this book right after my English class discussed Samuel Beckett's Endgame which really got me prepared for this style of writing. I had never read any absurdism or extistentialism but this work seemed go with this train of thought, at least according to my understanding from my professor.

I was really impressed with how the author was able to keep the plot going forward when the characters seemed to move backward. I was also impressed with the way that each of these novellas had similarities in their plots and repeated elements, such as the red notebook or the names, but they still remained separate stories. The stories actually seem to all be part of a whole but I have not gone to enough effort to completely figure that out. I will leave that for another day.

I look forward to reading more of his work.

R4

Well, it reads faster than Lord of the Rings, as far as trilogies go.

Paul Auster wrote three detective novels that break the traditional standard of what it means to detect, investigate, and deduce; and bundled them up in a "trilogy" that reflects the self as much as it does the urban landscape. 
In an age where the best-selling authors are thriller-suspense mystery pop once-amonth bogies (see Evanovich, Clancy, King, Patterson, etc), Auster almost pokes fun at the genre by flipping the proverbial tables on the art of the sleuth. In essence, his detectives are always investigating a case, but in truth, are investigating themselves.

Perhaps the most striking characteristic of the three books is the way Auster plays with names. In the first book alone, the title character Quinn writes under the pseudonym Wilson who has a character named Work and is confused with Auster (a name used in the books which obviously references the author's own self investigation through his characters). In the second book, Ghosts, the characters' names are colors. This fact brings interesting concepts to the proverbial table, which he's already flipped.

There is little that makes these books a trilogy, in the sense that they do not relate to one another (besides vague throw-ins for the faithful Auster reader), but thematically, the books remind us again and again that looking out is just another facet of looking in.

R5

The New York Trilogy has been on my reading list for over a year now, and it was one of my New Year's Day buys. It has the distinction of being the first book of 2011 that I truly loved-though love is perhaps an imprecise word for the relationship I formed with these three distinct, but intricately connected, novellas. It's hard to feel so messy and ardent a thing as love for an allegory, which is what the stories feel like (even though Auster denies that his work has any allegorical or symbolic intent).

It's also hard to describe City of Glass in any way that doesn't impoverish its power. On the most basic level, it's a book about three men who-either by choice or chance-are playing the role of detective. Each spends his days and nights watching another person closely, tracking him, tracing his steps through the world-all the while trying, and utterly failing, to comprehend the scraps of information so meticulously collected in the process.

In each case, the follower is transformed, by turn, into the followed. Each man begins to lose his grip on who he is. Identities are fluid, confounding, and often exchangedsometimes over and over. Words lose their meaning; coincidences strike with the force of fate. Is what a person does equivalent to who he is? If you perfectly mirror the moves of another, do you become him?

I believe Auster when he says "Nothing in any of my books means anything, as far as I know, except what I'm putting down on the page. There are no hidden meanings. On the other hand, if you're able to tell a story that resonates with the same power it has inside you, it's almost as if it's coming out of your dreams."

Reading The New York Trilogy is, in fact, a rather dreamlike experience. It's not a book whose characters you are likely weep over; but when you recognize yourself in them, as you will, you may well weep for yourself. 


\section{R6}

"As soon as we breath out our words, they live for a moment in the air, then die," says the character Paul Auster in an existential pronouncement about the meaninglessness of language, the dilemma of storytelling, and perhaps a sad metaphor for life in general, making this statement an overarching theme in this postmodern trilogy. The plot is easy enough to describe in all three novellas: A writer, turned private detective, hired or by his own volition follows a mysterious person for unknown reasons and records everything that person does. However, the Private eye becomes obsessive with the case and begins to alienate himself and others and suddenly descends into madness. Simplistic enough, the complexity of the novel comes from the numerous levels of identity Auster creates between himself and the characters in his novel, and furthermore with the connections between characters in the other two novellas. The character Paul Auster, one of the many identities of the author Paul Auster, in his three short novels, City of Glass, Ghosts, and The Locked Room, Daniel Quinn, another alter ego of Paul Auster, who is also an allusion to Don Quixote, Nathaniel Hawthorne's 'Wakefield', Walt Whitman, and a living Thoreau's Walden, Franshawe who is the absent Master who is compared to Shakespeare, all of which are characters in the novel. Confused yet? I wasn't too much, thanks to Auster's incredibly terse sentences and knack for storytelling.

One of the hallmarks of Postmodernism is that writers don't create, but copy former masterworks - think Dante, Shakespeare, Melville, and the Bible all of which are referred to in the Trilogy, and therefore create allusions to these works within their own. Before the reader can can accuse the writer of being ironic, the writer "beats the reader to the punch" by announcing that the writer is copying a masterpiece ("The Recognitions" has been the only book to present this problem and execute it so sublimely.). The New York Trilogy follows this equation, and albeit interesting, presents the problem of arrogance, screaming to the reader, "look how clever I am. Did you see what I did there?" Which I think deprives the reader from a genuineness one expects from reading a novel, a point where the reader wants to feel something humanlike from the characters. This is awfully hard when the characters of a story all named White, Black, and Blue.

This may be the point Auster was trying to make. As readers we try to connect ourselves to a character in a story, stare at ourselves through the looking glass, and answer some question we've been asking ourselves. However, how can the writer of a story, Auster for example, create a genuine character when he can't disconnect himself from the person he is creating - Quinn, Auster, Stillman, Franshawe, etc. It's impossible. Auster makes this problem perfectly clear and tinkers with it throughout the three novellas, wrapping himself in the characters, tangling mystery after mystery that goes nowhere, posing more questions than answers. The story reminded me of "The Crying of Lot 49" a novella I read in college about a woman, named Oedpia Maas, who tries to solve a mystery of the Postal Service but finds more and more clues with no connections and slowly descends into madness (brilliant book, highly recommended).

The genuineness that I was craving comes at the end of "The Locked Room," with 
Franshawe locked behind a door, about to end his life, despite his success with writing, hands over the Red Notebook over to the unnamed narrator, explaining that it will answer all his questions (of course its contents are incoherent and nonsensical, further driving home Auster's message of deconstructive language and narratives.). Before the narrator rips out the pages, trashing them at the train station, he bangs his fists on the locked door, screaming to let him in, so that he could see Franshawe, prevent him from doing the inevitable, save him, perhaps saving himself.

\section{R7}

NY Trilogy is certainly an entertaining and perplexing work of fiction, each story a variation on the theme of identity (lost and found), rootlessness, insecurity, what makes us human and individual, and other heavy themes.

However in this bleak, urban look at the impersonality of modern society, Auster is also having fun playing games with us, demonstrating (his) the writer's ability to create fictional characters - exploring how much of the characters are invention and how much autobiographical. Even the narrator - is that the writer's voice or an imposter? We, the readers, become the detective, encountering a trail of red herrings, unreliable witnesses and dead ends to try to discover the motives of author, narrator and characters. Can we find out the truth? Is that the message?

Each is a puzzling case, inter-related by characters who turn up repeatedly (including Auster himself - described in the third person). You're never sure whether it is the same person each time or another invention by the author. Confused? That's part of the charm of the book - I'm not sure there is a tidy solution - it is certainly an unsettling experience as the narrator in each case seems to be unreliable and more than a bit unstable, but it gets your brain working and that's got to be a good thing.

I enjoyed it - i don't really know why. I can't even decide whether it's well written. Certainly it's funny at times (in a nervous twitchy way) and if you're the sort who enjoys this sort of multi-layered mind game I can whole-heartedly recommend two English alternatives - Charles Palliser's "Unburied" or James Lasdun's "The Horned Man"

\section{R8}

I suppose a way of validating an original novel is seeing how many people are divided in their opinions about it. The reviews here are so varied and the stars given range from 1 to 5 ...but what are we to understand of all this variety?

That it is a book that will make you think. Like it or dislike it, it is in many ways an uncomfortable read that will lead you to a deeper awareness of consciousness and torment, while also bringing you the peace of recognition.

At least that is what it did for me. Auster plays with the reader, the three books of the trilogy are like puzzle pieces that connect only at times, there are detectives searching for people who turn out to be searching for them, chases within chases, there are 
mysteries without any resolution (which can be frustrating if you're the kind of reader who wants things to be all nice and tidy towards the end).

For the New York lover, whether you've only visited it or you've lived in it, or perhaps have never been there at all...the books offer vivid glimpses of Manhattan vibes, bringing you back to the places you've visited, or transmuting you to places you feel now drawn towards.

There is surely an air of vagueness which characterizes the NY trilogy, as if it were an experiment the author is playing with the reader, and you keep expecting for a solution, but it never comes. And towards the end of the trilogy, I already became at peace with that.

Try it. It's hard to pull away.

R9

The New York Trilogy isn't a trilogy in the sense that Steig Larsson's Millenium Trilogy is a trilogy or The Lord Of Rings is a trilogy, it's three extended short stories 'City Of Glass', 'Ghosts' and 'The Locked Room'. It's another example of metafiction, which I wasn't expecting, I can't remember who recommended it to me in the first instance or what they said about it. Whilst the use of metafiction is totally unintrusive in 'The Things They Carried', you knew it was there but it didn't effect the story, it is so intrusive in 'The New York Trilogy' that I think it probably counts as an example of 'breaking the fourth wall' or if it doesn't quite technically fit the criteria, it comes very close.

I hate it when authors break the fourth wall, I like to become immersed in the story, the characters, and pretend at least for the duration I read it that I am a visitor to the world about which I am reading. I don't like the authors wagging finger appearing in my face and saying 'this isn't REAL you know, it's just a STORY'. I know that already, I know the difference between fiction and non fiction.

I think one of the central discussion points of the trilogy is on the nature of authorship, and whether the story is more important than its author and the author is essentially irrelevant. In 'City Of Glass' Daniel Quinn is a formerly successful poet who following terrible tragedy now writes mystery stories, churning out one a year under the pseudonym 'William Wilson'. He receives a phonecall in the dead of night looking for a private detective named Paul Auster whom he then impersonates. Essentially all Auster has done here is use his own name as a character name but the effect is nonetheless jarring. A separate character who coincidentally also shares the name Paul Auster appears later on. I didn't like it. In the last story 'The Locked Room' the question of authorship arises again. A man publishes the work of his missing, presumed dead, friend and is asked whether he would consider writing a few more novels under his friends name, the public being none the wiser. I wondered briefly if Paul Auster wasn't a real person and that was part of the point but it seems that he is.

'The Locked Room' is actually quite a good story, but in it he re-uses several character 
names from 'City Of Glass' including, at one point, Paul Auster, and I just found this approach really very irritating. The characters in The Locked Room are not the ones from City Of Glass either they just have the same names. I think he's trying to make another point with this and that is that the names don't matter only the story. In Ghosts, Auster replaces every character name with a colour, which sounds like a small thing but actually makes it quite hard to read.

I wonder if a lot of reviews at the time praised Auster for playing with formats and BREAKING NEW GROUND, but I found something quite arrogant about it, a tone which suggests he thinks he's a better and more innovative writer than he actually is. The sense that he's writing for the critics, and the literary world at large. The first two stories are genuinely confusing, and I didn't really "take away" much from the book having finished it. I felt quite "so what?" about it.

In the first story Quinn meets a young woman reading one of his mystery novels, when she tells him she's finding it average without knowing he's the author, he leaves, because he is afraid he might punch her in the face. I kind of had the same feeling towards Auster throughout.

\section{R10}

OK, I read this all the way through. I'm not entirely sure why, but because I did, I'm giving this book 3 stars. It wasn't an unpleasant or boring book to read, but I found it ultimately pointless (ie without any point), and unfulfilling. The stories don't have a 'meaning', unless it's so hidden that only the author knows what it is. I do wonder whether the whole thing was a joke by the author to write a meaningless book and wait for people to assign meaning that isn't really there, just to appear high-brow and intellectual.

The description of the book is that it's a 'detective' book - well, if you like detective books, this probably isn't one for you. Yes, there are detectives in the book, and they do detecting, but they aren't investigating crimes, and they are all ultimately unsuccessful in their work.

I suppose the strength of the book is that it isn't so bad that you give up, and you keep hoping for it to mean something in the end, so you carry on reading. And when you get to the end, you wonder - what on earth was the point of that?

\section{R11}

Auster is playing with you from the start. When you are given characters name Black, White and Blue, you know you are in a realm of unreality. Since I just finished the first book in the New York Trilogy (City of Glass) I knew Auster was really infatuated with the author/reader/book "space" where what was of interest to him was not the plot/characters/"point" of the novel, but in how the reader responds to what he reads of the author's words, in how the reader re-formulates the story/characters in his head. 
This re-formulation is where Auster has staked his claim. He no longer wants it be the elephant in the room, he is dragging it out in front of it by the trunk!

The wonder of the book is that his sentence to sentence writing is somehow magically interesting. The danger is that this type of conceited (i.e. it has a trick or "conceit") writing can leave the reader with a big case of the "who cares?". But I think he pulls it off with his writing.

As far as the book - well, my running hypothesis was that the book was a metaphor for the act of reading and writing a novel, with one character being the writer, one the reader, and one the publisher - the one who actually sends it out into the world. More than "City of Glass", this one got me thinking of the act of creation as I was reading it.

And once again, I start out giving the book three stars, and then once I write the review, I find out I've really written a four star review...I guess I really liked it.

\section{Coraline reviews}

The following second set of anonymised reviews are taken from www.goodreads.com (RA-RE) [retrieved 15th February 2012], and amazon.co.uk (RF-RJ) [retrieved 17th April 2012]. All reviews are reproduced as they appear in the original context.

\section{RA}

There's something about the way Neil Gaiman writes that appeals to me greatly. He doesn't WASTE words. No flowery, adjective laden descriptions or ridiculous cliches. And yet, I never feel cheated. He'll often move a character from one place or situation to the next, and if you're new to him or have been reading someone else you might think for a second "That was abrupt", but he does it well and it serves the story.

More importantly, Coraline is an engrossing tale. Firstly, while Coraline the character isn't particularly warm or cute, she's smart, inquisitive, polite... you feel bad for her in the boring life she's so unsatisfied with, and in the journey she takes from there. And she's brave, while still admitting her fears and insecurities. And all of this is done without wasting words and while maintaining a reading level that kids could follow.

The best part about Coraline is the fun, interesting, vivid story. Neil Gaiman creates an imaginary world here that still feels like it could exist. He doesn't explain away the differences between the book's world and ours with magic or science; his fantasy world exists in or world, and it doesn't feel like it couldn't or shouldn't. And what a world it is. "Other" parents in a house just like yours but better (and far worse) in the subtlest of ways. Keys, mists, a talking cat and ghosts... all done with a class and timelessness that others in the genre (that I'm familiar with anyway) have failed to pull off (but not to attempt).

It also seems like Coraline is just begging to be read aloud. Plenty of other books are this way too, but it's obvious that Gaiman knows how to write a story that kids and parents will enjoy cuddling up together with. 


\section{RB}

I absolutely adore pre teen narrators. I love seeing their worlds from their POV. No melodrama, no hesitation, no wistful thinking about the hot guy/girl, no inner monologue and most importantly no gray shades. I am not saying that those are bad aspects of a story and that I don't enjoy them (except perhaps the continuous yakking about how handsome the new guy is). Still, books from the preteen perspective always prove to be a refreshing experience. A Relaxing yet fun experience, just like this book was.

Flavia De Luce will always remain my favorite preteen, but Coraline definitely gets the second spot. She is different, loves exploring, wants to wear rainbow colored gloves to school and hates it when people get her name wrong (they call her Caroline, how boring!). Her parents are always glued to the computer, making poor Coraline feel lonely and bored. She also has very interesting neighbors, like the actresses below with their dozens of dogs, or he mad man upstairs trying to train rats to dance and sing.

On one fateful rainy day, poor Coraline is confined to her house by her mother. So our little explorer decides to explore the house and comes across this peculiar door opening to ....nothing but a brick wall. Unfortunately, (fortunate for us) there is more to it than that. The tiny door in her house sometimes leads her to a place exactly like her original house, only it's perfect. It also has her parents, and they are perfect too, with her mother making delicious food and her father spending quality time with her. Something is amiss though, they have buttons sewed instead of eyes and calls themselves Coraline's "other mother "and "other father". Soon, Coraline realizes that she has chosen an adventure which is darker and more sinister than she earlier imagined.

Along with being an awesome adventure, the book focuses on Coraline's personality development through the novel. She doesn't gets all mature and serious (God gracious no! how dreadful would that be!) but finds courage and wisdom within her which she didn't know existed. She uses her wit to save herself and her parents, takes steps which are very hard for her and gives us some memorable quotes like these:

"I don't want whatever I want. Nobody does. Not really. What kind of fun would it be if I just got everything I ever wanted just like that, and it didn't mean anything? What then?"

And

"Because,' she said, 'when you're scared but you still do it anyway, that's brave"

Also, some other interesting characters come along. Like, the cat (cat's don't have a name you see); now if only cats were so witty in real life, and could talk :(. There are also her neighbors, and the ancient souls. On a whole, this book felt like a modern version of Alice in the Wonderland. It was jolly fun.

RC

As my sister observed, looking askance at me, Coraline is a book appropriate for "Ages 8 and up." I resisted the implication that such a designation meant that the material in question was any LESS appropriate to a 23 year old. My sister, meanwhile, likened my 
reading Coraline to an 18 year old playing on a $11+$ volleyball team. While I still feel that childrens' and Young Adult literature can have great merit to the adult reader, I did feel, in the end, that I would have gotten more enjoyment from Coraline if it were 1991 (I was a precocious reader). It seemed to me that in creating a "frighteningly" magical tale for a young reader, Coraline pulled back from a darker, profounder universe that was its provenance. I could sense that world behind the story, but the narrative seemed to simplify against it. This frustrated me, and I had a hard time believing and becoming engaged in the story. Even so, if being a child is not really LESS than being an adult, just a different way of understanding the world, then I think that the greatest books for children create worlds that are complete in and of themselves (and accessible to all readers AS SUCH), and do not feel like derivations oflarger more "adult" worlds.

\section{RD}

I began Coraline one night on my train-ride home from the city, and found myself immediately sucked into the story. My only prior exposure to Gaiman's work had been through the first installment of his Sandman comic-book series, which I thought mediocre at best, so I approached his children's novel with some ambivalence. I was surprised and pleased to discover that I enjoyed Gaiman's prose, and appreciated his perceptive depiction of the child's-eye view of the world around her.

The general obliviousness of adults to the realities and concerns of childhood, is a theme often explored in juvenile literature, and one Gaiman incorporates very ably into the opening of his book. Not only are Coraline's parents distant, and frequently unavailable, but the other adults around her seem to have trouble processing the reality of her existence. All of her new neighbors, from Miss Spink and Miss Forcible downstairs, to strange Mr. Bobo upstairs, have trouble remembering her name, and repeatedly refer to her as "Caroline." One gets the sense that they are simply incorporating her into a preexisting narrative, without really seeing her at all:"Coraline wondered why so few of the adults she had met made any sense. She sometimes wondered who they thought they were talking to"(20).

The fact that the "other" neighbors, created by the "other mother" in the strange mirrorworld Coraline wanders into one day, all manage to get her name right, is a testament to the beldam's focus on Coraline - her determination to keep her. But by the end of the novel, Coraline's real neighbors know who she is, and what to call her - an indication perhaps, of her growth as a character, her newfound strength and self-assurance.

There are many echoes here, from the alternate world, which (as Diana Wynne Jonesnotes on the back cover) reminds one a bit of Alice in Wonderland, to Coraline's boredom-inspired exploring, so reminiscent of the Pevensie children in The Lion, the Witch and the Wardrobe. But for all these parallels, Coraline is also a very distinctive book. I have heard it said that adult readers find Coraline frightening and horrific, whereas child readers take it in stride. For my part, I was neither scared, nor especially mystified, and guessed the location of Coraline's parents from the beginning. But I didcare - about Coraline, about her parents, about the (brilliant) nameless cat - and that's no small achievement for a brief, 162-page novel... 


\section{RE}

I actually picked up a signed copy at a local shop when Gaiman and I were both living in Minnesota. I've read a lot of Gaiman, and while appreciate that he is always a conscious, active writer, his stories sometimes fall flat for me.

They always work on the principle of a small person trapped in a large, unknown world. There are plenty of great examples of this story type, and Gaiman has been steadily working through them. He took inspiration from Fairy Tales in Stardust, from European myth in American Gods, and African myth in Anansi Boys. Though Morpheus was no small man, the individual story arcs dealt with normal folks. Sandman and Good Omens worked off of Christian mythos, while Neverwhere created myths from modern symbols.

If Neverwhere is a rewrite of Alice in Wonderland, Coraline is in some ways an even closer take on Carroll, except that here, Gaiman is exploring a more overtly frightening world, evoking Gothic ghost stories. Unlike his other stories, Gaiman has less to draw on here. He is not bringing in specific myths, but rather creating his own symbols. Since he is not bringing in the many and varied elements that mark most of his tales, Coraline sets a much barer stage.

When he does bring in mythological elements, he always put his own spin on them, so he cannot be faulted for a lack of creative force. Indeed, he is at his most engaging when he is exploring and subverting various world mythologies, of which he is well-versed.

Even in the less mythologized Neverwhere, he drew on the visual imagery and history of London itself, a great city which traces its roots from before Rome, and is not without its own legends. By eschewing any particular tradition in Coraline, Gaiman has little to play with. He has nothing to subvert, nothing to vaguely reference. He cannot play upon our expectations.

All this tracks back to the reason that Gaiman explores these mythologies in the first place: his interest in writing about storytelling itself. Each time he writes, he places himself in a tradition, recognizing how the ancients used myth and symbol to create stories that instruct, inspire, and surprise.

Coraline does not explore its own origins. It does not display the genre savvy play of Gaiman's other work. It is not an exploration of the ghost story, nor of 'Through the Looking-Glass'. It is not a deconstruction of the Gothic.

It is a simple little tale, and not without its charm. I found little frightening about it, simply because there was little that was either unexpected or psychologically gripping. The most interesting element was the way he played with how we learn about identity.

There is a point in childhood when we suspect that there us something that makes up identity beyond simply the appearance or form. The idea that a parent or friend could be replaced by a doppelganger is inherently terrifying. However, Gaiman does not produce a new twist on doppelgangers or changelings. 
Neither did the portrayal utilize surprise or subtlety to develop an unsettling mood. Rather, he presented overtly frightening or alien elements, bolstered then character reaction.

But it's not frightening to simply show scary things. Hearing a strange noise in the woods is not the same as being told that a character hears a strange noise in the woods. It only becomes frightening when the vividness of the description or the realism of the character's psychology allows us to tap into that sense of fear.

This little story could have made a passable entry in a horror story collection, but is not original enough to stand on its own. I found this rather odd, since Gaiman is entirely capable of creating frightening stories, as evidenced by the fairy tale rewrite 'Snow, Glass, Apples' (from 'Smoke and Mirrors').

He has been frightening, disturbing, and unusual elsewhere, but here, I found little to speak of his creative flair.

\section{$\mathbf{R F}$}

I discovered this book a little over four years ago. It was the first Gaimain novel I had come across, and remains--despite my delving into the fascinating depths of Neverwhere's London Below, the dangerous beauty of Stardust's Faerie and all the rest-my absolute favourite of all his works. His clear, unconvuluted style is really allowed to shine through here as this story is primarily for children, giving a wonderfully bleak, chilly feel. Also, Gaiman's masterful tendency of leaving much unexplained and not feeling the need to rationalise the extraordinary is, no doubt one that will appeal to children greatly.

Admittedly, the basic idea of a 'Looking-Glass' world is not original, but the intricacies of the storyline certainly are. This novel has that feel that so many horror films try (and largely fail) to obtain with their demonic children and evil dollies; Coraline is awash with a kind of twisted innocence that is infinitely eerie.

Black buttons have ever since made me edgy.

\section{RG}

This book is fantastic! I wish I was younger to enjoy the terror aspects more. The illustrations are perfect for the tone of the book and unlike many books enhance the narrative, not just illustrate it.

However if your child is of a sensitive nature and is easily frightened I would recommend reading the book for yourself first.

Coraline is a strong and inspirational character for children. She is intelligent and armed with street-smarts but also a approachable character.

The book also carries an important, albeit subtle, point namely beware of strangers; a point made poignant by the ghost children - a reminder that children do die from abduction. 
My main criticism is that the narrative is a little distant - a bit movieish and The language is a little ambitious in part for children to read alone - I had to look up a few words myself!

All in all a strong children book piece. A very dark fairy tale as all good fairy tales should be. If you are interested in this kind of book to encouage sytaxical and lexical growth I also can recommend Haroum and the Sea of Stories by Rushdie.

\section{RH}

Wow. My pleasant surprise for this book was barely contained after I gobbled it up in two (albeit very busy) days.

I admit I am a huge fan of the film and have watched it numerous times. There is actually more added to the film as the book is only around two hundred pages, however this did not disappoint me in the least.

Coraline is jam packed full of various themes, beautifully haunting imagery, and colourful characters. It also had a frightful scene including the Other Father that I will unashamedly say scared me witless.

Gaimans prose is also luscious and beautiful. This is the first and only book of his that I have read so far (The Graveyard Book is sitting patiently on my shelf) and was one of my best reads of the year. He speaks directly to you in third person but not down to you; he tells you stuff but not in a preachy way at all, we learn it along with Coraline, who would be an adventurer's dream to explore with!

Coraline is a modern gothic fairtale with a refreshingly active protagonist. A little warning this book (and its illustrations) may frighten the much younger ones. Five stars all the way.

\section{RI}

I'm giving Coraline 3 stars as I do think I may have enjoyed it a little more if I was younger - personally, I prefer some more development and more issues in a story than this one has. However, the writing deserves at least four stars. Gaiman portrayed this creepy other-world perfectly. His writing is simple - he doesn't go over-the-top with adjectives, yet very effective and sets the scene well. The imagery in this book was wonderful and is what made it so good, there is no doubt that Gaiman has a good, vivid imagination. I can certainly appreciate the writing and eccentricity of this novel and I would recommend it.

\section{RJ}

My first thought about this book is that I almost wish it wasn't marketed as a children's book. It is very dark and grisly, and had I watched or read this when I was a young girl, I'm pretty sure I would have had nightmares.

A brief synopsis: Coraline Jones moved into part of an old, pink house. Her parents are busy and often neglect her, and she is discontent and lonely. The new house has very strange neighbors, such as a crazy man trying to train a mice circus, and two aging 
retired theatre actresses who own many Scottie dogs and dream about their lost youth. Coraline finds a small door in her flat that during the day opens up to a brick wall. Yet that night she opens it again and it leads to a parallel world, where she has an "other mother" and "other father" and everything seems to be a dream come true. Yet this world is a twisted, evil mirror world, and once she has fallen into it, she discovers it is very dangerous for her and for her parents.

I love the imagination of Neil Gaiman, even if he does follow the same format over and over--girl or boy stumbles into a hidden mirror world: London Below in Neverwhere, the world in Mirrormask, gods who are actually in the real world like in American Gods and Anansi Boys and The Sandman, the world of magic in The Books of Magic, and the almost separate world in the graveyard of The Graveyard Book. Yet this was a very tidy book--the motifs tie into each other well, no loose ends are left untied, and it definitely develops a sense of suspense in the reader. Gaiman is very good at creating an atmosphere and entertaining his readers. 


\section{Index}

A Visit from the Goon Squad (Egan)

action chains

agent

Alice in Wonderland (Carroll)

alter-modernist fiction

archetypal role

attention

attenuation

attractors

billiard-ball model

clausal grounding

cognitive poetics

cognitive semantics

coherence

cohesion

compositional path

conceived reality

conditionals

construal

construction grammars

constructions

contemporary fiction

current discourse space

Coraline (Gaiman)

defamiliarisation

deixis 
discourse event frames

dominion

dynamicity

embodiment

emotion

Enduring Love (McEwan)

entrenchment

ethics

experiencer

fictivity

figure

force dynamics

foregrounding

gapping

generative grammar

gestalt

Gothic

ground

grounding

‘Here We Aren’t, So Quickly’ (Foer)

iconicity

ideology

image-schemas

mental spaces

metaphor

mind-modelling

mind style

modality

multimodality

narrative interrelation 
narrative urgency

narratology

negation

nominal grounding

object of conceptualisation

objective construal

objectification

participant roles

path

patient

perspective

point of view

postmodern fiction

potential reality

profiling

projected reality

projection

prominence

prototypicality

reader dispositions

reference point relationship

scalability

schematicity

schema theory

scope

sequential scanning

simile

simulation

specificity

splicing 
stylistics

subjective construal

summary scanning

symbolic correspondence

systemic functional linguistics

targets

tense

text worlds

texture

The New York Trilogy (Auster)

trajector/landmark alignment

transitivity

vantage point

viewing arrangement

viewing frame

windowing of attention 